Cite this: RSC Adv., 2014, 4, 29393

\title{
Nanocomposite films and coatings using inorganic nanobuilding blocks (NBB): current applications and future opportunities in the food packaging sector
}

\author{
Ilke Uysal Unalan, ${ }^{a}$ Guido Cerri, ${ }^{\text {b }}$ Eva Marcuzzo, ${ }^{c}$ Carlo A. Cozzolino ${ }^{a}$ \\ and Stefano Farris ${ }^{* a}$
}

The aim of this review is to provide an in-depth overview on the use of inorganic nano-sized entities for the generation of nanocomposite materials in the form of films and coatings for food packaging applications. According to recent trends toward "green" strategies, special focus has been dedicated to the development of nanocomposite coatings obtained using biopolymers as the main polymer matrix. After a first introductive part, the discussion has been addressed to the use of inorganic fillers, metals and metal-oxides, zeolites, and graphene. For each class of filler, a first 'in-depth' description of the most relevant physicochemical

Received 28th February 2014 Accepted 17th June 2014

DOI: $10.1039 / c 4 r a 01778 a$

www.rsc.org/advances properties for the food packaging sector has been followed by case-by-case references to recent developments and envisaged implementations. The technical aspects that may be crucial in the design and end use of (bio)nanocomposite coatings have been covered in the last part of this work, which also includes an updated list of current applications on nano-sized inorganic fillers in the food packaging field.
${ }^{a}$ DeFENS, Department of Food, Environmental and Nutritional Sciences-Packaging Division, University of Milan, Via Celoria 2, 20133 Milan, Italy. E-mail: stefano. farris@unimi.it; Fax: +39 0250316672; Tel: +390250316654

${ }^{b}$ Department of Natural and Territorial Science, University of Sassari, via Piandanna 4, 07100 Sassari, Italy
${ }^{c}$ Department of Food Science, University of Udine, via Sondrio 2/A, 33100 Udine, Italy

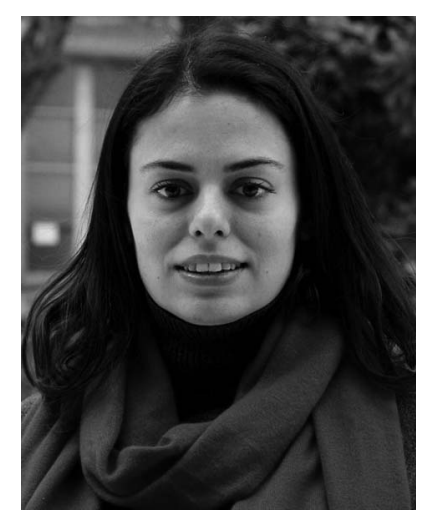

Ilke Uysal Unalan received her M.S. in Food Engineering from Izmir Institute of Technology, Turkey, in 2008 discussing a thesis on active food packaging by edible films. In March-June, 2010 she was a Federation of European Microbiological Societies (FEMS) research fellow at the National Food Institute, Technical University of Denmark (DTU), in the Prof. P. Dalgaard's group, where she worked on shelf life studies based on modified atmosphere packaging strategies. She has been doing her PhD since January 2012 in the Food Packaging lab under the guidance of Dr S Farris. Her research topic deals with the design and development of graphene-biopolymer nanocomposite films and coatings for food packaging applications. From July 2013 till May 2014 she has been a visiting research fellow at the University of Warwick, UK, in the Nanocomposite Research Group of WMG led by Prof. T. McNally, under the supervision of Dr Chaoying Wan.

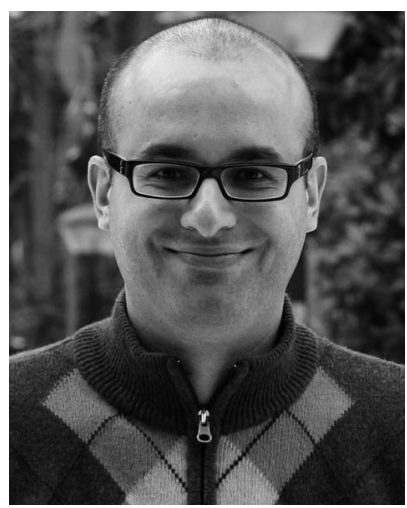

Carlo Alessio Cozzolino received his M.S. in Agricultural Science \& Technology in 2005 from the University of Sassari, Italy. In 2008 he joined the Food Packaging lab led by Prof. L. Piergiovanni at the University of Milan as a fellowship holder granted by the Government of Sardinia (September 2008October 2009). In 2013 he earned his PhD in Food and Microbial Biotechnology at the University of Milan (granted by the University of Sassari), under the supervision of Dr S. Farris. His thesis defense focused on the development of an active packaging from biomacromolecules for the controlled release of natural antimicrobials. At present, he holds a research position at the Metalvuoto Spa Company, while keeping ongoing collaborations with the Food Packaging lab. 


\section{Introduction}

From the 60's to date, the concept of nanotechnology has developed into a multidisciplinary field of fundamental and applied science and technology. Over the last decade, in particular, nanotechnology has become one of the most appealing topics within the research programs of both public agencies (e.g., universities) and private companies. At least by researchers, nanotechnology is generally deemed as an exciting area in which to work, allowing creativity in obtaining new materials with deliberately induced nano-sized architectures. Eventually, this field will yield new and innovative features and functions that can be profitably exploited in everyday life. Some authors, however, have expressed some skepticism about nanotechnology, the main question being whether it is a real opportunity or just a hype to extract funds. ${ }^{1}$

Although nanomaterials and nanoparticles have been consumed by humans for centuries, consumers' perceptions toward nanotechnology are not totally agreeable, mainly due to the still-existing uncertainties concerning the potential risks for humans and the environments associated with the use of nanomaterials for sensitive applications, such as many areas of the food industry, including packaging, nutrient delivery, and food quality. ${ }^{2}$ Nevertheless, in 2008 nanotechnology involved over \$15 billion in worldwide research and development money (public and private) and employed over 400000 researchers across the globe. ${ }^{3}$ Moreover, nanotechnologies will likely impact at least \$3 trillion across the global economy by 2020, and worldwide nanotechnology industries may require at least 6 million workers to support them by the end of the decade. ${ }^{3}$ Despite the still open debate about nanotechnology, it is not rash to say that the world is in the middle of a nano-revolution.

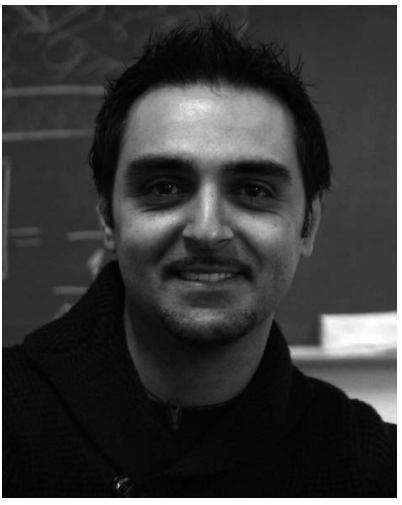

Stefano Farris received his M.S. in Agricultural Science \& Technology from the University of Sassari, Italy, in 2004. In 2007 he earned his PhD in Food and Microbial Biotechnology. From 2007 to 2008 he was a postdoctoral fellow at Rutgers University (NJ) in the Food Packaging lab led by Prof. K. Yam, where he worked on the development of films and coatings from renewable resources. In 2011 he joined Prof. M. Hedenqvist's group at KTH, the Royal Institute of Technology in Stockholm, in the Department of Fibre and Polymer Technology. There, he worked on the development of hybrid materials by means of in situ polymerization through sol-gel approaches. At present he is Assistant Professor in the Department of Food, Environmental and Nutritional Sciences (DeFENS) at the University of Milan, Packaging Lab. His current research activity is mainly devoted to the development and deposition of high-performance coatings.
The food industry seems to receive the largest benefits from nanotechnology, with potential uses already identified in virtually every segment of the sector (i.e., agriculture, food processing, food packaging, and nutrient supplements). ${ }^{4}$ Moreover, a number of the world's largest food companies are actively exploring the potential of nanomaterials for use in food applications. ${ }^{5}$ Within the food industry, however, packaging applications form the largest share of the current and shortterm predicted market for nano-enabled products, ${ }^{6}$ with an estimated annual growth rate of $\sim 12 \%$ by $2014 .^{7}$ One of the reasons for this trend is the consumers' willingness to embrace nanotechnology in "out-of-food" applications more than the direct addition of nanoparticles into the food. ${ }^{\mathbf{8}, 9}$ This is also why most nanotechnology applications for food and beverages are lagging behind applications for food packaging, which are already becoming a commercial reality. ${ }^{\mathbf{1 0}}$

One of the most successful applications of nanotechnology in the field of packaging concerns the development of "nanocomposites". ${ }^{11}$ In polymer science, while the term "composites" generally refers to mixtures of polymers with inorganic or organic additives having micron-length scale and certain geometries (fibers, flakes, spheres, and particulates), the use of nano-length-scale entities can be more specifically referred to as "nanocomposites." These entities are well-defined nanobuilding blocks (NBB), which consist of preformed objects that keep their integrity in the final nanocomposite materials. ${ }^{12}$ These NBB can be clusters, nano-core shells, organically pre- or post-functionalized nanoparticles (e.g., metal oxides), and layered compounds (e.g., clays). ${ }^{13}$ The preferential route to produce nanocomposites lies in the "top-down" approach, which progressively reduces the size of nanocomposite bulk materials using grinding, milling, etching, lithography, or precision engineering. ${ }^{14}$ Nanocomposites represent a radical alternative to conventional polymer composites, because if properly manipulated, they can offer extra benefits such as low density, transparency, good flow, better surface properties, and recyclability, even at very low filler contents (generally lower than $5 \mathrm{wt} \%) .{ }^{15-18}$

A new subclass of nanocomposite materials has recently stemmed from the increasing endeavor to replace oil-based polymers with polymers partially or totally obtained from renewable resources. The term "bionanocomposites" refers to those materials in which the polymer matrix carrying the nanosized fillers is a biopolymer (e.g., polysaccharides and proteins) or by a polymer of natural origin obtained by synthetic (e.g. polylactic acid, PLA) or biotechnological (pullulan, poly-hydroxyalkanoates-PHAs) routes. The use of NBB for the generation of bionanocomposites has enormous potential for overcoming the drawbacks exhibited by natural polymers, such as poor mechanical and thermal properties, sensitivity to moist environments, and inadequate barrier properties to gas and vapors; the development of bionanocomposites has thus drawn considerable attention in recent years. However, most examples concern the incorporation of the inorganic phase directly into the bulky biopolymer. Only very recently it has been proposed the use of fillers within coatings made of biopolymers to produce bionanocomposite coatings (i.e., thin layers of a 
biopolymer matrix loaded with a nanoparticle filler) to improve the properties of a plastic substrate without jeopardizing its original attributes and optimize cost efficiency. ${ }^{19-22}$

We conceived this review as guidance for tomorrow's research in the field of nanocomposite materials, especially in the form of coatings specifically intended for food packaging applications, with special emphasis on those solutions envisaging the use of biopolymer matrices. First, we provide a brief introduction, including key definitions and classifications. Second, we present an in-depth description of inorganic fillers with special focus to the following: inorganic clays (e.g. montmorillonite), which are the most widely used for food packaging purposes; metals and metal oxides, especially those obtained by sol-gel routes that have gained much attention for food packaging applications due to their high versatility; zeolites, which despite having many appealing features, are still under-exploited fillers; and graphene, which is one of the "fillers of the future", owing to its promising and attractive properties for the next generation of materials-not only for packaging applications. Besides discussing the most relevant physicochemical properties, a detailed description of current developments for the food packaging sector is also reported for each class of filler. Among other aspects, in the final "technical" section, we first thoroughly discuss the processing of inorganic fillers within (bio)polymer matrices to obtain (bio)nanocomposite coatings. Successively, we describe the most important aspects that may impact the ultimate performance of (bio)nanocomposite films and coatings in light of their end use as food packaging materials. We also provide an outlook on future trends with the goal of prompting new research on (bio)nanocomposite coatings as potential alternatives to the currently used solutions. We have deliberately kept a discussion of the toxicological and regulatory aspects associated with the nano-dimension of the inorganic fillers out of the scope of this review, as these topics have been deeply addressed in other recent works. ${ }^{4,18,23-33}$

\section{Classification of fillers}

A first distinction within the huge field of fillers can be done according to their chemical composition. Accordingly, it is useful to distinguish between organic fillers, namely those containing carbon atoms and most often directly derived from biomass, and inorganic fillers, which may be also of natural origin but as a general rule do not consist of any carbon atoms. Graphene is an exception to this rule, as it is arbitrarily included within the inorganic filler class although it is only consists of carbon atoms. As both classes (organic and inorganic) encompass a wide assortment of examples, each including many different applications, it would be impossible to provide an exhaustive overview that takes into account all of them. Therefore, our focus will be only on the inorganic fillers.

\subsection{Inorganic fillers: physicochemical properties and main developments for food packaging applications}

The use of inorganic nano-sized building blocks as fillers in the preparation of polymer/inorganic nanocomposites has attracted increasing interest in recent years, owing to their unique properties that find numerous applications in many industrial fields. As shown in Chart 1, a first arbitrary classification of inorganic fillers, primarily based on chemical composition and crystal structure, is between silicate and nonsilicate minerals. Both families include several classes and many groups that, in turn, comprise different mineral species potentially suitable to produce nanocomposites. However, only few of these minerals have so far been exploited in practice. If, on one hand developers have thus far used layered silicates (e.g. clays) the most extensively as fillers to obtain nanocomposites, ${ }^{4,34-36}$ on the other hand, developers have introduced carbon-based nanofillers such as carbon black, ${ }^{37-39}$ expanded graphite, ${ }^{40-42}$ carbon nanotubes (CNTs), ${ }^{43-45}$ and carbon nanofibers $^{46-48}$ in the preparation of polymer nanocomposites to achieve properties otherwise unattainable, such as electrical and thermal conductivity of the final nanocomposite material. Among these, CNTs have proven effective as conductive fillers. ${ }^{45,49-52}$ The only drawback of CNTs as a nanofiller is their relatively high production cost. ${ }^{43,51,53,54}$ Therefore, as Nicholos said, ${ }^{55}$ "When carbon fibers just won't do, but nanotubes are too expensive, where can a cost-conscious materials scientist go to find a practical conductive composite? The answer could lie with graphene sheets".

In this section, we first review the most widely used inorganic fillers, i.e. clays, with also a brief mention of other layered minerals of interest, i.e. micas and layered double hydroxides. Next, we discuss the current and potential use of zeolites, while the last part of this section will be dedicated to the rise of graphene as a promising candidate for the development of new advanced materials. We will place special emphasis on the structure-property relationships that eventually lead to the enhancement of material properties of interest for food packaging applications, such as barrier, mechanical and thermal properties.

2.1.1 Clay minerals. Clay minerals used in the manufacturing of nanocomposite materials are natural or synthetic layered hydrated aluminum phyllosilicates, often hydrated, with neutral or negative charged layers. ${ }^{56}$ The building blocks of clays include tetrahedral and octahedral sheets. In the tetrahedral sheet each tetrahedron shares three corners with the adjacent tetrahedrons, ideally defining a surface with hexagonal mesh. The tetrahedrons are centered by one silicon atom (sometime substituted by aluminum and/or iron), which coordinates four oxygen atoms located at the corners. A plane of octahedrons sharing edges, arranged in a hexagonal pattern, defines the octahedral sheet. Depending on the number of octahedral sheets, two different structures can be eventually encountered, i.e. the gibbsite-like structure (dioctahedral) and the brucite-like structure (trioctahedral). The center of the octahedron is occupied by aluminum or magnesium, whereas six oxygen atoms, some of them also linked to a hydrogen atom, are located at the corners. $\mathrm{Fe}^{3+}$ and $\mathrm{Fe}^{2+}$ can also be found at the center of the octahedron. The superimposition of tetrahedral $(\mathrm{T})$ and octahedral $(\mathrm{O})$ sheets may originate both $2: 1$ (T-O-T) and $1: 1(\mathrm{~T}-\mathrm{O})$ layered structures, where the sum of each sheet originates a layer (known as a platelet). ${ }^{57} \mathrm{In}$ 


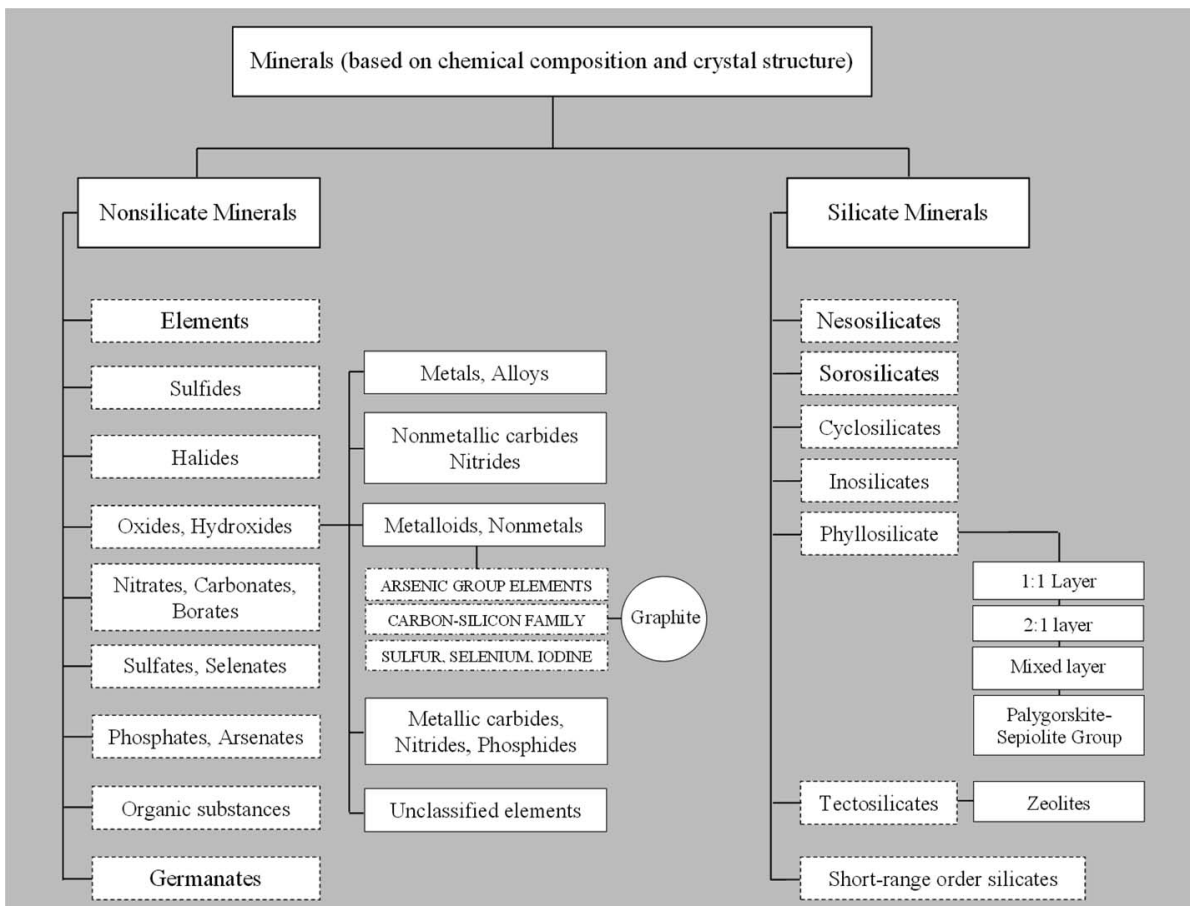

Chart 1 Classification of inorganic fillers based on chemical composition and crystal structure.

$2: 1$ layered structures, if isomorphic substitution of silicon and/or aluminum with a lower-valence atom takes place (either in the octahedral or tetrahedral sheets), the mineral is characterized by a negative surface charge, which, in some clay groups, will be naturally counterbalanced by positive inorganic ions $(e . g$. $\mathrm{Li}^{+}, \mathrm{Na}^{+}, \mathrm{Ca}^{2+}, \mathrm{K}^{+}, \mathrm{Mg}^{2+}$, etc.) in the interlayer. In these cases, the nature of the cations plays a crucial role in determining the swelling tendency of the clay upon water adsorption. As a general rule, the smaller is the cation and the lower is its charge, the more the clay swells. For example, in montmorillonite (a clay belonging to the smectite group), the swelling increases according with the following trend: $\mathrm{Li}^{+}>\mathrm{Na}^{+}>\mathrm{Ca}^{2+}>\mathrm{Fe}^{2+}>\mathrm{K}^{+} .^{58}$ The $\mathrm{K}^{+}$ion provides the lowest swelling capability because it stabilizes the structure due to the fact that, more than the other ions, its size well fits with the hosting size represented by the center of the hexagon defined by six Si-centered tetrahedrons.

The capability of layered silicates to exchange cations is quantified by the cation-exchange capacity (CEC), usually expressed as meq per $100 \mathrm{~g}$. Ideally, the CEC of a clay mineral is equivalent to its (negative) layer charge. This parameter can greatly vary depending on the type and origin of the clays, as well as within the same clay, because the surface charge is locally randomly distributed (i.e. it may vary from layer to layer or within the same layer). ${ }^{59}$ The layers of mineral clays generally organize to form stacks with a regular van der Walls gap in between them called the "interlayer distance" or "gallery", while the " $d$-spacing" $\left(d_{001}\right)$, also called the "basal spacing", accounts for the sum of the interlayer and the platelet thickness (Fig. 1). When the hydrated cations are ion-exchanged with organic cations (e.g. more bulky alkyammoniums), which is normally done to increase the affinity towards more hydrophobic polymers such as polyolefins or PLA, the final result is a larger interlayer spacing, thus a larger " $d$ " value. Three organization levels can be recognized within clays: (i) the layer (or platelet), with thickness of approximately $1 \mathrm{~nm}$ and length varying from a few hundreds of $\AA$ to several microns, depending on the type of clay; (ii) primary particle, composed of five to ten platelets stacked on top of one another; (iii) micro-aggregates (or tactoids), structures of approximately 0.1 to $10 \mu \mathrm{m}$ formed through the association of randomly oriented several primary particles. ${ }^{60}$ One common feature of clays is the high aspect ratio (i.e., the ratio between length and thickness). Although this parameter can vary greatly depending on the type and origin of clays, it may be of the order of $1000 .^{15}$

Based on our bibliographic search, the four main groups of clay minerals of technological interest for the fabrication of nanocomposite materials are-in order of relevance for this field-smectite, kaolin, palygorskite-sepiolite, and vermiculite.

2.1.1.1 Smectite clays. The smectite group includes the most commonly used types of clays for the production of nanocomposites, due to their large availability, low cost and favorable technological attributes, such as ease of exfoliation, which results in optimal distribution in the polymer matrix. ${ }^{61-66}$ Smectites include $2: 1: 1$ (or T-O-T) hydrated clays primarily constituted of $\mathrm{Si}$ and $\mathrm{Al}$ and/or $\mathrm{Mg}$. These clays consist of a central octahedral sheet containing $\mathrm{Al}^{3+}, \mathrm{Fe}^{3+}, \mathrm{Mg}^{2+}$ and $\mathrm{Fe}^{2+}$ sites coordinated to either oxygen anions and hydroxyl groups, sandwiched between two tetrahedral sheets constituted of $\mathrm{Si}^{4+}$, $\mathrm{Al}^{3+}$ and $\mathrm{Fe}^{3+}$ coordinated to oxygen anions arranged in a hexagonal fashion. ${ }^{67}$ The smectite group includes several types of clay minerals, among which montmorillonite, saponite, laponite, and hectorite have potential for the generation of 


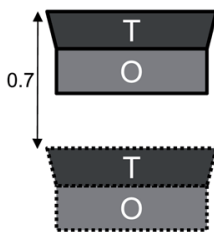

a
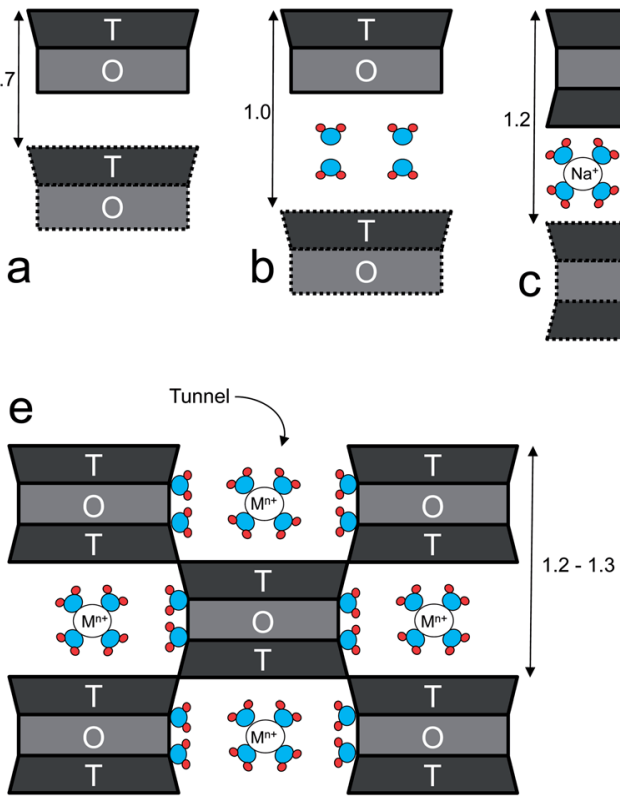

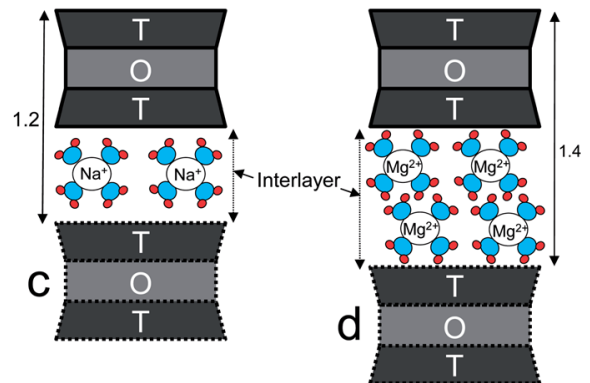

f

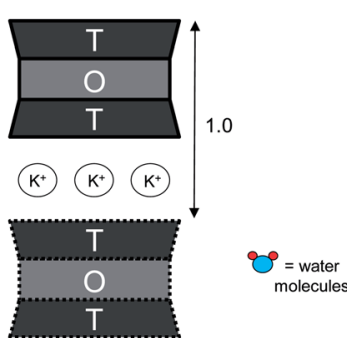

Fig. 1 Schematic representation of some phyllosilicates viewed perpendicularly to the tetrahedral (T) and octahedral (O) sheets: (a) kaolinite; (b) halloysite; (c) $\mathrm{Na}^{+}$-montmorillonite (a smectite) partially hydrated; (d) Mg-vermiculite fully hydrated; (e) palygorskite-sepiolite structure; (f) muscovite (a flexible mica). Spacing in $\mathrm{nm} . \mathrm{M}^{\mathrm{n}+}$ stands for a generic cation.

nanocomposite materials. Although rectorite does not belong to the smectite group, it has arbitrarily been included in this section because it is partially constituted by montmorillonite layers.

2.1.1.1.1 Montmorillonite. Montmorillonite (MMT) (Fig. 2a) is the most widely exploited clay for the fabrication of polymer/ clay nanocomposites. ${ }^{68}$ In MMT's structure, with a general formula $\left(\mathrm{M}_{y}^{+} \cdot n \mathrm{H}_{2} \mathrm{O}\right)\left(\mathrm{Al}_{2-y} \mathrm{Mg}_{y}\right) \mathrm{Si}_{4} \mathrm{O}_{10}(\mathrm{OH})_{2} \quad\left(\mathrm{M}_{y}^{+}\right.$refers to a generic monovalent interlayer cation), ${ }^{67}$ the negative surface charge coming from the partial substitution of the trivalent Al-cation in the octahedral gibbsite layer by the divalent $\mathrm{Mg}$ cation is balanced by sodium and calcium ions, which exist hydrated in the interlayer. ${ }^{69}$ Because the layers are held together by relatively weak forces, water and other polar molecules can enter between the layers, causing the lattice to expand. ${ }^{70} \mathrm{~A}$ typical sodic MMT ( $\left.\mathrm{Na}^{+}-\mathrm{MMT}\right)$ is characterized by a $d_{001}$ of 11.7 $\AA$ (at relative humidity values $\sim 50 \%$ ), aspect ratio of $100-200$, surface area of $700-800 \mathrm{~m}^{2} \mathrm{~g}^{-1}$, and CEC ranging between 70 and $120 \mathrm{meq}$ per $100 \mathrm{~g}$, depending on their extraction site. ${ }^{71,72}$

The development of oil-based polymer/MMT nanocomposites is well documented, and includes polymethylmethacrylate (PMMA), ${ }^{73}$ polyethylene terephthalate (PET) ${ }^{74-84}$ polypropylene (PP), ${ }^{85-99}$ ethylenvinylacetate (EVA), ${ }^{100-103}$ polyamide (PA), ${ }^{\mathbf{9 6 , 1 0 4 - 1 1 0}}$ polyethylene (PE),${ }^{\mathbf{9 0 , 1 0 0 , 1 1 1 - 1 2 1}}$ polyethylenimine (PEI), ${ }^{122}$ polyvinylchloride (PVC), ${ }^{\mathbf{1 2 3 , 1 2 4}}$ natural rubber latex, ${ }^{125}$ and polyurethane (PU), ${ }^{126-129}$ to provide some examples.

In addition to "single polymer matrix" nanocomposites, researchers have also proposed blends of two or more polymeric materials (i.e. binary or ternary blends) for the development of MMT-based nanocomposites with enhanced physicochemical properties ensuing from synergistic effects. Blends of modified
PA and nylon-6, ${ }^{130}$ PET and aromatic PA, ${ }^{131}$ PP and PA 6,6, ${ }^{132}$ nylon-6 and ethylenevinylalcohol $(\mathrm{EVOH})^{\mathbf{1 3 3}}$ were reinforced with MMT for the improvement of barrier, thermal and mechanical properties. Developers have also used MMT to build multifunctional thin films by alternating two or more layers of anionic and cationic polymer aqueous solutions or dispersions; this process could theoretically include an infinite number of layers. For instance, one study described the film growth and structure of assemblies made with cationic PEI and anionic MMT clay and polyacrylic acid (PAA), referring to one deposition sequence of PEI/PAA/PEI/MMT as a quadlayer. The study asserted the resulting polymer nanocomposite thin films have unprecedented barrier performance, especially in terms of oxygen permeability. ${ }^{\mathbf{1 3 4}}$

Due to the increasing concerns about environmental issues linked to the waste disposal of plastics at the end of the service, research has focused on the possibility of extending the technical benefits of nanocomposites to polymers of natural origin, with the main goal of overcoming the traditional shortcomings of biopolymers, such as sensitivity to water or humid environments, as well as poor barrier and mechanical properties. More specifically, because the food industry is among the sectors that takes advantage of poorly biodegradable petroleum-based plastic materials, the development of eco-friendly bionanocomposite films and coatings is one of the greatest challenges that has become imperative to this industry. Within the food packaging sector, several studies have reported on the improvement of the mechanical, thermal, barrier, active, optical, and water-resistance properties of several bionanocomposites based on MMT, as reported in Table 1. Although MMT clays have attracted much attention due to their undeniable advantages over other type of clays, researchers have also 


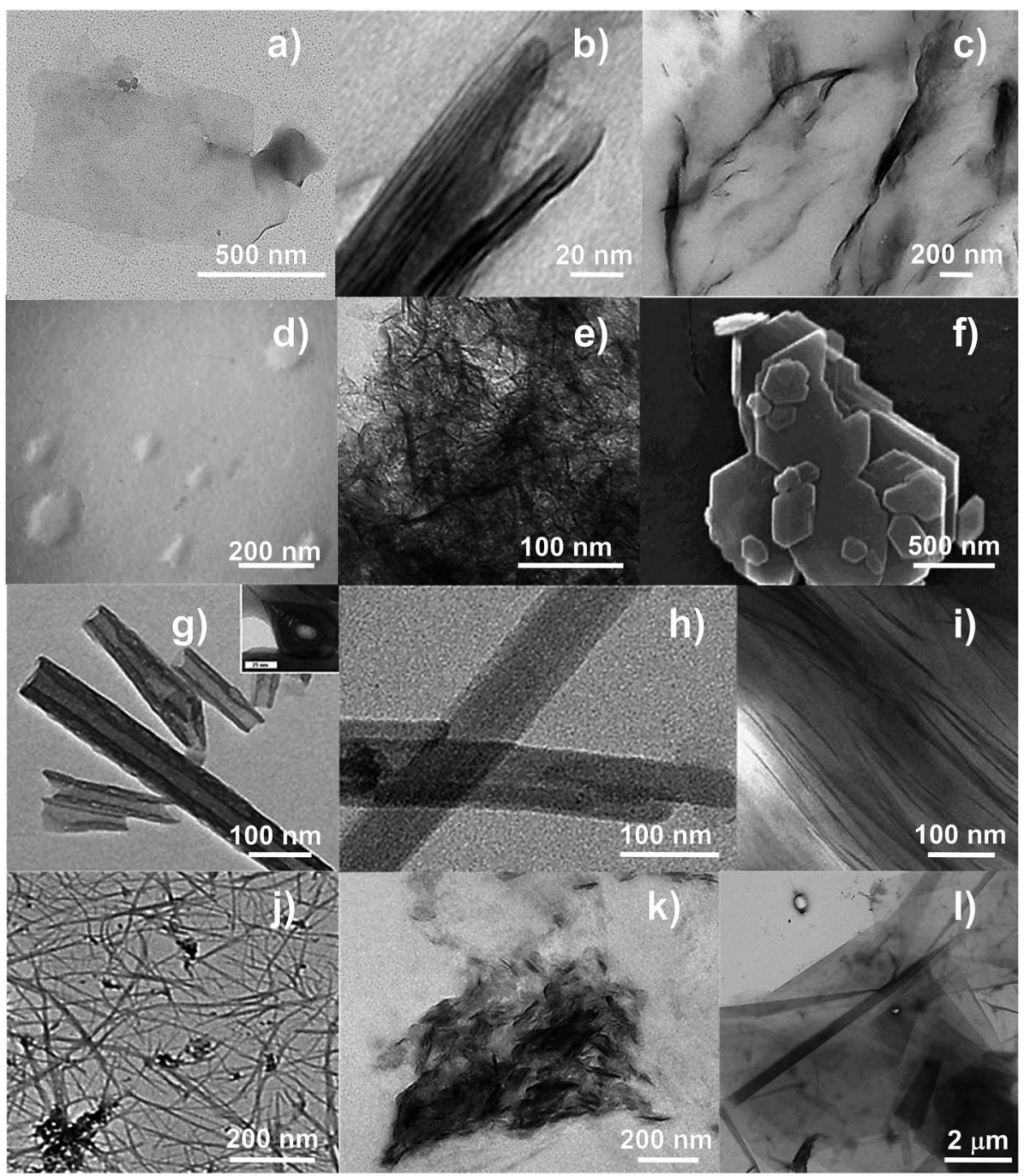

Fig. 2 TEM images of: (a) Na+-MMT; (b) REC (reproduced with permission from Elsevier Ltd ${ }^{191}$ ); (c) SAP (reproduced with permission from Elsevier Ltd ${ }^{197}$ ); (d) LAP (from http://www.laponite.com); (e) HEC (reproduced with permission from Elsevier Ltd ${ }^{220}$ ); (f) KAO (reproduced with permission from Elsevier Ltd $^{224}$ ); (g) HNTs including tube cross-section in the inset (reproduced with permission from Elsevier Ltd ${ }^{230}$ ); (h) SEP (reproduced with permission from Elsevier Ltd ${ }^{263}$ ); (i) VMT (reproduced with permission from Elsevier Ltd ${ }^{272}$ ); (j) IMO (reproduced with permission from Elsevier Ltd ${ }^{280}$ ); (k) LDHs (reproduced with permission from Elsevier Ltd ${ }^{297}$ ); (l) synthetic mica (product name NTS-5, Topy Industries Limited, Tokyo, Japan).

explored the use of other clays belonging to the smectite group to fabricate bionanocomposites for food packaging applications.

2.1.1.1.2 Rectorite. Rectorite (REC) (Fig. 2b) is a yellowishwhite layered silicate consisting of a regular interstratification of $2: 1$ dioctahedral mica layers (see paragraph 2.2.2.2) and $2: 1$ dioctahedral smectite (MMT-like) layers. The structure and properties of REC thus fall between completely expanded MMT and completely collapsed mica. The proportion of smectite layers in a mixed-layer clay determines the clay's expandability. In REC, since the distribution of smectite and mica layers in a clay crystallite is ordered (or regular), the final properties are virtually in between those of smectite and mica. ${ }^{184}$ The presence of mono- and divalent charge-compensating exchangeable cations in the smectite expandable sheet makes it possible to prepare polymer/REC nanocomposites by solution-mixing or melt-mixing processing techniques. ${ }^{185}$ Yang et al. reported for $\mathrm{Na}^{+}$-REC a CEC $\sim 45$ meq per $100 \mathrm{~g}$ and $d$-spacing of $22.1 \AA \AA^{186}$ while Jinhong et al. calculated a CEC of 32.2 meq per $100 \mathrm{~g}$ and $d$-spacing of $19.47 \AA^{187}$ The Brunnuer, Emmet and Teller (BET) surface area was $\sim 30 \mathrm{~m}^{2} \mathrm{~g}^{-1},{ }^{188}$ whereas the length and thickness of REC layer were $\sim 100-200 \mathrm{~nm}$ and $2 \mathrm{~nm}$, respectively, yielding an aspect ratio of 50-100, lower than MMT. ${ }^{189}$ Examples of bionanocomposite coatings based on REC are reported in Table 1.

2.1.1.1.3 Saponite. Saponite (SAP) (Fig. 2c) is another mineral clay belonging to the smectite group, with a chemical formula $\left(\mathrm{M}_{x}^{+} \cdot n \mathrm{H}_{2} \mathrm{O}\right) \mathrm{Mg}_{3}\left(\mathrm{Si}_{4-x} \mathrm{Al}_{x}\right) \mathrm{O}_{10}(\mathrm{OH})_{2},{ }^{67}$ surface area $\sim 200 \mathrm{~m}^{2} \mathrm{~g}^{-1},{ }^{193} \mathrm{CEC}$ of $\sim 80-120$ meq per $100 \mathrm{~g}$, aspect ratio of 50-60, ${ }^{17,194-197}$ and basal spacing between $12 \AA$ (ref. 198) and 14.1 A. ${ }^{197}$ Unlike MMT, which is a dioctahedral smectite, SAP has $\mathrm{Mg}^{2+}$ in the trioctahedral brucite-like sheet. Substitution of 


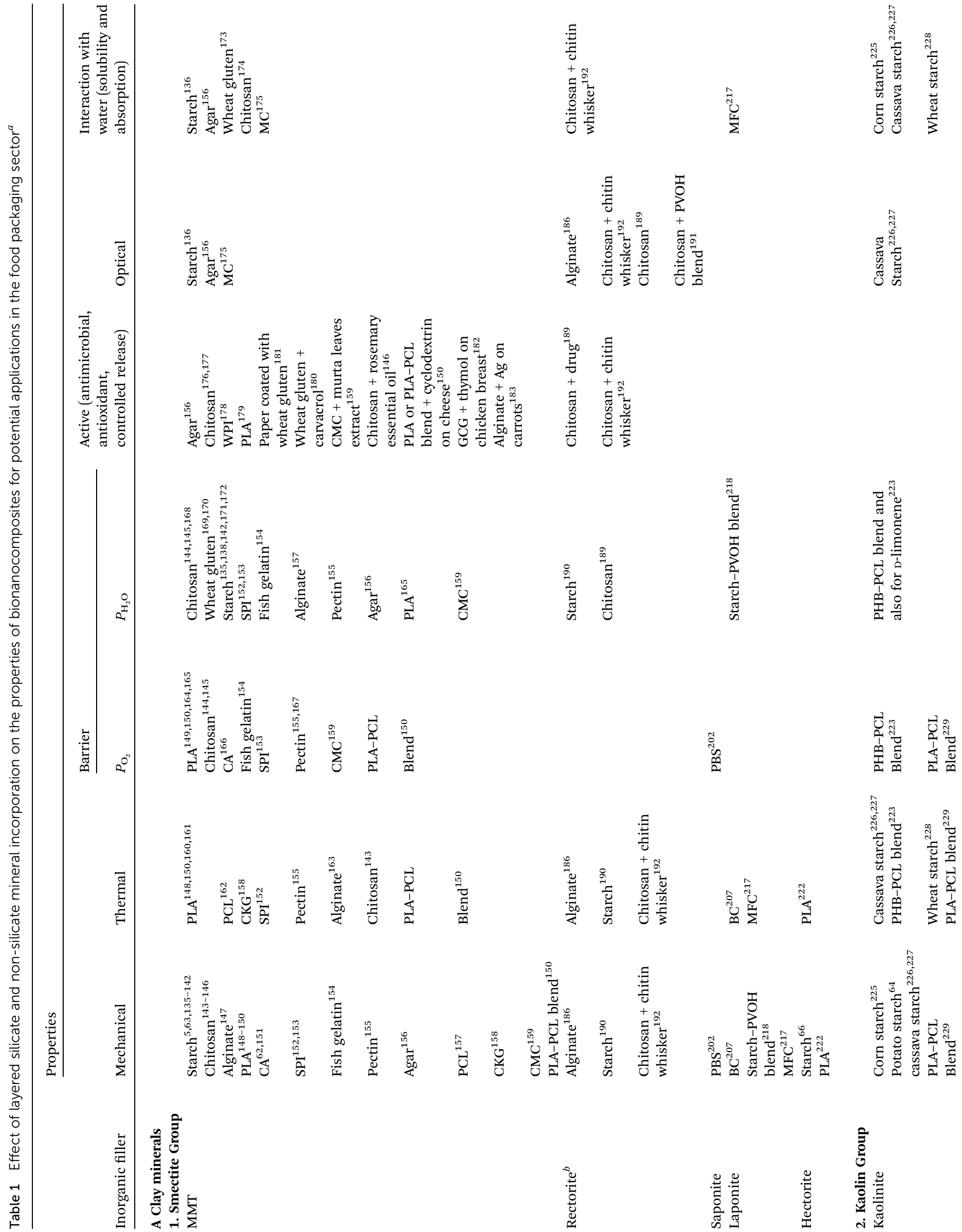



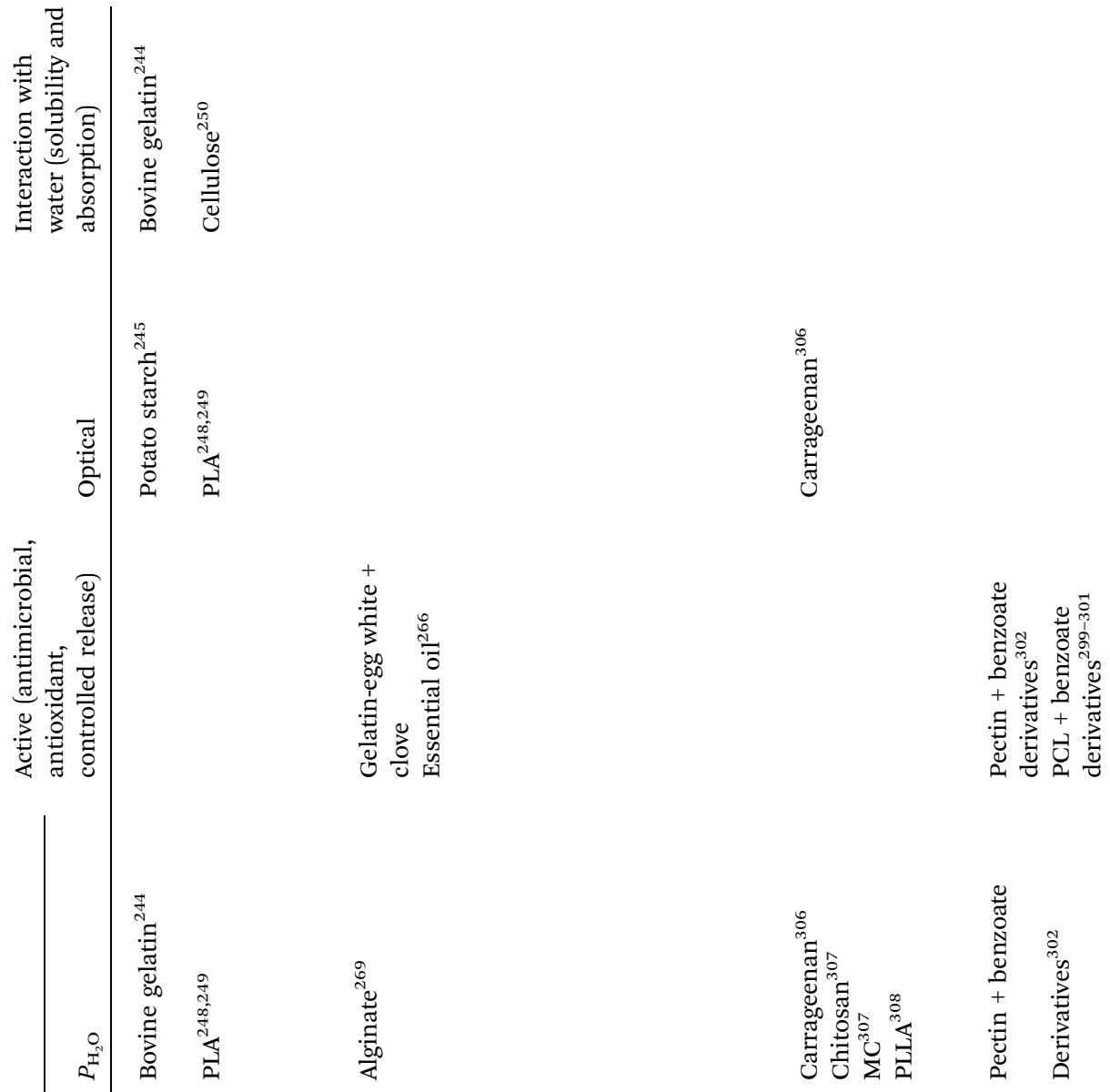

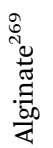
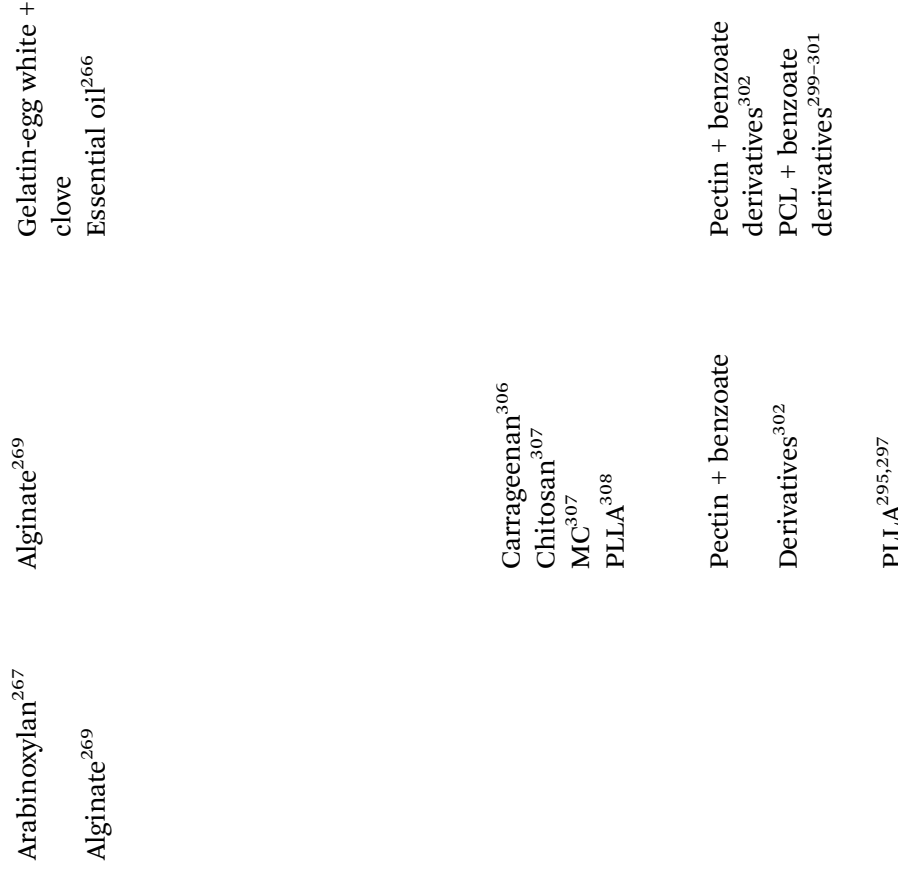

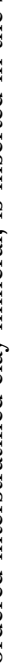

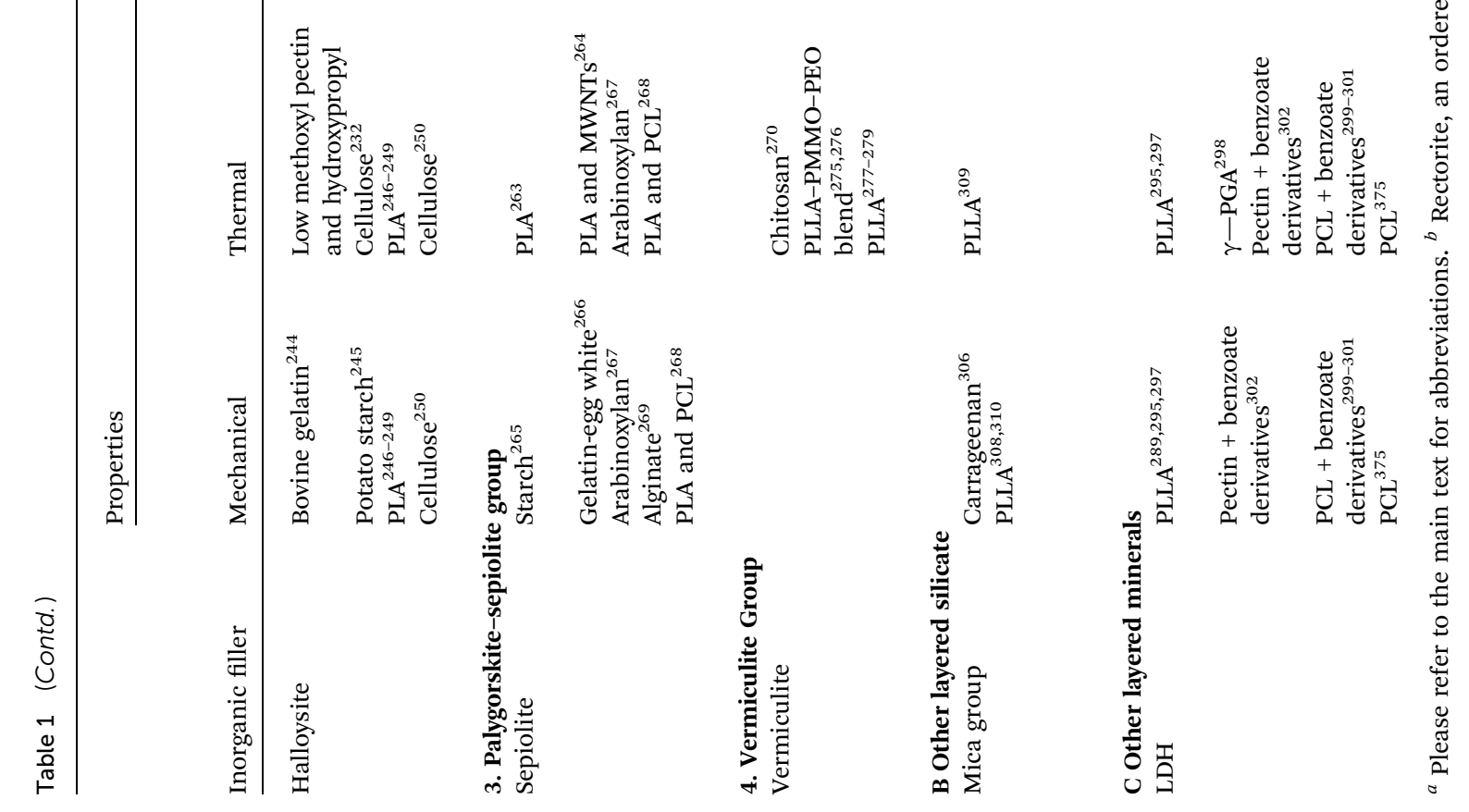


$\mathrm{Mg}^{2+}$ with $\mathrm{Al}^{3+}$ gives rise to a positive excess charge in the octahedral sheets, ${ }^{67,199}$ which is, however, over-compensated by the positive charge deficiency in the tetrahedral sheets due to substitutions of $\mathrm{Si}^{4+}$ with $\mathrm{Al}^{3+}$ (tetrahedral $\mathrm{Al}$ reported to be as high as $90 \%$ of the total $\mathrm{Al}$ in the sample). ${ }^{193}$ This eventually leads to an overall negative charge of SAP clays. The excess of positive charges in the octahedral sheet of SAP gives it a weaker aptitude to hydration compared with MMT, similar to vermiculite. ${ }^{194}$ However, the charge deficiency in the tetrahedral sheet of SAP has an important implication on the state of the interlayer water. In minerals in which the greatest part of the charge deficiency comes from tetrahedral substitutions (as in SAP), water molecules arrange in a three-dimensional organization mediated by the formation of hydrogen bonds between water and some negatively charged surface oxygen. ${ }^{200}$ Relatively rigid bridges are thus formed from one layer to another, the exchangeable cations acting as intermediaries. ${ }^{194}$ Therefore, with respect to water, SAP has a higher water affinity, but a lower hydration tendency than MMT. Another difference between SAP and MMT concerns the morphology. Whereas the structure of MMT is in the form of hexagonal lamellae, SAP shows a structure in the form of ribbons and laths. ${ }^{201}$

Developers have used SAP in combination with biodegradable polymers such as poly(butylene succinate) (PBS), in which the addition of the filler yielded better mechanical and oxygen permeability properties ${ }^{202}$ (Table 1). SAP used in combination with poly(vinyl alcohol) (PVOH) yielded PVOH/SAP nanocomposites with remarkable mechanical properties, thermal stability, ${ }^{197,203}$ water resistance, ${ }^{197,204}$ optical properties, ${ }^{203}$ and oxygen permeability. ${ }^{203}$

2.1.1.1.4 Laponite. Laponite (LAP) (Fig. 2d) is a fully synthetic smectite clay similar in structure and composition to natural hectorite (see next section). In this clay part of the $\mathrm{Mg}^{2+}$ in the trioctahedral sheet is replaced by $\mathrm{Li}^{+}$, resulting in a net negative charge of the layer, which is counterbalanced by $\mathrm{Na}^{+}$ cations located between adjacent layers in a stack. ${ }^{205}$ LAP is currently available in the market under two main types, with the following empirical formulae: $\left[\mathrm{Si}_{8}\left(\mathrm{Mg}_{5.5} \mathrm{Li}_{0.3}\right) \mathrm{O}_{20}(\mathrm{OH})_{2.5} \mathrm{~F}_{1.5}\right]-$ $\mathrm{Na}_{0.7}$, (type 1) and $\left[\mathrm{Si}_{8}\left(\mathrm{Mg}_{5.5} \mathrm{Li}_{0.3}\right) \mathrm{O}_{20}(\mathrm{OH})_{4}\right] \mathrm{Na}_{0.7}$ (type 2). ${ }^{206} \mathrm{LAP}$ has a plate-like shape with dimensions typically around 20$30 \mathrm{~nm}$ in length and $0.92 \mathrm{~nm}$ in width, basal spacing of $\sim 1.3 \mathrm{~nm},{ }^{207-209}$ estimated surface area of over $900 \mathrm{~m}^{2} \mathrm{~g}^{-1}$ (206) and CEC typically 90 to 100 meq per $100 \mathrm{~g}$ for type 1 products and 50 to 60 meq per $100 \mathrm{~g}$ for type 2 products. ${ }^{210}$ One of the main technological advantages of LAP lies in the absence of silica and iron oxides in its composition, which allows producing clear and transparent colloidal suspensions of clay particles in water. ${ }^{211}$ Commercial application of LAP have thus far mainly involved household products, personal care items, horticulture, and the preparation of paper and polymer films..$^{212}$ The materials science field has used LAP in combination with both hydrophobic and hydrophilic synthetic polymers, such as $\mathrm{PE}^{213} \mathrm{PVC}^{214}$ and $\mathrm{PVOH},{ }^{215,216}$ respectively. Developers have also used LAP in the production of bionanocomposites with claimed potential application in the food sector as biodegradable packaging films, as summarized in Table 1.
2.1.1.1.5 Hectorite. Hectorite (HEC) (Fig. 2e) is another $2: 1$ trioctahedral smectite with a theoretical chemical formula $\left(\mathrm{M}_{y}{ }^{+} \cdot n \mathrm{H}_{2} \mathrm{O}\right)\left(\mathrm{Mg}_{3-y} \mathrm{Li}_{y}\right) \mathrm{Si}_{4} \mathrm{O}_{10}(\mathrm{OH})_{2} ;{ }^{67}$ one study reported the CEC and surface area of HEC are 70-80 meq per $100 \mathrm{~g}$ and $\sim 200-300 \mathrm{~m}^{2} \mathrm{~g}^{-1}$ (measured by $\mathrm{N}_{2}$ adsorption at liquid nitrogen temperatures), respectively. ${ }^{219}$ Sànchez et al. measured a BET surface area of $\sim 220 \mathrm{~m}^{2} \mathrm{~g}^{-1}$ and basal spacing between $13.4 \AA$ and 14.2 A. ${ }^{220}$ Sinha Ray and Okamoto reported a CEC of $\sim 120$ meq per 100 g..$^{17}$ A more recent study reported a CEC of 43.9 meq per $100 \mathrm{~g}$, a surface area of $\sim 65 \mathrm{~m}^{2} \mathrm{~g}^{-1}$ and basal spacing of $14.4 \AA$ for $\mathrm{Ca}^{2+}$-HEC. ${ }^{66}$ Other research confirmed a surface area of $63 \mathrm{~m}^{2} \mathrm{~g}^{-1}$. ${ }^{221}$ HEC generally exhibits an aspect ratio of $200-300,{ }^{196}$ which is higher than MMT and SAP. To the best of our knowledge, only two works have been published on HEC-based bionanocomposites with potential application for the food packaging sector (Table 1).

2.1.1.2 Kaolin clays. The term kaolin refers to a rock, white or near white in color, mainly constituted by kaolinite (i.e., $\mathrm{KAO}$ ), which is the most important mineral within the group of kaolin clays. KAO is a $1: 1$ (or T-O) layered silicate with a chemical formula $\mathrm{Al}_{2} \mathrm{Si}_{2} \mathrm{O}_{5}(\mathrm{OH})_{4}$ consisting of one gibbsite-like dioctahedral sheet and one tetrahedral sheet layer (Fig. 2f). ${ }^{56}$ The ultimate structure is an asymmetric configuration with very little substitution in the structural lattice; thus it has a minimal layer charge and a low exchange capacity $(\sim 3-15$ meq per $100 \mathrm{~g}){ }^{148}$ This asymmetric structure allows the formation of hydrogen bonds between consecutive layers, providing a large cohesive energy. ${ }^{223}$ In turn, this makes intercalation of polymers more difficult, which is probably the main reason for the fewer occurrences of kaolin in the preparation of nanocomposite polymer materials, despite it being inexpensive, abundant, readily available, and environmental friendly. Another important technological property of KAO is the low absorption capacity, which relates to the minimal layer charge and the low surface area $\left(5-20 \mathrm{~g} \mathrm{~m}^{-2}\right)$ in comparison to smectite clays. ${ }^{148}$ Also, KAO exhibits a lower aspect ratio compared to smectite clays, usually around 10 but can vary widely from very low values $\sim 2$ for laminated stacks (or "books") to more than 11 up to 36 for very thin platelets in the 4-22 range. ${ }^{224}$ Although the largest use of kaolin is for coating paper, ${ }^{148}$ kaolinite has also been used to produce bionanocomposite materials especially in combination with corn starch derived from different sources (Table 1).

Within the kaolin group, halloysite (HAL) has recently gained researchers' attention. HAL is a $1: 1$ two-layered aluminum hydrated phyllosilicate with a predominantly hollow tubular structure in the submicron range. ${ }^{230} \mathrm{HAL}$ may be regarded as a hydrated kaolinite $\mathrm{Al}_{2} \mathrm{Si}_{2} \mathrm{O}_{5}(\mathrm{OH})_{4} \cdot 2 \mathrm{H}_{2} \mathrm{O}$ (or even $4 \mathrm{H}_{2} \mathrm{O}$ ) with curved layers and a basal spacing of $1 \mathrm{~nm}$ that decreases to about $0.7 \mathrm{~nm}$ upon dehydration. ${ }^{67}$ The neighboring alumina and silica layers and their waters of hydration, curve and form multilayer tubes with average diameters of $50 \mathrm{~nm}$ and inner lumen diameters of $15 \mathrm{~nm}$, while the length may vary between 500 and $1000 \mathrm{~nm}^{231}$ This peculiar tubular shape gives rise to the commonly used term "halloysite nanotubes" (HNTs) (Fig. 2g). ${ }^{232}$ HNTs have CEC of 5-10 meq per $100 \mathrm{~g}^{233}$ whereas the typical surface area is $65 \mathrm{~m}^{2} \mathrm{~g}^{-1}$. The basal space of HNTs is $0.73 \mathrm{~nm} .{ }^{234}$ 
HNTs are able to entrap a range of molecules with specific sizes and can serve as a viable nano-cage for active molecules, owing to the empty space inside the nanotubes (pores volumes of $\left.\sim 1.25 \mathrm{~mL} \mathrm{~g}^{-1}\right) .{ }^{235}$ For example, some studies asserted HAL as a suitable carrier for the controlled release of anticorrosion coating agents, herbicides, and fungicides. ${ }^{231,236-239}$ HNTs have also served as supports to immobilize catalyst molecules such as metallocomplexes. ${ }^{240}$ Like MMT nanosheets, HNTs can also be incorporated into polymers to modify their functional properties. ${ }^{241-243}$ However, we found very few works on this topic (Table 1). The results reported support the concept of bionanocomposite technology as a valuable tool to improve the water barrier, mechanical, and thermal properties of biopolymer films, with high potential for food packaging purposes.

2.1.1.3 Palygorskite and sepiolite clays. Palygorskite and sepiolite contain a continuous two-dimensional tetrahedral sheet (that is why they are considered phyllosilicates), whereas the octahedral sheet lacks of continuity. Their framework contains ribbons with a $\mathrm{T}-\mathrm{O}-\mathrm{T}$ structure, and the apices of tetrahedra belonging to adjacent ribbons point in opposite directions. ${ }^{67}$ This periodic inversion of the $\mathrm{SiO}_{4}$ tetrahedra determines channels or tunnels (extended along $X$-axis ${ }^{67}$ ) of rectangular section, which is the reason of the fibrous structure of these two non-swelling clays. The channels (wider in sepiolite) contain water and, due to the low CEC of both minerals, a small amount of exchangeable cations. Palygorskite (often called attapulgite in industrial and trade applications) is intermediate between di- and trioctahedral, whereas sepiolite is essentially trioctahedral. As far as their cell parameters, the major difference concerns $b$, respectively $1.78-1.80 \mathrm{~nm}$ and 2.68-2.72 nm. ${ }^{67}$

Sepiolite (SEP - Fig. 2h), with a theoretical half-unit-cell formula $\mathrm{Mg}_{8} \mathrm{Si}_{12} \mathrm{O}_{30}(\mathrm{OH}, \mathrm{F})_{4}\left(\mathrm{OH}_{2}\right)_{4} \cdot 8 \mathrm{H}_{2} \mathrm{O},{ }^{251}$ is a clay of relevance for the nanocomposites manufacturing. It shows a pore volume of $\sim 0.4 \mathrm{~cm}^{3} \mathrm{~g}^{-1},{ }^{252-256}$ a surface area of $\sim 200-400 \mathrm{~m}^{2} \mathrm{~g}^{-1}$ $(257,258)$ and a CEC generally about 30 to 40 meq per $100 \mathrm{~g} \cdot{ }^{148} \mathrm{SEP}$ is a "high silanols carrying filler", with silanols spaced every $5 \AA$ along the length of the SEP needle. ${ }^{259}$ This very high density of silanol groups (2.2 groups per $100 \AA^{(260)}$ ) suggests that forces such as hydrogen bonding and van der Waals interactions are largely involved in coupling reactions with both polymers and organic surfactants as well as in adsorption phenomena at the interface. ${ }^{261}$ Both the excellent affinity with polymeric matrices and the strong anisotropy of this mineral account for the outstanding reinforcing effect on polymers, which results in a marked increase of the elastic modulus of the final compounds. However, the high concentration of hydroxyl groups on SEP surface is responsible for the strong catalytic effect of SEP on the thermal degradation of polyolefins. ${ }^{262}$ Compared to other inorganic fillers, SEP has found wide use in obtaining bionanocomposites with potential for food packaging applications (Table 1).

\subsubsection{Other clay minerals}

2.1.1.4.1 Vermiculite. Vermiculite (VMT) (Fig. 2i) is a $2: 1$ clay, generally trioctahedral. As in smectite, hydrated cations are located in the interlayer, although in VMT the negative layer charge, larger than that of smectite, arises mostly from substitution of $\mathrm{Al}^{3+}$ with $\mathrm{Si}^{4+}$ in the tetrahedral sheets. ${ }^{67}$ Occasionally isomorphic substitutions of $\mathrm{Mg}^{2+}$ with $\mathrm{Al}^{3+}$ determine an excess of positive charge in the brucite-like sheet $(+0.62$ electrostatic valence units), which is overcompensated by the excess of negative charge in the tetrahedral sheet $(-1.81$ electrostatic valence units). ${ }^{271}$ The location of the layer charge determines the strength of the Lewis base: VMT behaves as a hard base, whereas MMT, which presents relevant octahedral substitutions, behaves as a soft base. ${ }^{271}$ Furthermore, the intensity of negative charge and its position explain the overall tendency of VMT to swell less compared with MMT. ${ }^{194,271-274}$ Besides, VMT has a slight higher CEC compared with MMT, generally between 100 and 150 meq per 100 g. ${ }^{72}$ Brigatti et al. reported $\mathrm{CEC}=84.4 \mathrm{meq}$ per $100 \mathrm{~g}$ for MMT and $142 \mathrm{meq}$ per $100 \mathrm{~g}$ for VMT, ${ }^{271}$ whereas Wang et al. reported CEC $=86.5 \mathrm{meq}$ per $100 \mathrm{~g}$ for $\mathrm{Na}^{+}-\mathrm{VMT} .{ }^{272}$ One study measured the basal spacing $\left(d_{001}\right)$ of vermiculite at $11.2 \AA .{ }^{272}$ Considering that the thickness of the $\mathrm{Na}^{+}$-VMT platelet is reported between $9.6 \AA$ and $10 \AA \AA^{273,274}$ it follows that the VMT interlayer distance (layer thickness subtracted from the basal spacing) ranges between 0.16 and $0.12 \mathrm{~nm}$. Compared to MMT, VMT shows slightly lower surface area (500-700 $\left.\mathrm{m}^{2} \mathrm{~g}^{-1}\right)$, whereas $\mathrm{Xu}$ et al. reported VMT layers with thickness of $\sim 2-5 \mathrm{~nm}$, and length of $\sim 200 \mathrm{~nm} .^{72} \mathrm{VMT}$ is not as widely used as, for example, MMT for the generation of bionanocomposites. Few examples of VMT-based bionanocomposites are reported in Table 1.

2.1.1.4.2 Imogolite. Imogolite (IMO) is a clay-size hydrous alumino-silicate of short-range order with the chemical formula $(\mathrm{OH})_{3} \mathrm{Al}_{2} \mathrm{O}_{3} \mathrm{SiOH} .{ }^{67} \mathrm{IMO}$ forms slender hollow tubules (Fig. 2j). The $\mathrm{SiOH}$ groups are located on the inner surface of the nanotube, while $\mathrm{AlOH}$ groups are on the outer surface. The hydroxyl groups on the walls and rims make the nanotube hydrophilic. Naturally occurring IMO is a few micrometers length with an internal diameter of about $1 \mathrm{~nm}$, and an external diameter of about $2 \mathrm{~nm} .{ }^{\mathbf{2 8 0 - 2 8 2}}$ Synthetic IMO has a monodisperse nanotube length of $100 \mathrm{~nm}$ in solution, as determined by dynamic light scattering. ${ }^{283}$ These dimensions are considerably lower than HAL (halloysite); therefore IMO can provide higher surface areas than HAL for the same volume.

In IMO the tetrahedral sheets are located in the interior of the nanotubes, while the dioctahedral gibbsite-like sheets are on the exterior, with the hydroxyl groups of the $\mathrm{Al}_{2} \mathrm{OH}$ groups pointing outward, i.e. to the surrounding medium. As a consequence, the surface charge (and thus the exchange capacity) varies with the $\mathrm{pH}$ of the medium, which greatly affects the dissociation of hydroxyls. In this respect, the high $\mathrm{pH}$ at pointof-zero charge $(\mathrm{pH}>11)$ on the outer parts of the tube and the anomalously high chloride adsorption of IMO may originate a weak positive charge on the outer tube walls, while a negative charge develops in the tubular pores. ${ }^{281}$ Therefore, IMO can have a positive charge under acidic conditions. ${ }^{284}$ However, chloride adsorption is largely equimolar with sodium adsorption when $\mathrm{NaCl}$ is added over a wide $\mathrm{pH}$ range, ${ }^{\mathbf{2 8 5 , 2 8 6}}$ thus indicating the simultaneous presence of a weak positive charge and a weak negative charge along the outer and inner IMO nanotubes, respectively. 
The surface area of IMO as measured by $\mathrm{N}_{2}$-BET adsorption is $\sim 300-400 \mathrm{~m}^{2} \mathrm{~g}^{-1} \cdot{ }^{281}$ The repeating distance along the tubule axis is $0.84 \mathrm{~nm} .{ }^{67}$ The formation of IMO occurs in a gibbsite sheet through the displacement of three hydroxyl groups surrounding a vacant octahedral site by an orthosilicate anion. This requires a considerable shortening of the $\mathrm{O}-\mathrm{O}$ distances around the site (to $<3 \AA$ ), which causes the gibbsite sheet to curl and form a tube. Doubly coordinated $-\mathrm{Al}_{2} \mathrm{OH}$ groups are found on the outer tube walls, whereas the inner tube walls carry $\mathrm{SiOH}$ groups. ${ }^{281}$ Although IMO does not swell under ordinary conditions, it retains 1.5 times more water than $\mathrm{Na}^{+}$-MMT due to micropores formed by intertwining fibrous particles. ${ }^{287}$

IMO is a "green" nanomaterial, although natural IMO is not sufficient to fulfill current demands. Recent advances thus concern IMO synthesis and new methods for large quantity production, which developers have performed without using toxic reagents or aggressive solvents, making this nanomaterial easily available. ${ }^{284}$

\subsubsection{Other layered minerals of interest}

2.1.2.1 Layered double hydroxides. Layered double hydroxides (LDHs) (Fig. 2k), also called "non-silicate oxides and hydroxides", have many physical and chemical properties that are surprisingly similar to those of clay minerals. ${ }^{288}$ LDHs have a general chemical formula represented by $\left[\mathrm{M}_{1-x} \mathbf{M}_{x}{ }^{\mathrm{III}}(\mathrm{OH})_{2}\right]^{y^{+}}\left[\mathrm{A}_{y /}\right.$ $\left.m^{m-} \cdot n \mathrm{H}_{2} \mathrm{O}\right] ; \mathrm{M}$ is an univalent or a divalent metal ion such as $\mathrm{Li}^{+}, \mathrm{Mg}^{2+}, \mathrm{Ni}^{2+}, \mathrm{Cu}^{2+}, \mathrm{Ca}^{2+}$, or $\mathrm{Zn}^{2+} ; \mathrm{M}^{\mathrm{III}}$ is a trivalent metal ion such as $\mathrm{Al}^{3+}, \mathrm{Fe}^{3+}, \mathrm{Cr}^{3+}$, or $\mathrm{Ga}^{3+} ; y$ is the value of the layer charge for an octahedral unit; and $\mathrm{A}^{m-}$ is an exchangeable anion with valence $m$ like $\mathrm{NO}_{3}{ }^{-}, \mathrm{Cl}^{-}, \mathrm{CO}_{3}{ }^{2-}$, or $\mathrm{SO}_{4}{ }^{2-}$. Therefore $y$ is equal to $2 x-1$ or $x$ for $\mathrm{M}$ is a univalent or a divalent metal ion. ${ }^{289}$

LDHs consist of stacked brucite $\left[\mathrm{Mg}\left(\mathrm{OH}_{2}\right)\right]$-like trioctahedral sheets that are positively charged due to the replacement of $\mathrm{Mg}$ atoms by $\mathrm{Al}$ atoms, which is why LDHs are called "anionic clays" (indeed LDHs encase anionic exchangeable species intercalated between the layers). Hydrotalcite, $\mathrm{Mg}_{0.75} \mathrm{Al}_{0.25}(\mathrm{OH})_{2^{-}}$ $\left(\mathrm{CO}_{3}\right)_{0.5} \cdot 0.5 \mathrm{H}_{2} \mathrm{O}$ (formula often abbreviated as $\mathrm{Mg}-\mathrm{Al}-\mathrm{CO}_{3}$ ) is one of the most representative mineral of the group. LDHs possess a high anion exchange capacity (AEC) of 200-500 meq per $100 \mathrm{~g},{ }^{290}$ whereas the BET surface area for $\mathrm{Mg}-\mathrm{Al}-\mathrm{CO}_{3} \mathrm{LDH}$ can be as high as $21.6 \mathrm{~m}^{2} \mathrm{~g}^{-1} \cdot{ }^{291}$ The ion exchange or coprecipitation methods can introduce inorganic or organic anions between the octahedral hydroxide layers. ${ }^{292}$ Because many biomolecules (e.g. polysaccharides) are negatively charged, LDHs can find advantageous use in enhanced biopolymer/filler complexes.

Studies have reported the basal spacing of $\mathrm{Mg}-\mathrm{Al}-\mathrm{CO}_{3}$ (given by the sum of a brucite-like octahedral sheet and the interlayer spacing) as $7.8 \AA$ (ref. 293) and $7.9 \AA \AA^{289}$ Assuming the brucitelike layer of $4.8 \AA{ }^{289,294}$ the interlayer spacing can be deducted as $\sim 3 \AA$ thick, indicating the presence of strong interaction between the water molecules and the lattice $\mathrm{OH}$ groups of hydroxide layers. ${ }^{295}$ While modification of LDHs can be carried out to modify the surface properties, delamination of LDHs has been proven to be very difficult. ${ }^{296}$ One study derived a nominal aspect ratio of $\mathrm{Mg}-\mathrm{Al}-\mathrm{NO}_{3} \mathrm{LDH}$ incorporated in PLA by the Nielsen model and calculated it as 50, while the same parameter increased to 85 for the same $\mathrm{LDH}$ after organo-modification with sodium $\gamma$-polyglutamate $\left(\gamma\right.$-PGA). ${ }^{295}$ Several works have reported on the fabrication of LDHs-based bionanocomposites, indicating the potential application of these complexes for the food packaging field (Table 1).

2.1.2.2 Micas. The mica group (Fig. 2l) includes sheet silicates that are ubiquitous in nature, and often readily available at low cost, like muscovite. These minerals (natural or synthetic), are $\mathrm{T}-\mathrm{O}-\mathrm{T}$ phyllosilicates, and both di- and trioctahedral micas exist. In some naturally occurring micas, $\mathrm{Si}^{4+}$ nearly fills all of the tetrahedral sites, whereas in the most common species (muscovite and phlogopite) $\mathrm{Al}^{3+}$ substitutes for $\mathrm{Si}^{4+}$ in a ratio close to $1: 3 .{ }^{67}$ However, the $\mathrm{Al}^{3+}$ for $\mathrm{Si}^{4+}$ substitution can reach even a $1: 1$ ratio. This mineral group is subdivided in flexible (or true) micas, where the negative charge of the tetrahedral sheet is balanced by an interlayer monovalent cation (usually potassium), and brittle micas, where a bivalent cation (generally calcium) compensates a higher negative charge of the tetrahedral sheet. As a rule, the cations hosted in the mica interlayer are anhydrous. A typical example is muscovite (ideal formula $\mathrm{KAl}_{2}\left[\mathrm{AlSi}_{3} \mathrm{O}_{10}\right](\mathrm{OH})_{2}$ ), which has layers well held together because the size of the $\mathrm{K}^{+}$matches the hexagonal hole present in the tetrahedral mesh. Therefore, micas do not swell in water and, like pyrophyllite (a $2: 1$ dioctahedral phyllosilicate without any substitution of atoms), have no internal surface area. ${ }^{303,304}$ However, micas able to expand with very high aspect ratios (up to 1000) have been obtained by synthesis. ${ }^{305}$ Micas, in combination with different biopolymers, could serve as potential filler for the production of bionanocomposites for food packaging applications (Table 1).

Despite the wide range of nanofillers currently available on the market, selecting the most appropriate solution for a specific (bio)polymer system and for a given application may be not easy as it might seem. This choice requires accounting for a number of parameters with care, all of them generally relying on the maximization of the affinity between polymer matrix and filler, with the goal of making the latter an integrative part of the former. The chemical compatibility between the two phases (polymer and filler) is the first aspect to discriminate between natural and organo-modified fillers. The overall charge in its multifaceted aspects, namely type (negative or positive), amount (density of the charge), and location (tetrahedral or octahedral layers, bulk charge or edge charge), is another important parameter to consider especially if polyelectrolyte polymers (e.g. the negatively charged pectins, carrageenans, hyaluronic acid, or positively charged chitosan) have to be associated with the filler, or if active molecules (e.g. drugs, antimicrobials, antioxidants) must be hosted within the inorganic lattice. The water absorption and swelling capability of the filler may also be critical. While most often these properties coincide, they do not necessarily appear in the same filler; physical (e.g. porosity) and chemical (e.g. interlayer forces, type of counterions) characteristics may contribute in different ways. Thus, a "zero-point-charge" porous filler may absorb water but not swell and vice versa. Another important aspect is the shape of the filler and thus its aspect ratio, which becomes of utmost importance in light of the specific application. For example, selecting a needle-like shape or a platy shape can make a 


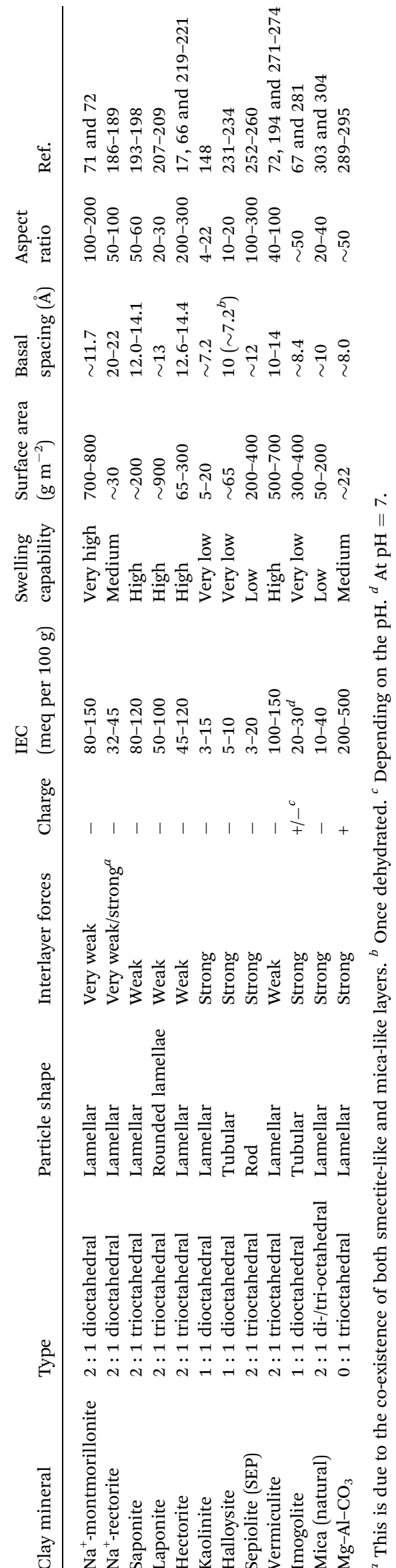

difference if the ultimate goal is to improve the mechanical properties or the barrier performance of the final nanocomposite material.

We report a summary of the information gathered during our literature search in an "all-inclusive" table (Table 2) that has never been proposed before. The aim is to provide a useful (although not exhaustive) tool for scientists working in the design and development of nanocomposite materials by offering the possibility to compare the most relevant properties or features of well-known silicate and non-silicate minerals (with the exclusion of metals and metal oxides) in one resource.

2.1.3 Metals and metal oxides. Silver is by far the most widely used metal for the generation of functional (bio)nanocomposite materials, due to its long time known antimicrobial properties. ${ }^{306}$ Compared to other antimicrobial agents (e.g., molecular antimicrobial), silver is effective against a wide spectrum of bacteria as well as fungi, algae, and possibly some viruses. ${ }^{307}$ In addition, being an element, silver is shelf stable for an extended temporal window, which is a pivotal aspect for several applications. More recent uses of silver as an antimicrobial agent concern silver nanoparticles (AgNPs). It is believed that the profound activity of AgNPs is due to two main mechanisms: (i) $\mathrm{AgNPs}$ act as a source of $\mathrm{Ag}^{+}$ions, which detach from the surfaces of AgNPs and interact with negatively charged biomacromolecular components (disulfide or sulfhydryl groups of enzymes) and nucleic acids, causing structural changes and deformation in bacterial cell walls and membranes that lead to a disruption of metabolic processes, followed by cell death; ${ }^{308}$ and (ii) AgNPs bind membrane surfaces, causing morphological changes (pitting) with subsequent loss of structural integrity and impermeability. ${ }^{309}$ Besides medical and pharmaceutical applications, AgNPs are increasingly used in the food industry; for example, to produce (bio)polymer nanocomposites for food packaging applications. Compared to silver zeolites (which will be discussed shortly), AgNPs-based nanocomposites provide slower silver ion release rates into stored foods, but also lower acute antimicrobial responses. ${ }^{310}$ From a practical point of view, this means that while a zeolite-based material might offer a superior immediate effect, the sustained antimicrobial activity of the nanocomposite would be better suited for the packaging of foods that require long transportation distances or storage times. $^{4}$

Silver nanoparticles based on silver salts or metallic silver have been demonstrated to be readily incorporated into thermoplastic packaging polymeric materials such as PE, PP, PS, and nylon. ${ }^{311}$ Sánchez-Valdes et al. coated a five layer (PE/tie/PA6/tie/PE) plastic film with an AgNPs/polyethylene nanocomposite layer and found antimicrobial activity against the fungus $A$. niger, a common food contaminant. ${ }^{312}$ From a practical point of view, the same authors interestingly observed that the activity was dependent on the coating method: methods that gave rise to a rougher surface (and hence more surface area for silver-ion release) had higher activity than those that resulted in a smoother surface. Colloidal silver particles have also been coated 90-150 $\mathrm{nm}$ thick onto paper using ultrasonic radiation, and this coated paper was shown to manifest excellent antimicrobial activity against $E$. coli and $S$. aureus, 
suggesting its potential application as a food packing material for longer shelf life. ${ }^{313}$ The incorporation of AgNPs also included biopolymer films such as alginate, chitosan, and starch, which exhibited strong antimicrobial activity against both Grampositive and Gram-negative bacteria. ${ }^{314-317}$

These (bio)nanocomposite films and coatings with potent antimicrobial function have suggested the potential application in food packaging for the extension of shelf life and enhancement of the safety of packaged food..$^{318-320}$ It has been pointed out that to make the Ag-based (bio)nanocomposite materials fully effective it is of utmost importance to consider various factors such as particle size, size distribution, degree of particle agglomeration, silver content, and the interaction of silver surface with the base polymer. ${ }^{321}$ This is because the antimicrobial efficacy of AgNPs, as any other nanocomposite antimicrobial system, strongly relies on the high surface-to-volume ratio and enhanced surface reactivity of the nano-sized antimicrobial particles, making them able to inactivate microorganisms more effectively than their micro- or macro-scale counterparts. $^{322}$

Another metal with well-recognized antimicrobial properties is copper, although its potential biocidal activity is lower compared to $\mathrm{Ag}$ ions (about $10 \mathrm{mg} \mathrm{Cu} \mathrm{kg}^{2+}$ in water is necessary to kill 106 cells of Saccharomyces cerevisiae). ${ }^{323}$ The activity of copper ions has been exploited only in few polymer nanocomposites, such as $\mathrm{Cu}-\mathrm{PE}$ nanocomposite films ${ }^{324}$ and $\mathrm{Cu}$-chitosan bionanocomposite films intended for food packaging applications. ${ }^{325}$ The main reason for this restricted use is probably because copper is regarded as toxic in contact with food, and it would accelerate biochemical deterioration with foods due to its catalytic action of oxidation. ${ }^{326}$

Metal oxides also exhibit excellent antimicrobial properties against a wide spectrum of microorganisms. For this reason, (bio)polymer nanocomposites based especially on $\mathrm{TiO}_{2}, \mathrm{ZnO}$, and $\mathrm{MgO}$ have been developed for food packaging applications. Among them, $\mathrm{TiO}_{2}$ nanocomposites are the most widely investigated. The antimicrobial properties of $\mathrm{TiO}_{2}$ lie in its photocatalytic activity, which is intimately linked to its crystal structure. There are three different forms of titanium dioxide (rutile or anatase, tetragonal, brookite, and orthorhombic) with different reactivity depending on their characteristic band gap. The irradiation of $\mathrm{TiO}_{2}$ at higher energies than the band gap generates electron-hole pairs, while giving rise to redox reactions. Negative electrons generate $\mathrm{O}^{2-}$, and positive electric holes generate hydroxyl radicals. Reactive oxygen species oxidize organic molecules, and kill bacteria and viruses. ${ }^{323} \mathrm{TiO}_{2}$ coated polypropylene films illuminated with UV light sources, were effective in decreasing the counts of $E$. coli in in vitro experiments up to $3 \log _{10} \mathrm{CFU} \mathrm{g}{ }^{-1}$, but also during the storage of lettuce a reduction over $1 \log _{10} \mathrm{CFU} \mathrm{g}^{-1}$ was observed..$^{327}$ EVOH films loaded with $\mathrm{TiO}_{2}$ nanoparticles were produced by Cerrada et al., specifically for food packaging applications. ${ }^{328}$ The authors observed the effective photo-activated biocidal properties of the films against the nine microorganisms (bacteria and yeasts) cited to be involved in food poisoning and spoilage. From a practical point of view, the main limitation of $\mathrm{TiO}_{2}$ nanoparticles for the food packaging sector is due to its low photon utilization efficiency and necessity of the ultraviolet (UV) as an excitation source (i.e., $\mathrm{TiO}_{2}$-based antimicrobials are only active in the presence of UV light). ${ }^{329}$ Besides the antimicrobial activity, $\mathrm{TiO}_{2}$ nanoparticles may provide new features to the advantage of the overall performance of the final packaging material. In principle, food packaging films incorporating $\mathrm{TiO}_{2}$ nanoparticles may have the additional benefit of protecting food content from the oxidizing effects of UV irradiation while maintaining good optical clarity, as $\mathrm{TiO}_{2}$ nanoparticles are efficient short-wavelength light absorbers with high photostability. ${ }^{4}$ As for AgNPs and $\mathrm{TiO}_{2}$, their photoactivity can oxidize ethylene to $\mathrm{H}_{2} \mathrm{O}$ and $\mathrm{CO}_{2} \cdot{ }^{323} \mathrm{TiO}_{2}$ nanoparticles have also been used to produce oxygen scavenger films. ${ }^{330}$ In addition, incorporation of $\mathrm{TiO}_{2}$ into synthetic plastic matrix has shown to increase the biodegradability. ${ }^{331}$ Another interesting development concerns the 'intelligent' packaging nanocomposite films, i.e., those intended to monitor the condition of packaged food or the environment surrounding the food. Lee et al. developed an UV-activated colorimetric oxygen indicator, which uses nanoparticles of $\mathrm{TiO}_{2}$ to photosensitize the reduction of methylene blue (MB) by triethanolamine in a polymer encapsulation medium using UVA light. After UV irradiation, the sensor bleaches and remains colorless until it is exposed by oxygen, when its original blue color is restored. The rate of color recovery is proportional to the level of oxygen exposure. ${ }^{32}$

$\mathrm{TiO}_{2}$ thin films can be prepared on several substrates by various techniques such as chemical vapor deposition, evaporation, magnetron sputtering, ion beam technique, chemical spray pyrolysis, electro-deposition, and sol-gel method. The sol-gel process is suitable for producing composite materials of high purity without multiple steps. ${ }^{33}$

Zinc oxide ( $\mathrm{ZnO})$ particles are also known for their antimicrobial activity. Compared to AgNPs, ZnO have some advantages: first of all, the lower cost, which is related to the abundance of zinc as ubiquitous trace metal; and second, $\mathrm{ZnO}$ nanoparticles have also claimed to possess UV-blocking properties. $^{334}$ Different ZnO-based nanocomposite films specifically intended for food packaging applications have been developed in recent years. For example, PVC films coated with $\mathrm{ZnO}$ nanoparticles were reported to have antimicrobial activities against $E$. coli and $S$. aureus. ${ }^{335}$ In a more recent work, Li et al. also verified the potential of the nano-packaging containing ZnO nanoparticles during the storage of Fuji apple cuts, observing a better preservation of quality indicators such as ascorbic acid and polyphenol content, and lower counts of typical altering microorganisms. ${ }^{336}$ Nanocomposite films of LDPE containing AgNPs and $\mathrm{ZnO}$ were claimed to exhibit antimicrobial activity, showing an impressive impact of the proposed nano-packaging on the shelf life of orange juice. ${ }^{337}$ It was also demonstrated that combinations of allylisothiocyanate, nisin, and zinc oxide nanoparticles coated on glass jars were able to effectively inactivate Salmonella in liquid egg albumen. ${ }^{338}$ It was observed that the antibacterial activity of ZnO nanoparticles increases with decreasing particle size. ${ }^{339}$ In addition, this activity does not require the presence of UV light (unlike $\mathrm{TiO}_{2}$ ), but it is stimulated by visible light. ${ }^{340}$ 
2.1.4 Zeolites. Zeolites (Fig. 3a), also known as "framework silicates", are the only aluminosilicates in the form of hydrated crystals within the tectosilicates subclass, with a three-dimensional channel system giving rise to a highly porous structure, with pore size ranging from 2.5 to $15 \AA^{\text {(341) }}$ (Fig. 3b). Zeolites have the following general formula $\mathrm{M}_{x} \mathrm{D}_{y}\left[\mathrm{~A}_{x+2 y} \mathrm{Si}_{n-(x+2 y)} \mathrm{O}_{2 n}\right]$. $\left.m \mathrm{H}_{2} \mathrm{O}\right] ; \mathrm{M}$ and $\mathrm{D}$ represent univalent and divalent cations, respectively, that balance the excess of negative charge due to $\mathrm{Al}^{3+}$ for $\mathrm{Si}^{4+}$ substitutions in the tetrahedral framework. Water molecules and cations are extra-framework components, which are located inside the channel system and can migrate throughout its length. This explains the cation exchange capacity and dehydration/rehydration ability of zeolites. There is a large variety of naturally occurring as well as synthetic zeolites with different pore structures, crystal sizes, and chemical compositions. Common features of zeolitic materials include the following: adsorption capacity; catalytic sites with different strengths; sizes of cages and channels very similar to those of many molecules of interest; and high cation exchange capacity and selectivity. ${ }^{342}$ Concerning synthetic zeolites, adjusting the size, shape, and polarity allow enhancing or depressing the above properties according to the targeted application. On the other hand, also some natural zeolites are currently used in industrial applications.

With regard to zeolitic membranes, despite many announcements in the last 15 years that have claimed the release of new commercial products for industrial applications, ${ }^{342}$ solvent dehydration remains to date the only industrial application able to exploit the multifaceted potential of zeolites profitably. ${ }^{343}$ This represents quite a surprising circumstance, in light of several excellent results in laboratory studies on zeolite membranes specifically intended for gas- and liquid-phase separations. ${ }^{343}$ Incorporation of zeolites into polymer gave rise to the fabrication of mixed-matrix membranes, ${ }^{344}$ which developers claimed were superior in selectivity compared to the traditional synthetic polymeric membranes used in the petroleum and petrochemical industries for separation applications $^{345-347}$ such as pervaporation, e.g. for separation of volatile organic compounds (VOCs)-water mixtures, ${ }^{348-352}$ liquid separation by reverse osmosis, ${ }^{353}$ forward osmosis techniques, ${ }^{354}$ and ultrafiltration. ${ }^{355}$ Zeolites have also shown great potential for the catalysis of a variety of hydrocarbon reactions, including
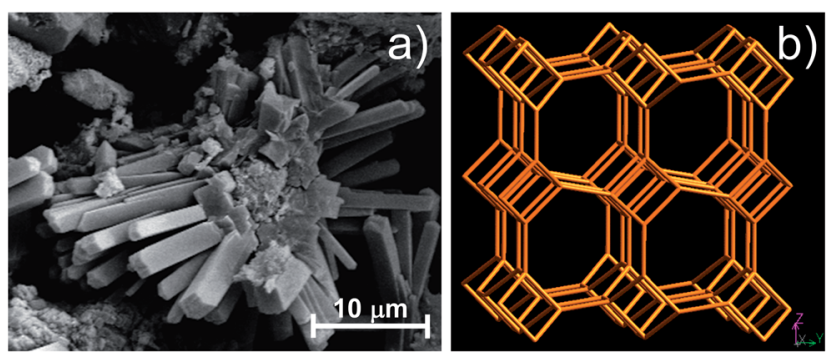

Fig. 3 (a) Crystals of phillipsite (a natural zeolite). Sample from Palombara quarry, Italy; (b) Schematic representation of phillipsite channel system plotted along $X$ axis. Width of the channel is about $0.37 \mathrm{~nm}$ (http://izasc.ethz.ch/fmi/xsl/IZA-SC/ft.xsl). cracking, hydrocracking, alkylation, and isomerization, based on their combination of high thermal stability, high acidity and shape selectivity. ${ }^{356}$

Zeolite nanoparticles are of particular interest also for their adsorption capability. For example, zeolites successfully removed the pungent smell components identified in a coffee aroma-containing gas, ${ }^{357,358}$ reduced the odor and VOCs emissions of natural-flour-filled PP composites, ${ }^{359}$ and removed toxic and carcinogenic compounds (e.g. $\mathrm{NO}$ and $\mathrm{NO}_{x}$ ) from the main tobacco smoke stream by direct addition either in the cigarette filter or in the smoking tobacco leaves. ${ }^{360-365}$ Present and possible future applications of natural and synthetic zeolites also concern the biomedical field and the cosmetic sector. ${ }^{366}$

Silver ions $\left(\mathrm{Ag}^{+}\right)$-loaded zeolite micro- and nanocomposites are among the most widely used materials that include zeolites. In these composites, ionic exchange mechanisms replace the alkaline and alkaline earth metal ions naturally present within the zeolite with silver. ${ }^{323} \mathrm{Ag}^{+}$ions, due to their inherent antimicrobial activity, allow the production of potentially profitable new materials with antimicrobial features for use in many applications, including food contact and active food packaging scopes. For example, developers in Japan have used Agsubstituted zeolites as the most common antimicrobial agent associated with plastics to preserve packaged food products, in particular for those systems in which the use of volatile agents is not feasible, i.e. where the bioactivity is based on the migration of the antimicrobial molecule by direct contact with food. ${ }^{367}$ According with the Food and Drug Administration (FDA) Food Contact Substance Notification, in the USA, zeolite-based materials may be used in all types of polymers intended to come in contact with food, ${ }^{368}$ while the European Food Safety Agency expressed a positive opinion of in 2005 about the use of two different zeolites containing silver ions in food contact surfaces. ${ }^{369}$ However, the use of $\mathrm{Ag}^{+}$-zeolites for food packaging applications is limited to $0.05 \mathrm{mg} \mathrm{Ag}^{+} \mathrm{kg}^{-1}$ of food, which represents the no observable adverse effect level for humans. ${ }^{370}$ The extensive research on the development of $\mathrm{Ag}^{+}$-zeolite antimicrobial food packaging systems has led to manifold applications over the last two decades, as reported in recent reviews. ${ }^{29,323}$ However, the use of $\mathrm{Ag}^{2+}$-zeolites nanoparticles for food packaging applications is still highly debated, due to some evidences pointing to potential risks associated with these new types of antimicrobial materials. ${ }^{323}$

Most recent uses of zeolites-based composites for food packaging applications concern membranes and films for fresh or minimally processed fruits and vegetables, which require selective permeation of carbon dioxide, oxygen, ethylene, and water vapor. Most research in this field involves ethylene, a plant growth regulator that plays a key role in physiological processes and during postharvest. Controlling the presence of ethylene in packages and storage environments could extend the shelf life of many fresh fruits and vegetables. Monprasit et al. incorporated a commercial hydrophobic zeolite (5 wt\%) into low-density polyethylene (LDPE), achieving much higher ethylene permeability and selectivity, with concomitant appropriate tensile properties. ${ }^{371}$ In another study, ${ }^{372}$ the quality of broccoli packaged in LDPE-containing zeolite (as an ethylene 
absorber) resulted as the most similar to fresh broccoli. Boonruang et al. compared the effects of the use of various types of packaging films in maintaining the quality and extending the shelf life of mangoes fruit. ${ }^{373}$ The authors demonstrated that an ethylene-removing mechanism based on the use of zeolites incorporated into PE films extended the shelf life of mangoes up to 40 days, as compared with 20 days for the control (i.e. nonpackaging treatment) and 5 days with common non-perforated $\mathrm{PE}$ film. Another study described the use of zeolite as $\mathrm{CO}_{2}$ absorber in combination with $\mathrm{Na}_{2} \mathrm{CO}_{3}$ to develop a suitable packaging system for kimchi, with controlled pressure and volume conditions. ${ }^{374}$ Metal-doped (e.g. iron, palladium, and platinum) zeolites are suitable oxygen scavengers for products sensitive to oxidation, ${ }^{323}$ as has also been demonstrated for zeolites with adsorbed terpenes or phenol derivatives loaded in packaging bags. ${ }^{375}$ Another study investigated the possibility of using zeolite modified with a series of organosilane compounds to control the gas permeability properties of membranes containing the inorganic filler. ${ }^{346}$ The addition of zeolite into PP films made PP a water- and water vapor-sensitive material. ${ }^{376}$ Developers have also produced $\mathrm{PP} /$ zeolite composite films coated with aluminum to obtain a packaging material impermeable to light, impermeable to moisture from the outer surface, and permeable to water and adsorbing moisture from the inner surface. ${ }^{377}$

The use of zeolites as inorganic filler may also improve the mechanical and thermal properties of plastics commonly used in food packaging. Biswas et al. reported that increasing zeolite $4 \mathrm{~A}$ content up to $50 \mathrm{wt} \%$ increased the Young's modulus and yield stress of linear low density polyethylene (LLDPE) from 127 to $179 \mathrm{MPa}$ and 9.4 to $11.1 \mathrm{MPa}$, respectively. ${ }^{378}$ Yuzay et al. reported that increasing zeolite $4 \mathrm{~A}$ concentration up to $5 \mathrm{wt} \%$ resulted in increased Young's modulus of PLA from 1295 to $1465 \mathrm{MPa}$ and tensile strength from 62.5 to $67.6 \mathrm{MPa}$, although elongation at break slightly decreased from 6.9 to $6.6 \% .{ }^{379}$ Other studies attributed the poor mechanical properties of zeoliteloaded PP to the weak interfacial interactions between polymer and inorganic filler. ${ }^{376,380}$ To address this issue, developers have improved the filler compatibility and mechanical properties of the composites by surface treatments of natural zeolite. ${ }^{381}$ Similarly, studies have reported that an activated natural zeolite has a compatibilizing effect on a recycled tetra-component polymer blend consisting of PP (40 wt\%), LDPE, high density polyethylene (HDPE) (15 and $40 \mathrm{wt} \%$, respectively), and polystyrene (PS) (5 wt \%). ${ }^{382}$

Zeolites have also improved the thermal properties of oilbased polymers such as $\mathrm{PP},{ }^{359,376,383}$ polymers of natural origin such as PLA, ${ }^{384}$ sodium alginate, ${ }^{385}$ and blends of oil-based and natural-origins polymers, such as PE/thermoplastic starch (PE/ TPS). ${ }^{386}$

2.1.5 Graphene. Graphene is the building unit of graphite, a three-dimensional layered mineral allotrope of carbon composed of several stacked layers of graphene ${ }^{387}$ (Fig. 4a). More specifically, graphene is a two-dimensional material composed of a single planar sheet of $\mathrm{sp}^{2}$-bonded carbon atoms packed in a honeycomb crystal lattice with large specific surface area (Fig. 4b). Although the first reported method for

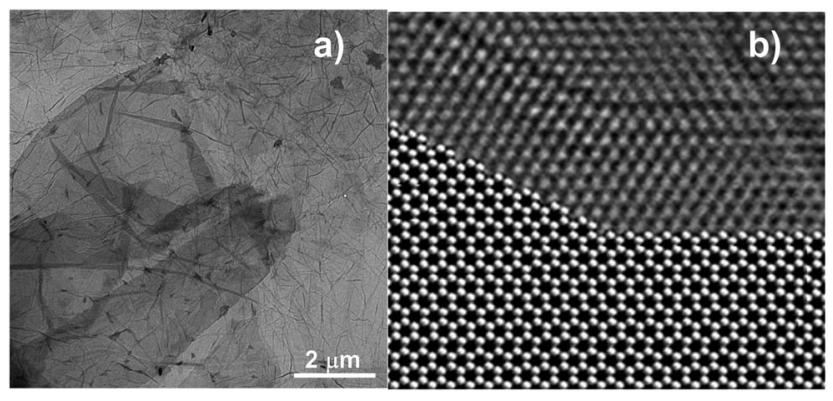

Fig. 4 (a) TEM image of graphene sheets (dark areas denote overlapping zones); (b) HRTEM image of 3 overlapping zigzag-armchair edges obtained by applying Joule heating to a graphitic nanoribbon inside a HRTEM; hexagonal models are depicted for clarity (reproduced with permission from Elsevier $\operatorname{Ltd}^{387}$ ).

production of graphene nanosheets dates back to $1970,{ }^{388}$ its individual layered form was first discovered in 2004 through a micromechanical cleavage method using flake graphite as a starting material. ${ }^{389}$ Graphene nanosheets have extremely high Young's modulus values ( 1000 GPa), ${ }^{390}$ fracture strength $(\sim 125 \mathrm{GPa}),{ }^{390}$ thermal conductivity $\left(\sim 5000 \mathrm{~W} \mathrm{~m}^{-1} \mathrm{~K}^{-1}\right),{ }^{391}$ mobility of charge carriers $\left(\sim 200000 \mathrm{~cm}^{2} \mathrm{~V}^{-1} \mathrm{~s}^{-1}\right), 392$ specific surface area (calculated value, $\sim 2630 \mathrm{~m}^{2} \mathrm{~g}^{-1}$ ), ${ }^{393}$ fascinating transport phenomena (e.g., the quantum Hall effect ${ }^{394}$ ), and gas impermeability. ${ }^{395}$ These properties make graphene one of today's most exciting materials, as it represents the best candidate for the enhancement of electrical, mechanical, thermal and gas barrier properties for advantageous exploitation in many areas, such as photovoltaics, biosensors, supercapacitors, super adsorbents and fuel cells, ${ }^{396}$ just to provide some examples. Despite the broad spectrum of potential applications, there are still many challenges for graphene to reach its full potential. Among others, production costs represent the main limitation to large scale utilization, mainly due to the highly expensive and low-yielding methods and procedures to obtain graphite monolayers.

The first attempt to produce graphene was based on the chemical conversion of graphite into graphite oxide by chemical oxidation, with subsequent dispersion and exfoliation in water or suitable organic solvents. Several researchers, such as Staudenmaier, ${ }^{397}$ Hummers and Offeman, ${ }^{398}$ developed oxidation methods to produce graphene oxide (GO) from graphite flakes. The main drawback involved in the chemical oxidation process is the use of hazardous strong oxidizing reagents (e.g., $\mathrm{HNO}_{3}$, $\mathrm{KMnO}_{4}$, and/or $\mathrm{H}_{2} \mathrm{SO}_{4}$ ) necessary to overcome the enormous van der Waals-like forces between graphene layers to yield a complete exfoliation of graphite flakes and to disperse the resulting graphene sheets stably in a liquid media. ${ }^{398-400}$

The new functional groups arising from chemical oxidation are mostly in the form of hydroxyl and epoxy groups on the basal plane, with smaller amounts of carboxyl, carbonyl, phenol, lactone, and quinone at the sheet edges. ${ }^{401,402}$ These highly reactive oxygen functionalities, besides making possible the grafting of both small molecules and polymers onto GO sheets, are responsible for the strongly hydrophilic character of 
GO, such that intercalation of water molecules between the layers readily occurs, leading to an interlayer spacing between 6 and $10 \AA$, depending on the water content. ${ }^{403}$

Most recent methods to produce graphene fall within either the bottom-up or the top-down strategies. The bottom-up approach, based on the organic synthesis starting from small precursors (e.g. atoms, molecules, and so on) includes chemical vapor deposition (CVD), ${ }^{\mathbf{4 0 4 , 4 0 5}}$ epitaxial growth on silicon carbide ${ }^{\mathbf{4 0 6 - 4 0 8}}$ and metals, ${ }^{\mathbf{4 0 9 , 4 1 0}}$ reduction of $\mathrm{CO},{ }^{411}$ and conversion of $\mathrm{CO}_{2}{ }^{412}$ In particular, CVD and epitaxial growth produce relatively good-quality large graphene sheets with fewer defects, but are not suitable for the fabrication of polymer nanocomposites, because these require large quantities of graphene sheets.

Top-down methods are based on the exfoliation of graphite into few or single-layered graphene sheets by breaking the van der Waals-like forces between graphite layers. Top-down methods account for two main routes. The first route, which includes a micromechanical cleavage based on "Scotch tape" 389 method and mechano-chemical methods such as ball milling ${ }^{413}$ and roll milling, ${ }^{\mathbf{4 1 4}}$ consists of the separation of strongly layered graphite into individual graphene sheets without basal plane distortion. The second route involves the basal plane distortion of graphene sheets and includes sono-chemical methods such as sonication $^{415}$ and ultrasonication. ${ }^{416}$ Micromechanical cleavage of graphite, referred to as "Scotch tape" method, gave birth to renewed interest in graphene because it disclosed the huge potential of the material. ${ }^{389}$ Although the Scotch tape method provides large and high-quality sheets, it enables only limited production, which makes it suitable exclusively for fundamental studies. ${ }^{389}$ By contrast, sonication and milling techniques allow industrial-scale outputs that make them effective and low-cost strategies for mass production of highquality graphene sheets.

The use of graphene even at low loading, makes it possible to obtain nanocomposite polymer systems with highly improved properties, such as tensile strength and elastic modulus, electrical and thermal conductivity, thermal stability, gas barrier, and flame retardance. Due to this broad multifunctionality, graphene/polymer nanocomposites can find application in various fields. These include the following: advanced biochemical and electrochemical applications with flexible and electrically conductive properties; ${ }^{\mathbf{4 1 7 , 4 1 8}}$ sensors, including electrochemical biosensors ${ }^{\mathbf{4 1 9 , 4 2 0}}$ and prototype gas sensors; ${ }^{\mathbf{4 2 1}}$ thermal interface applications with high thermal conductivity, low electrical conductivity, and highly compliant nature (e.g. thermal pads and thermal adhesives); ${ }^{\mathbf{4 2 2 , 4 2 3}}$ electric and electronic engineering materials, such as touch panels or flexible displays, where high optical transparency, good barrier properties, thermal stability, and mechanical strength are required; 404,424-427 automotive engineering, e.g. parts where thermal, mechanical, and flame-retardant properties are necessary; ${ }^{428}$ highly efficient visible-light plasmonic photocatalysts; ${ }^{\mathbf{4 2 9 , 4 3 0}}$ biomedical applications, where controlled release behavior, long term biocompatibility, better mechanical properties, faster tissue regeneration, and less thrombogenicity are sought-after properties; ${ }^{\mathbf{4 3 1 , 4 3 2}}$ transportation and space technologies with high thermal conductivity; ${ }^{\mathbf{4 3 3}}$ piezoelectric applications; ${ }^{\mathbf{4 3 4}}$ aerospace and radar evasion applications with electromagnetic wave shielding effects at microwave frequencies; ${ }^{\mathbf{4 3 5 , 4 3 6}}$ electronic, energy storage, and photovoltaic devices with enhanced electrical conductivity; ${ }^{\mathbf{4 0 5 , 4 3 7 , 4 3 8}}$ package-free flexible photovoltaic devices; ${ }^{\mathbf{4 2 , 4 3 9}}$ and anticorrosion coatings with outstanding barrier properties against both $\mathrm{O}_{2}$ and $\mathrm{H}_{2} \mathrm{O} .{ }^{440}$

Potential use of graphene-based polymer nanocomposites also includes food packaging applications due to the expected

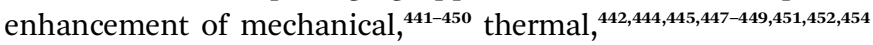
and thermo-mechanical properties ${ }^{\mathbf{4 5 4 , 4 5 5}}$ of the final materials. Another benefit arising from the use of graphene that can boost its application in the food packaging field relies on its gasimpermeable atomic membrane, which would allow producing barrier materials against permeation of $\mathrm{O}_{2},{ }^{445,455,456} \mathrm{~N}_{2},{ }^{444,455}$ and He. ${ }^{444}$ Graphene exhibits a unique tunable water-permeable atomic membrane, which is of paramount importance for food packaging applications. For example, Geim et al. recently reported the tunable permeation rate of water across a GO membrane that is completely impermeable to other liquids, vapors, and gases. $^{457}$

Yoo et al. have recently published a comprehensive review on the potential applications of graphene and GO to produce barrier polymers. ${ }^{458}$ In addition, a recent study tested the transparency and water resistance of graphene-based polymers, ${ }^{\mathbf{4 5 0 , 4 5 6}}$ making this the preferential filler for exploring new packaging applications. Although only few works have clearly addressed the potential impact of graphene/polymer nanocomposites in the food packaging area (Table 3), this number is increasing considerably, demonstrating the interest in graphene-based nanocomposites also for this sector.

The impact at biological level of the newly developed graphene-based nanocomposites is not yet a major focus of research. Because a thorough understanding of the biological behavior of nanomaterials would guarantee the sustainability of nanotechnology, ${ }^{473-478}$ future research toward this topic must fill in the current lack of this important information.

In light of the recently obtained exciting results, which may make the production costs of graphene accessible, the use of graphene, even though it is in its early stages, may be the most promising approach to guide future advancement in the development of new, revolutionary packaging materials.

\section{Fabrication of (bio) nanocomposites}

To take full advantage of the great potential of (bio)nanocomposites for real applications, the integration of the selected nano building blocks in the polymer matrices is of primary importance. Many factors, including the exfoliation degree of the fillers, their spatial arrangement (wrinkling or stretched), the morphology of the composite, and the dispersion state in the polymer matrix (stacked or agglomerated)-hence the extent of the interfacial interactions between filler and polymer-may dictate the final performance of the nanocomposite packaging material. ${ }^{479}$ Accordingly, for example, the ultimate 


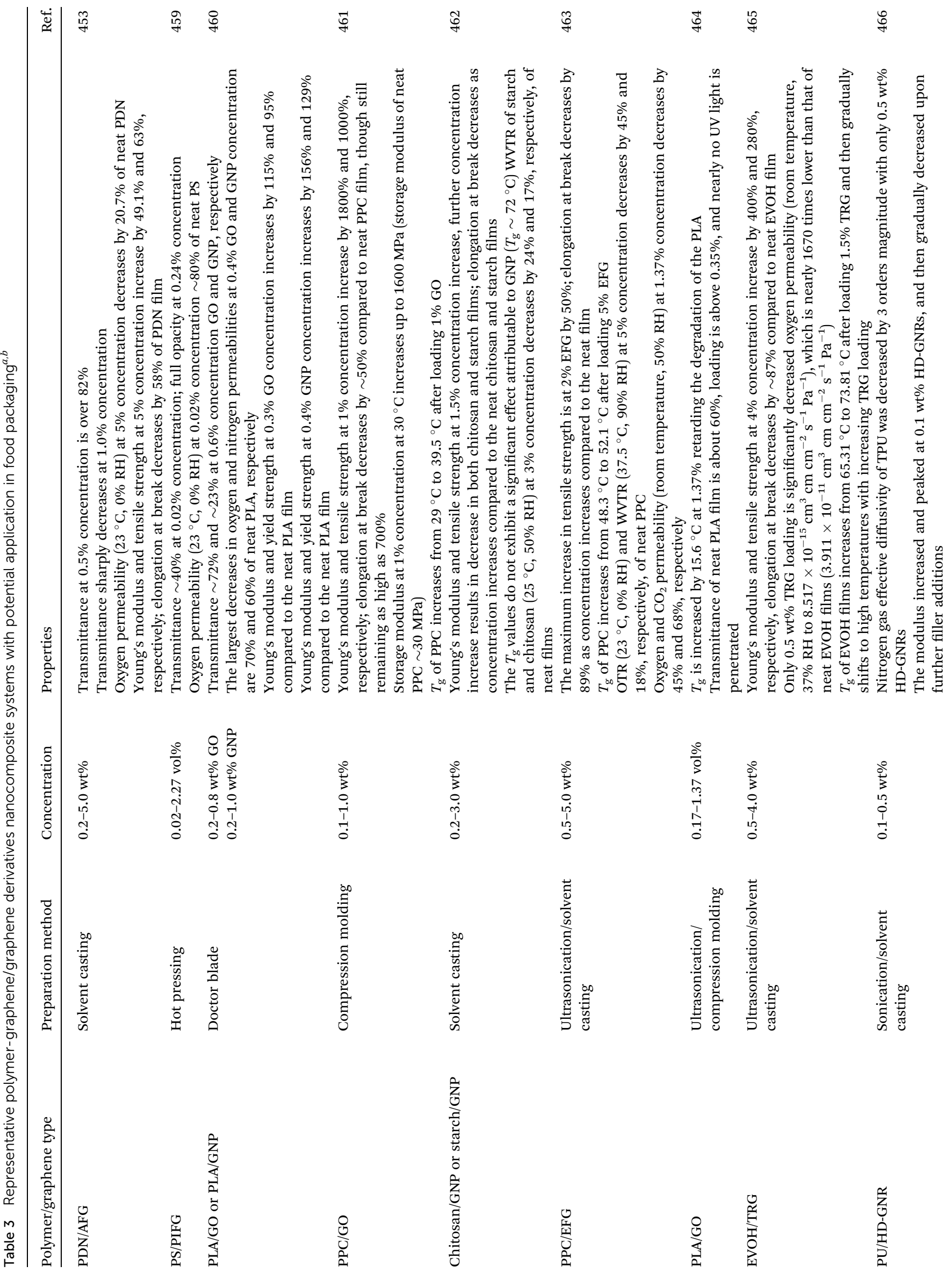




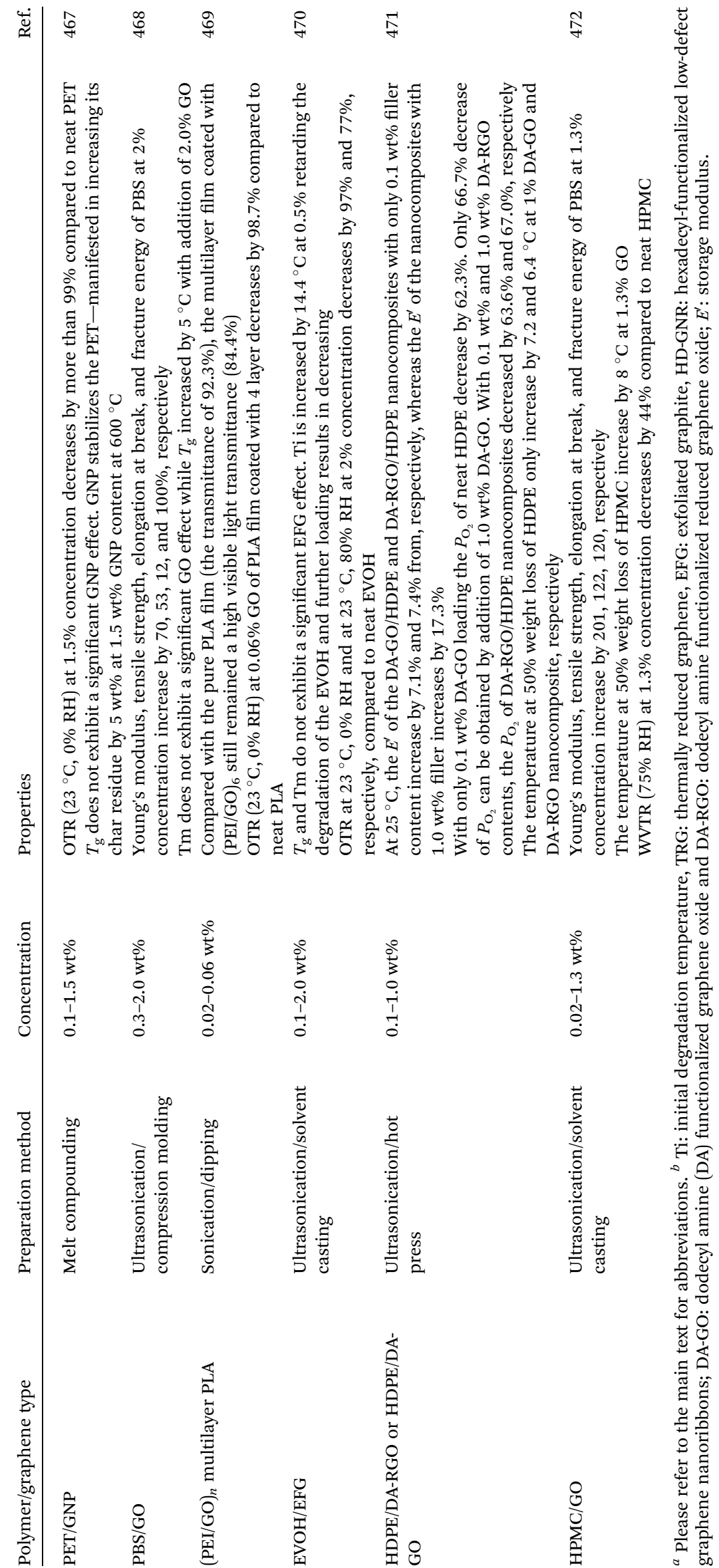


barrier properties of nanocomposite polymers will be affected by nanosized fillers in two specific ways: (i) a more tortuous path for diffusion of the permeant and (ii) local changes in the polymer matrix properties (e.g., molecular mobility) at the interfacial (polymer nanoparticle) regions. ${ }^{4}$

Historically, the nanofiller incorporation into the polymer matrix takes place through three main methods, i.e. (i) the in situ polymerization, (ii) the solution casting or (iii) the melt processing. ${ }^{15,60,480,481}$ Most recently, sonication and high-shear mixing have been proposed as alternative techniques to prepare (bio)nanocomposite materials.

\subsection{In situ polymerization}

This process involves the polymerization of monomer species in the presence of the layered materials. In this process, the nanoclays are first swollen within the liquid monomer or monomer solution, which is followed by its polymerization in between the intercalated sheets (Fig. 5a). Polymerization can be initiated either by heat or radiation, by the diffusion of a suitable initiator or by an organic initiator or catalyst fixed through cationic exchange inside the interlayer and before the engorgement step when required. ${ }^{17}$ The macromolecules molecular weight increases, leading to a $d_{001}$ increase and sometimes to an almost fully exfoliated morphology for some studied systems. ${ }^{17}$ One of the main drawbacks of this method lies in the tendency of inorganic particles to phase separate and sediment quickly from the organic polymer. To enhance the interaction at the solvent/filler interface, specific groups have to be linked onto their surface to stabilize the nanoparticle dispersions. ${ }^{\mathbf{4 8 2}}$ Another relevant aspect concerns the unsuitableness of this method for biomacromolecules such as proteins and polysaccharides (that are already extracted as 'polymerized' entities), which indeed represent target polymers for the generation of bionanocomposites. ${ }^{60}$

\subsection{Melt processing}

In the melt processing technique, the nanoparticles are mixed with the polymer in the molten state (Fig. 5b). More specifically, the process involves mixing the particles with the polymer and heating the mixture above the softening point of the polymer, statically or under shear interlayers. ${ }^{\mathbf{4 8 3 , 4 8 4}}$ The main advantages of the melt processing method are the absence of any solvent throughout the process and its compatibility with current industrial processes, such as extrusion and injection molding. Several factors may affect the extent of exfoliation/intercalation by melt processing, such as the thermodynamic interaction between the polymer and the nanoparticle and the transport/ diffusion of polymer chains from the bulk melt into the silicate interlayers. ${ }^{\mathbf{4 8 3 , 4 8 4}}$ To increase the compatibility between polymer and nanoparticles to ensure proper dispersion, two main factors have to be taken into consideration, namely the favorable enthalpic interaction between the polymer and the nanoparticle (which can be manipulated by chemical modification of the filler and/or the polymer) and proper processing conditions. ${ }^{481}$ In this regard, shearing is necessary to induce the platelets delamination from tactoids, while an extended residence time is needed to allow the polymer chains to diffuse into the inter-layer gallery and then obtain an exfoliated morphology. ${ }^{485}$
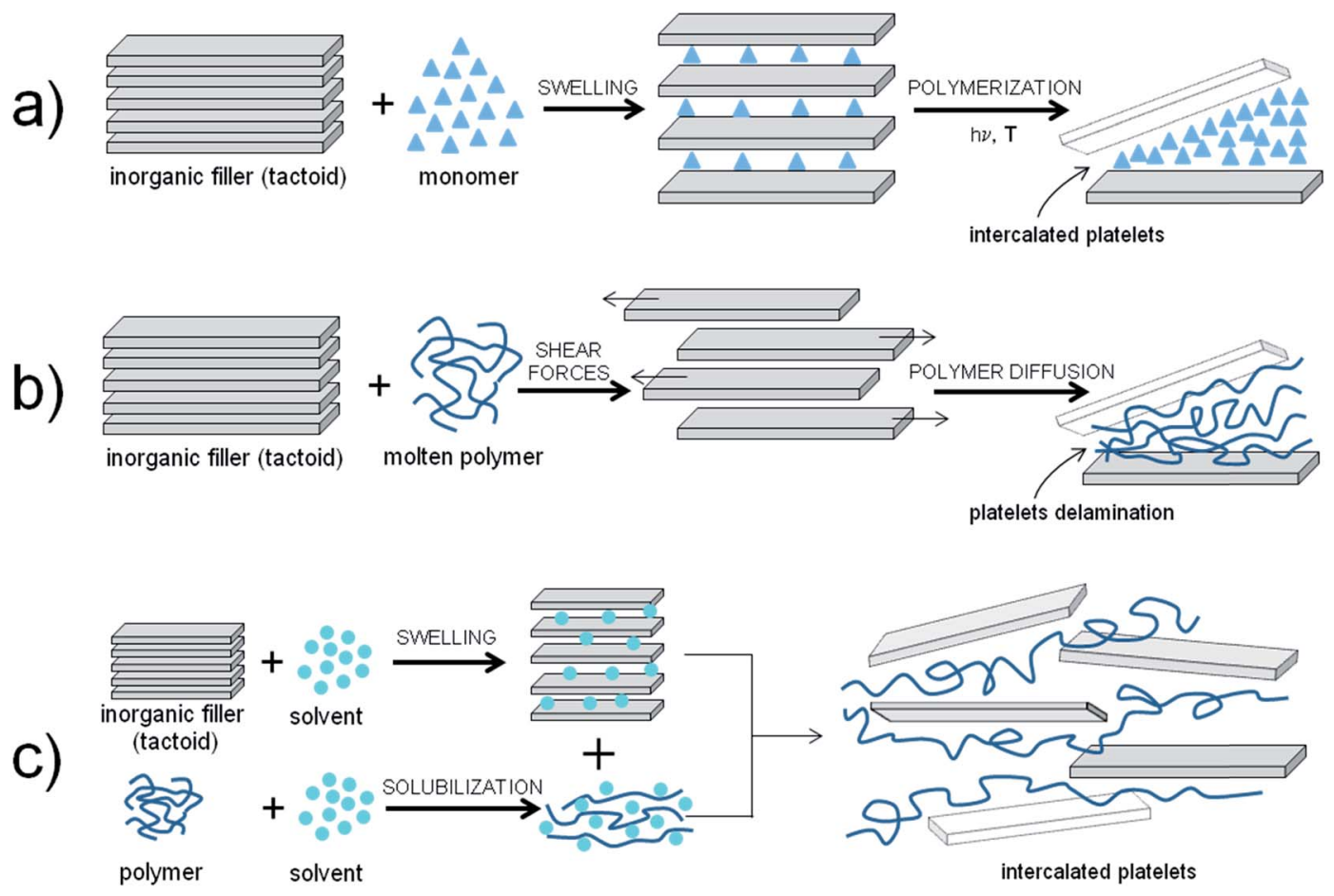

Fig. 5 Schematic representation of (a) in situ polymerization, (b) melt processing, and (c) solution casting. 
However, in the case of most bionanocomposites (e.g., PLA-, chitosan-, and pullulan-based nanocomposites), the melt processing technique is not adequate in principle because these polymers tend to degrade due to either the mechanical shearing force or the temperature applied during processing. For example, PLA experiences processing instability (i.e., thermal, oxidative, and hydrolytic degradations) may occur during processing, which leads to the cleavage of polymer chains and consequently to a decrease in molecular weight. This degradation could even be accelerated in nanocomposites that have organically modified clays, which could initiate the degradation. ${ }^{481}$ Therefore, careful optimization of the processing parameters is required for the majority of thermally sensitive biopolymers. ${ }^{60}$

\subsection{Solution casting}

The solution casting method is based on a solvent system in which the polymer (or pre-polymer, in case of insoluble polymers) and any other component of the mixture (e.g., surfactants) is soluble. The polymer is usually dissolved in a suitable solvent while the nano-fillers are dispersed in the same or a different solvent before the two are mixed together to generate a homogeneous dispersion (Fig. 5c). The main advantage of this method is the relatively rapid exfoliation of the stacked layers by the use of an appropriate solvent. ${ }^{\mathbf{1 7 4 8 4}}$ The successive addition of polymer solution to the dispersion of the complete delaminated nanoparticles (e.g., platelets) leads to the strong interaction between macromolecules and individual layers. The driving force for the intercalation of the biopolymer into the clay galleries from solution is the entropy gained from the desorption of the solvent molecules, which compensates for the decreased entropy of the confined, intercalated chains. When the solvent is evaporated, the intercalated structure remains, which results in the final nanocomposites. ${ }^{481}$ Due to the large amount of the solvent required, this method is perceived as unsafe and non-environmentally benign when organic solvents are required (e.g., for non-polar or highly hydrophobic polymers). ${ }^{\mathbf{4 8 6}}$ Conversely, this method has gained increasing attention for water-soluble polymers such as $\mathrm{PVOH}$, especially in the form of thin coatings, which reduces the amount of water used throughout the process. More recently, the solution casting method has been adopted for the generation of bionanocomposites, for which both in situ polymerization and melt intercalation are often unsuitable due to the inherent characteristics of most biopolymers, as discussed before. From a practical point of view, the fabrication of (bio)nanocomposite films and coatings through the solution casting method requires special attention during the removal of the solvent (evaporation) step. Indeed, if a small amount of solvent remains entrapped in the final product, a lower interfacial interaction between the polymer and the filler can arise. ${ }^{487}$ For this reason, coupling infra-red lamps with high performance air ovens is the best strategy to prevent this potential drawback. ${ }^{488}$

\subsection{Sonication}

Sonication is increasingly used in the top-down generation of nanoparticles. This is achieved through deagglomeration and reduction of microsized particles (e.g., tactoids) by means of sound waves (more frequently, ultrasound waves) as a result of the mechanical effects of the phenomenon called cavitation, which refers to the formation, growth, and implosive collapse of bubbles in a liquid (Fig. 6). ${ }^{489}$ The speed of sound in a typical liquid is 1000 to $1500 \mathrm{~m} \mathrm{~s}^{-1}$, and ultrasonic wavelengths will vary from roughly $10 \mathrm{~cm}$ down to $100 \mathrm{~mm}$ over a frequency range of $20 \mathrm{kHz}$ to $15 \mathrm{MHz}$, much larger than the molecular size scale. The chemical and physical effects of ultrasound therefore arise not from a direct interaction between chemical species and sound waves, but rather from the physical phenomenon of acoustic cavitation. ${ }^{\mathbf{4 9 0 - 4 9 2}}$

After bubbles collapse, a number of major local events prompt the deagglomeration of microsized particles dispersed in the medium: heating $(\sim 5000 \mathrm{~K})$, high pressure $(\sim 1000 \mathrm{~atm})$, huge heating-cooling rates $\left(>10^{9} \mathrm{~K} \cdot \mathrm{s}^{-1}\right)$, and abrupt liquid jet streams $\left(\sim 400 \mathrm{~km} \cdot \mathrm{h}^{-1}\right) .{ }^{493-495}$ The extreme, transient conditions produced during acoustic cavitation allow the formation of unique materials and also permit syntheses on the benchtop in a room-temperature liquid that would otherwise require high temperatures, high pressures, or long reaction times. The most important physical phenomena for the preparation or modification of nanomaterials are microjets and shock waves. Microjets occur when bubbles collapse near an extended surface (i.e., surfaces several times larger than the bubble radius). ${ }^{496}$ In addition, shock waves can accelerate solid particles suspended in the liquid. Interparticle collisions can reach velocities of hundreds of meters per second, which is the main cause, among other phenomena, of the exfoliation of layered materials into 2-D layers. ${ }^{497-499}$

Ultrasonication, first adopted to develop nanocomposites based on oil-derived polymer/inorganic clay systems, has

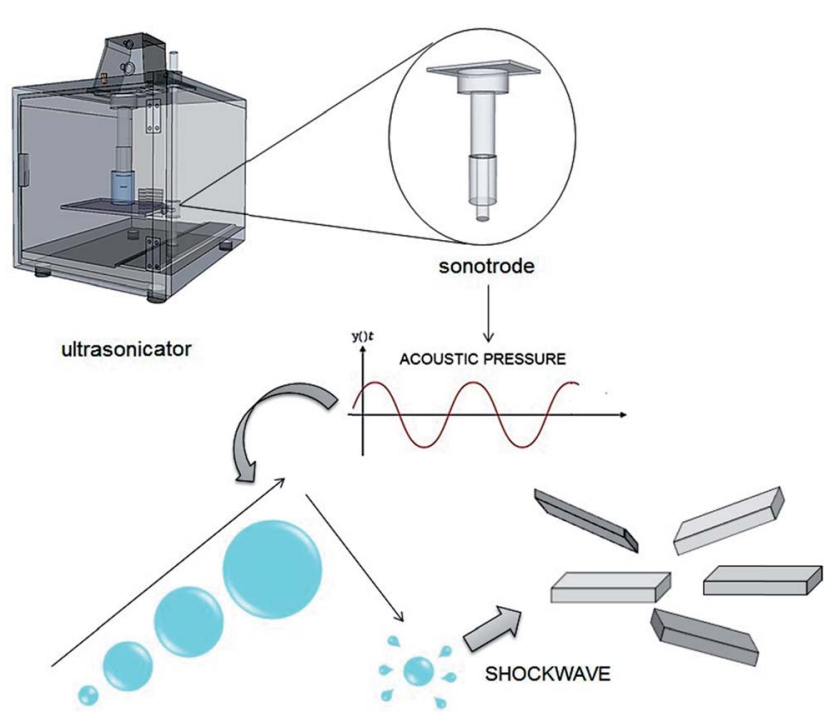

Fig. 6 Schematic illustration of the ultrasonication method based on the acoustic cavitation. The sonotrode of an ultrasonicator generates high intensity ultrasound waves of alternating expansive and compressive cycles. This causes the formation, growth, and collapse of bubbles, which in turn yields intense shockwaves that promote interparticle collisions and, eventually, the exfoliation of the layered filler. 
gradually been extended to polymers of natural origin (e.g., polysaccharides, proteins, and lipids) for the development of bionanocomposites. ${ }^{19,22,167,500-503}$ More recently, ultrasonication has been suggested as a valuable tool for the preparation of graphene-based nanocomposites starting from graphite flakes or particles dispersed in a liquid medium, both non-aqueous and aqueous systems. Due to the significant advantages of aqueous systems over non-aqueous systems (e.g., lower costs and fewer potential health risks and environmental issues), the former approach (i.e., using water as a solvent) has been attracting much attention over the recent years. Lotya et al..$^{504}$ firstly reported the ultrasonication-assisted exfoliation of graphite in an aqueous system using a cationic surfactant, i.e., sodium dodecyl benzene sulfonate (SDBS). A later development accounted for a 'one-pot' procedure to obtain graphene-based bionanocomposite materials, which involves the use of biopolymers directly in the ultrasonication reactor, without the necessity to recover the nanoparticles in a second step. According to this method, it is believed that biopolymer works similarly to surfactants (i.e., as a spacer), but without the formation of micelles. More specifically, the biopolymer adsorbs onto the exposed surfaces of the graphene layers, thus preventing any possible aggregation or restacking phenomenon, which would represent the simplest, most efficient, and environmentally friendly strategy for the preparation of bionanocomposite materials. ${ }^{505}$ Examples of direct exfoliation of graphite into few layers graphene sheets by (bio)polymerassisted ultrasonication concerned poly(vinyl pyrrolidone) (PVP) and $\mathrm{PVOH},{ }^{506}$ a pyrene-functionalized amphiphilic block copolymer, ${ }^{507}$ pyrene polymers, ${ }^{508}$ gum arabic, ${ }^{509-511}$ and acrylate polymers. ${ }^{512}$

\subsection{High-shear mixing}

High-shear mixing methods for the exfoliation of layered materials have been developed more recently compared to other routes in an attempt to provide an alternative approach that is able to boost the progress from the laboratory to commercial applications. High-shear mixing methods, although still at an early stage, have shown the great potential for the exfoliation of graphene and other two-dimensional materials, providing a viable route for the industrial scaling of applications based on these layered crystals in large amounts. ${ }^{513-515} \mathrm{~A}$ recent study has demonstrated that graphite can be exfoliated to give graphene by generating shear in a very thin liquid layer in a rapidly rotating tube. ${ }^{516}$ However, this method gives very small quantities of graphene and is inherently un-scalable. Recently, Paton et al. demonstrated a method to exfoliate graphite into graphene nanosheets by high-shear mixing using a closely spaced rotor/stator combination. ${ }^{517}$ This method is claimed to be many times more efficient than sonication in terms of yield, enabling large quantities of defect-free, unoxidized graphene to be obtained. In addition, the same method can be scaled-up to an industrial level. The same authors developed a simple model showing that exfoliation occurs once the local shear rate exceeds $10^{4} \mathrm{~s}^{-1}$ in liquid volumes from hundreds of milliliters, up to hundreds of liters and beyond.
Ball milling is another commonly used high-shear mixing technique, which involves a solid-state mixing at room temperature.$^{518}$ It is a simple and efficient technique based on the pure shear among balls of various diameters, which is able to break the van der Waals interactions between layers. ${ }^{519}$ Clay dispersion is thus promoted by the energy transfer between milling tools (generally balls) and polymer/clay mixture, which in turns results grinded and intimately mixed. ${ }^{513}$ At the same time, the newly obtained layer would be wrapped up by polymer matrix, not only preventing the layers from sticking together, but also keeping the inherent structure of the layers. ${ }^{519}$ Among the available techniques used for nanocomposites preparation, ball milling has the considerable advantage of not requiring the use of high temperature or solvent treatments, which makes the composites preparation more green, convenient and effective. ${ }^{520}$ The ball milling method was introduced to fabricate bionanocomposites such as MMT/pectin ${ }^{513}$ and LDH/PCL. ${ }^{514}$

\section{Technological aspects linked to the manufacture of (bio)nanocomposite coatings}

The success of (bio)nanocomposite materials strongly depends on some important factors during the design and development steps. Besides significant costs, technological aspects may act as the "go-no go" gate before market applications. These aspects concern the coating system both before (e.g., the coating suspension) and after (i.e., the dry (bio)nanocomposite coating) the deposition on the selected substrate.

\subsection{Compatibility between polymer and filler}

The affinity between organic and inorganic components at the hybrid interface plays a key role in determining the final performance of (bio)nanocomposite polymer systems. Maximizing the advantages of the interface effect between polymer and filler therefore requires selecting the best possible starting materials. In this respect, a significant difference applies between petrol-based polymers and biopolymers. Most plastic polymers derived from oil are inherently hydrophobic (e.g., polyolefins), while inorganic fillers (e.g., clays) are naturally hydrophilic, thereby resulting in a marked incompatibility between phases.

To enhance the compatibility with oil-based polymers, production methods generally replace the alkali or alkalineearth interlayer cations by means of ion exchange reactions with organic ammonium and phosphonium cations to reduce the surface energy of the inorganic phase. ${ }^{13}$ In other circumstances, an alternative approach consists in the tailored functionalization of the filler by grafting new moieties with high affinity for the polymer. For example, researchers have achieved the interfacial adhesion between graphene and the polymer matrix by chemical functionalization of graphene surface via "grafting from", ${ }^{521-523}$ "grafting on", ${ }^{399,524,525}$ and "grafting to"526 techniques. Unlike common plastics, most biopolymers are hydrophilic, which makes their miscibility easier with natural fillers 
such as cellulose-derivatives, protein-derived whiskers, and especially clays.

In practice, enhancing the compatibility between organic and inorganic components allows the minimization of phase separation during processing as well as successful intercalation, swelling, and exfoliation of nanoclays. In turn, this will yield an even dispersion and distribution of the filler within the polymer matrix, avoiding the formation of traditional filled polymers with fewer applications due to the depression of the "interface effect". Eventually, efficient dispersion of the filler in the hosting matrices should enable low-cost solutions ${ }^{527-530}$ for sustainable and lightweight nanocomposite materials.

\subsection{Rheological properties}

Manufacturers of nanocomposite polymer systems widely use rheological measurements, as they represent an indirect method to assess the state of dispersion of the nano-objects (i.e., fillers), such as the degree of intercalation, exfoliation, and dispersion in the polymer matrix. ${ }^{531}$ Because most synthetic routes adopted to obtain the final nanocomposite polymer system (i.e., solution processing, melt processing, in situ polymerization, and mesophase mediated processing) involve flow, rheological properties of polymer nanocomposites may help to achieve optimum process conditions ${ }^{17,532,533}$ while an understanding of the rheological behavior can provide insightful information on the structure-property relationship in the final materials. ${ }^{17}$

Although melt intercalation is the most widely adopted approach for the preparation of nanocomposite materials, the use of solvent-based systems is predominant within the coating technology, whereby water is the main (sometimes the unique) solvent when biopolymers are used as the organic matrix. The study of the rheology of nanoclay suspensions has a relatively long history because of the application of nanoclays as thickening and thixotropic agents in different fields than food packaging, such as cosmetics, inks, and paints. Even filler concentrations as low as $4-5 \mathrm{wt} \%$ can drastically affect the rheological properties of these suspensions, particularly the viscoelastic behavior. The association of filler particles (which generally takes place for concentrations above $3 \mathrm{wt} \%$ for clay platelets) induces the formation of a continuous structure, leading to gel-like behavior. ${ }^{534-536}$ Van Olphen (1964) first described different nanoplatelet associations: (i) face-to-face, (ii) edge-to-face, and (iii) edge-to-edge aggregations (Fig. 7). ${ }^{537}$ Face-to-face association leads to thicker and larger tactoids, whereas edge-to-face and edge-to-edge lead to three-dimensional "house of cards" structures. Aggregation is described by the face-to-face association, whereas the continuous gel-like structure is a consequence of edge-to-face and edge-to-edge association. Moreover, the nanoclay dispersion could be destabilized by salts (coagulation) or by polymers (flocculation). One of these systems has to be realized as a function of the final application. To achieve a true nanocomposite polymer system with improved properties compared to conventional microcomposites, the filler must be uniformly dispersed and not aggregated. This will first allow developing the highest

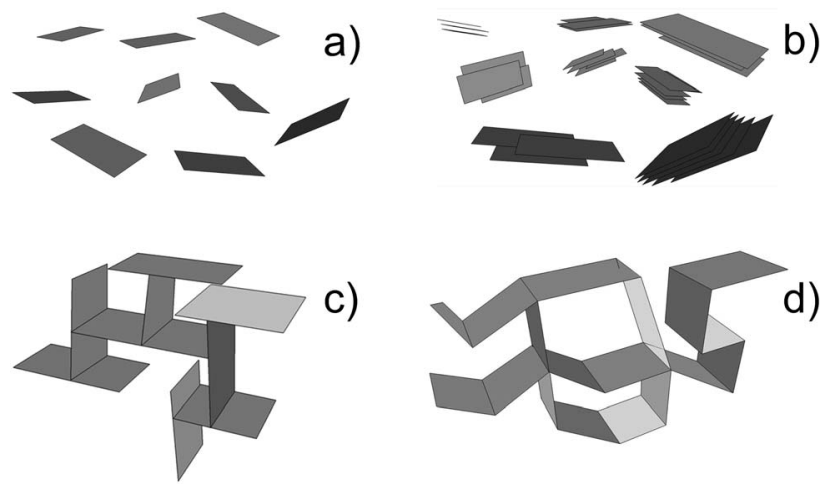

Fig. 7 Modes of particle association in clay suspensions: (a) dispersed; (b) face-to-face; (c) edge-to-face; (d) edge-to-edge (adapted from ref. 537)

proportion of an interfacial zone, thus maximizing the adsorption of the polymer chains onto the sheets. ${ }^{535}$ Secondly, efficient dispersion of the filler is the key to obtaining suspensions that are stable over time. Generally, stable suspensions show liquid-like (viscous) non-Newtonian flow behavior with a shear thinning or thickening character; the presence of colloidal aggregates imparts viscoelastic behavior to colloidal suspensions, which frequently show a time-dependent flow behavior known as thixotropy ${ }^{538-540} \mathrm{In}$ fact, during rest periods, all solid particles connect and form a gel characterized by a perceptible limiting shear stress, or yield stress, at which the material begins to flow: if the system is subjected to a constant shear rate, viscosity decreases with time as the gel structure is broken down, until equilibrium viscosity is reached. Most gelling colloidal systems follow Herschel Bulkley's rheological model; in contrast, most non-gelling colloidal dispersions follow Ostwald's rheological model (or power law). ${ }^{536}$ While gelation is a sought-after property in certain systems to stabilize the structure (e.g., food systems) it must be carefully controlled in all those applications requiring ease of flow, e.g. in coating technology. ${ }^{534-541}$

\subsection{Optical properties}

Optical properties of materials are particularly important in certain sectors, where they can impact either the performance of the final material or the consumer's choice. In the food packaging field, both aspects are relevant and worth high consideration when designing a new (bio)nanocomposite coating. On one hand, UV radiation (wavelengths below $\sim 340 \mathrm{~nm}$ ) should be prevented, because it may cause photooxidation of photosensitive foods such as meat, beer, and milk, resulting in changes in color, flavor, and taste. On the other hand, high transmittance of visible light (wavelengths between $\sim 340 \mathrm{~nm}$ and $\sim 800 \mathrm{~nm}$ ) should be guaranteed at the same time, as it allows consumers to see through the package (visual inspection of the packaged food).

Researchers have developed (bio)nanocomposite systems (e.g., coatings) with UV-shielding/absorbing properties based on the use of metal oxides such as $\mathrm{TiO}_{2}$ (ref. 542 and 543) and 
$\mathrm{ZnO}^{544}$ or clays. ${ }^{167}$ However, after coating deposition and solvent removal by evaporation, the optical properties (e.g., transparency) of the substrate beneath can dramatically be impaired due to the presence of the filler. This can be due to three main reasons: (i) unsuccessful dispersion and distribution of the filler within the polymer matrix, generally caused by either erroneous selection of the (bio)polymer/filler system (incompatibility) or inefficient deagglomeration procedure/set up; (ii) high concentration of the filler-increasing the filler volume fraction leads to a proportional increase in haze due to an increase in scattering centers, ${ }^{19}$ and reaggregation phenomena-for the same filler volume fraction, the reaggregation of previously-exfoliated platelets may occur as a consequence of high energy input to the system (e.g., prolonged ultrasonication time), with subsequent restoration of the original macro-sized tactoids. In this case, also the size of the scattering centers play a role in decreasing the transparency of the (bio)nanocomposite coating. ${ }^{19}$

Therefore, the effect of the (bio)nanocomposite coatings on the optical properties of the substrate (e.g., plastic films) can be controlled by two main routes: (i) selecting suitable methods and procedures throughout the overall manufacturing process, and (ii) selecting the most appropriate filler type. Regarding procedure selection for example, in the exfoliation step of the filler, physical, chemical, or mechanical methods can be more or less efficient depending on the filler. Moreover, regardless of the specific methods, pinpointing the best process conditions (e.g., time, temperature, energy input, amount of additives, solvents and co-solvents, and so on) may dictate the final size of the filler (macro-sized aggregates or nano-sized entities). In selecting the most appropriate filler type, depending on the final application, the final choice will affect the optical properties of the final materials differently. For example, if the transparency of the final material is mandatory, the synthetic clay LAP offers higher performance over sheet-like and needlelike clays such as MMT and SEP, respectively, due to both its well-defined chemical composition and dimensions and lack of common inorganic components (e.g. silica and iron oxides) generally carried in natural clays, which allows the production of clear and transparent colloidal water suspensions.

\subsection{Surface properties and the scalping effect}

The addition of fillers to the formulation of coatings may also have an impact on the surface properties of the final material. In food packaging, the surface properties play a major role in several converting operations, such as printing, lamination, and co-extrusion. As a general rule, the addition of an inorganic filler, especially for a high filler volume fraction, is first reflected by changes in the surface topography, i.e. an increase in the surface roughness, which is linked to the spatial distribution of the fillers within the coating thickness (Fig. 8). ${ }^{19,167,545}$ For example, platy clays with large surface areas often display a "house-of-cards" or "cell-like" configuration after solvent removal. ${ }^{19}$ An increase in roughness, besides leading to an increase in the haze of the final material, ${ }^{546}$ may have great impact on the wettability attribute of the surface, as described by both Wenzel's and Cassie-Baxter's theories. ${ }^{547,548}$ In addition, highly porous fillers (e.g., zeolites) as well as fillers with high affinity towards water molecules (e.g., natural MMT) might boost absorption phenomena at the solid/liquid interface. ${ }^{167}$

Not only the surface properties, but also mechanical properties can be influenced by an increase in roughness. Depending on both filler loading and the nature of the (bio)polymer carrying the filler, an increase in roughness may be associated with either an increase or a decrease in the slipping properties of the surface, which is quantitatively described by a decrease and an increase in the coefficient of friction, respectively. ${ }^{549-551}$ Whether this change is positive or negative strongly depends on the final application. For example, low coefficient of friction values aid the unwinding operations of plastic films on industrial lines, to avoid the "blocking effect" on the reels and decreasing overall throughput. Conversely, lower coefficient of friction values are problematic if the final packages (e.g., plastic bags) have to be stacked on top one of another; high coefficients of friction can keep the stack from collapsing.

Finally, but not less important, is the adverse effect that can potentially arise from the use of (bio)nanocomposite coatings on the overall quality of packaged food. "Scalping" is the sorption of food constituents, especially aroma compounds, by the packaging materials. Both porosity and chemical affinity of the filler for aromas and volatile molecules must be taken into account in the design of a (bio)nanocomposite coating, especially if it will face the inner side of the package and be close to the food. Scalping phenomena have received considerable attention within the food packaging industry as they may negatively influence consumer acceptance of the food product due to loss of aroma intensity or the development of an unbalanced flavor profile. ${ }^{552}$

\section{Advantages of bionanocomposite coatings in food packaging}

From an industrial perspective, the development of (bio)nanocomposite coatings has aimed at improving three main properties of the base resin: mechanical (stiffness, impact, and wear resistance), flame-retardance (anti-flammable materials), and barrier properties (against gases, vapors, and radiation). In the food and beverage packaging sector, however, considerable industrial and research developments of nanocomposite coatings have focused on improving the barrier properties, which has led to several applications in recent years. The excellent barrier properties of (bio)nanocomposite coatings may be explained by the "tortuous path" theory, ${ }^{25}$ i.e. the formation of a labyrinth ensuing from the spatial dispersion of nano-clay platelets within the polymeric structure, which physically decreases the diffusion of the permeant (e.g., gases and vapors) across the thickness of the material.

Studies have reported examples of applications of modified atmosphere packaging for food (meats, cheese, confectionery, cereals and "boil-in-the-bag" foods), extrusion-coating applications in association with paperboard for fruit juice and dairy products, and in combination with co-extrusion processes for 

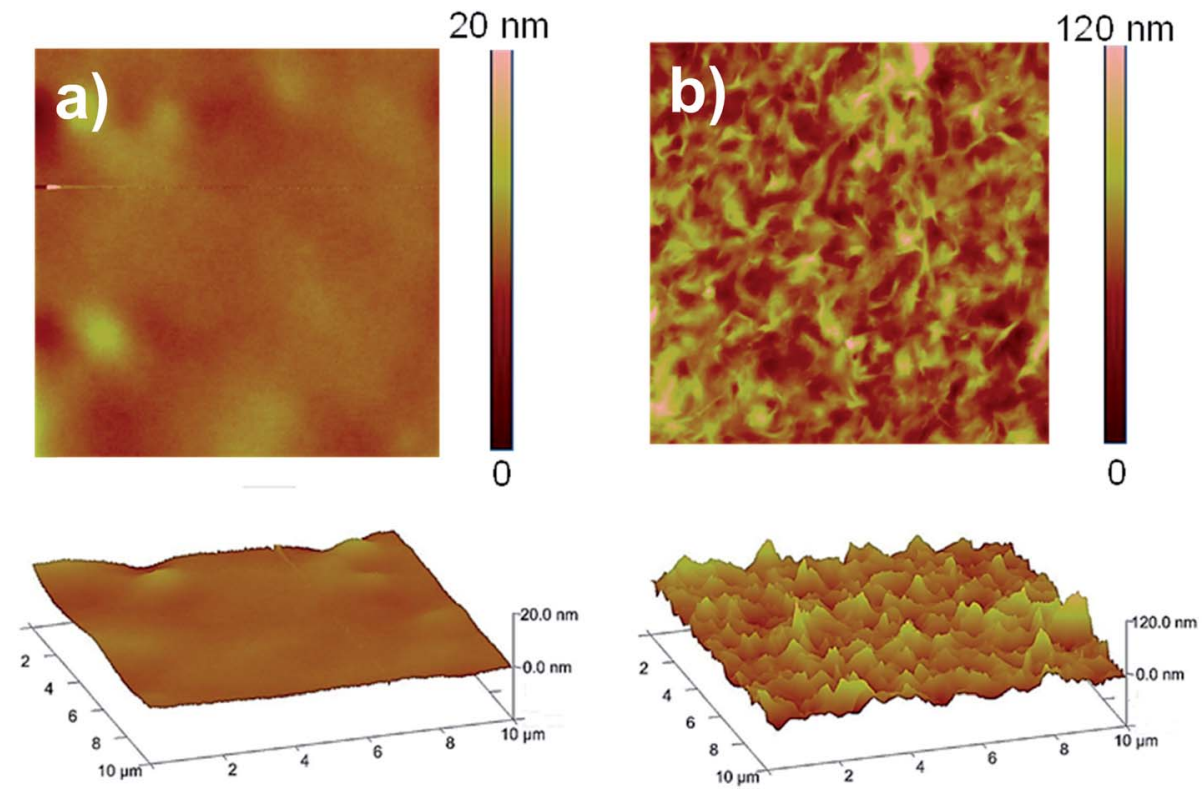

Fig. 8 Influence of the clay loading on the surface roughness of biopolymer coatings. AFM height (upper) and 3D (lower) images (10 $\left.\times 10 \mu \mathrm{m}^{2}\right)$ of pure pullulan coating (a) and pullulan $/ \mathrm{Na}^{+}-\mathrm{MMT}$ nanocomposite coating (b) (filler volume fraction $\varphi=0.12$ ) (reproduced with permission from American Chemical Society ${ }^{19}$ ).

the manufacture of beer and carbonated drink bottles. ${ }^{553}$ Several nanocomposite materials intended for food packaging applications are available in the market. Nanocor and Mitsubishi Gas Chemical Company developed the MXD6 high barrier semi-aromatic nylons in nanocomposite form. ${ }^{554}$ The latest development of the resin MDX6 led to the Imperm ${ }^{\circledR}$ products, a family of superior gas barrier resins particularly useful in extending package shelf life. ${ }^{555}$ Honeywell has developed a polyamide-based nanocomposite with passive barrier properties against oxygen under the Aegis ${ }^{\circledR}$ trade name. Passive barriers use clay particles, which render the oxygen transmission inside the composite more difficult. ${ }^{556}$ The U.S. military and NASA, in conjunction with Triton Systems, Inc., worked together on nanoclays as barrier enhancers for ethylene vinyl alcohol (EVOH) in long-shelf life packaging (i.e., non-refrigerated food). This collaboration led to an experimental thermoformed food tray from EVOH loaded with $3 \%$ of Southern Clay's Cloisite ${ }^{\circledR}$ in a layer sandwiched between two PP layers. It reportedly imparts a three- to five-years shelf life without refrigeration, plus good clarity, processability, and recyclability. ${ }^{557}$ InMat Inc. developed Nanolok ${ }^{\mathrm{TM}}$, a high barrier, waterbased, environmentally friendly nanocomposite barrier coating for transparent packaging applications. They claim the nanocomposite coating provides an excellent oxygen barrier up to $80 \%$ relative humidity and is more cost effective than EVOH. ${ }^{558}$ Finally, NanoPack Inc. has developed a water-based coating made of PVOH and VMT. This coating, sold under the NanoSeal ${ }^{\mathrm{TM}}$ trade name, is specifically intended for food packaging applications where protection of food against oxygen and aromas is required. ${ }^{559}$

Besides advantages directly linked to their functional properties, the use of (bio)nanocomposite coatings may indirectly provide additional benefits, often underestimated or neglected. For example, the weight advantage could present a significant impact on environmental concerns. According to the "packaging optimization" principle, ${ }^{560}$ the use of high-performance thin layers may be a valuable approach to down-gauging current packaging structures, e.g. laminates and/or co-extruded materials (Fig. 9). (Bio)nanocomposite coatings thus have the great potential to allow reducing the thickness of the package without jeopardizing (rather improving) the overall performance, at
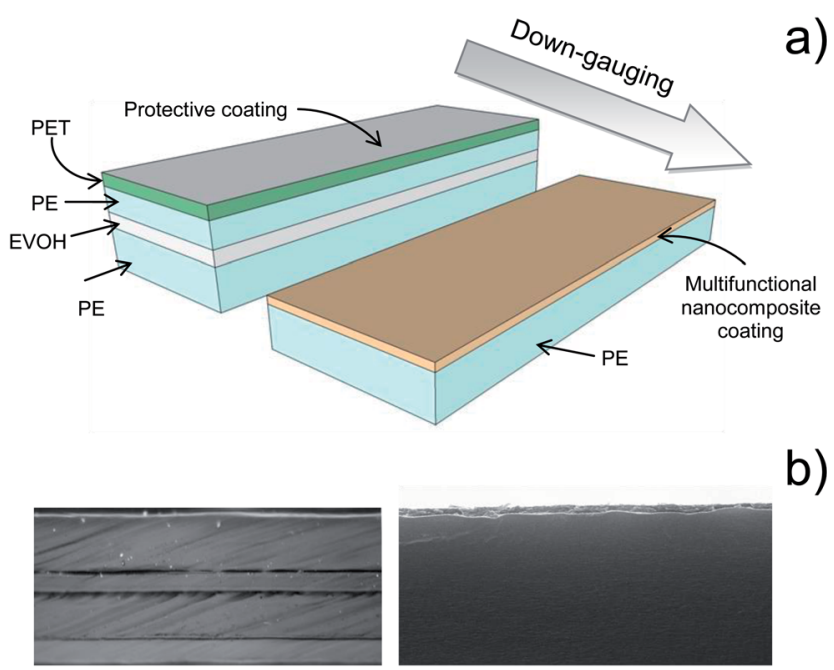

Fig. 9 (a) Schematic illustration of the 'packaging lightweighting' concept: the use of multifunctional nanocomposite coatings makes possible avoiding multiple layers packages; (b) optical microscope cross-section of a multi-layer (total thickness $90 \mu \mathrm{m}$ ) package (left) and SEM of a nanocomposite coating $(\sim 0.7 \mu \mathrm{m})$ on a $12 \mu \mathrm{m}$ PET substrate (right). 
reasonable cost. In turn, this would mean an upstream reduction of plastics, hence a less amount of plastics dumped into the environment, which would help in facing the waste disposal issue. From a strict economical point of view, the use of (bio) nanocomposite coatings to obtain lighter packages has the additional advantage to reduce the energy inputs for production, transport, and storage. Of course, the higher the degree of multi-functionality integrated in the (bio)nanocomposite coatings, the wider the environmental and economic advantages.

\section{Concluding remarks}

The development of new packaging materials offering new functionalities, less environmental impact, and economical benefits is now an urgent necessity. The driving forces behind this pressing task are manifold. On one hand, the shelf life extension of packaged products can be an answer to the exponential increase of worldwide demand for food. On the other hand, the increase in the price of crude oil, together with the uncertainty related to its durability, has imposed the necessity to manufacture new structures to replace oil-derived polymers partially or totally in the future. Finally, consumers' awareness towards environmental issues increasingly pushes industries to look with renewed interest to "green" solutions.

Coating technology is one of the most efficient and convenient approaches to exploit toward this goal. This versatile technique enables manipulating matrices of completely different origins and compositions (e.g., water-based/organic solvent-based, biopolymer/oil-derived polymers, solutions/ dispersions) to yield thin layers that ennoble the substrate beneath (e.g., plastic webs) by conferring new (sometimes unexpected) functional properties. Within a shelf life extension perspective, the generation of biopolymer nanocomposite coatings is one of the most striking and promising outcomes of coating technology for tomorrow's challenges.

\section{Abbreviations}

$\begin{array}{ll}\text { AFG } & \text { Amine-functionalized graphene } \\ \text { BET } & \text { Brunnuer, Emmet and Teller } \\ \text { BC } & \text { Bacterial cellulose } \\ \text { CEC } & \text { Cation-exchange capacity } \\ \text { CMC } & \text { Carboxymethyl cellulose } \\ \text { CMKG } & \text { Carboxymethyl konjac glucomannan } \\ \text { CNCs } & \text { Cellulose nanocrystals } \\ \text { CNTs } & \text { Carbon nanotubes } \\ \text { CVD } & \text { Chemical vapor deposition } \\ \text { EVA } & \text { Ethylene vinyl acetate } \\ \text { EVOH } & \text { Ethylene vinyl alcohol } \\ \text { GCG } & \text { Gelidium corneum-gelatin } \\ \text { GNP } & \text { Graphene nanoplatelet } \\ \text { GO } & \text { Graphene oxide } \\ \text { HAL } & \text { Halloysite } \\ \text { HDPE } & \text { High density polyethylene } \\ \text { HEC } & \text { Hectorite } \\ \text { HNTs } & \text { Halloysite nanotubes }\end{array}$

HRTEM

\section{IMO}

$\mathrm{KAO}$

LAP

LDHs

LDPE

LLDPE

MFC

MMT

MWNTs

PA

PBS

PCL

$\mathrm{PE}$

PEI

PEO

PET

$\gamma$-PGA

PHAs

PHB

PHBV

PIFG

PLA

PLLA

PMMA

PND

Poly(S-co-

BuA)

PP

PPC

PS

PU

PVC

$\mathrm{PVOH}$

REC

SAP

SEP

SNCs

SPI

VMT

VOCs

WPI
High-resolution transmission electron

microscopy

Imogolite

Kaolinite

Laponite

Layered double hydroxides

Low density polyethylene

Linear low density polyethylene

Microfibrillated cellulose

Montmorillonite

Multi walled carbon nanotubes

Polyamide

Poly(butylene succinate)

Polycaprolactone

Polyethylene

Polyethylenimine

Poly(ethylene oxide)

Poly(ethylene terephthalate)

$\gamma$-Polyglutamate

Poly-hydroxyalkanoates

Poly(3-hydroxybutyrate)

Poly(3-hydroxybutyrate-co-3-hydroxyvalerate)

Phenyl isocyanate-functionalized graphene

Poly(lactic acid)

Poly(L-lactic acid)

Poly(methyl methacrylate)

Polynorbornene dicarboximide

Poly(styrene-co-butyl acrylate)

Polypropylene

Poly(propylene carbonate)

Polystyrene

Polyurethane

Poly(vinyl chloride)

Poly(vinyl alcohol)

Rectorite

Saponite

Sepiolite

Starch nanocrystals

Soy protein isolate

Vermiculite

Volatile organic compounds

Whey protein isolate

\section{References}

1 D. R. Baer, P. E. Burrows and A. A. El-Azab, Prog. Org. Coat., 2003, 47, 342.

2 A. L. Chun, Nat. Nanotechnol., 2009, 4, 790.

3 M. C. Roco, C. A. Mirkin and M. C. Hersam, J. Nanopart. Res., 2011, 13, 897.

4 T. V. Duncan, J. Colloid Interface Sci., 2011, 363, 1.

5 Q. Chaudhry, M. Scotter, J. Blackburn, B. Ross, A. Boxall, L. Castle, R. Aitken and R. Watkin, Food Addit. Contam., Part A, 2008, 25, 241.

6 Cientifica, Nanotechnologies in the food industry, 2006, http://www.cientifica.com/www/details.php?id=47, accessed December 2012. 
7 IRAP, Nano-enabled Packaging for Food and Beverage Industry, 2009, http://www.innoresearch.net/report summary.aspx id $=68 \& p g=107 \&$ rcd $=$ FT102\&pd $=7 / 1 / 2009$, accessed December 2012.

8 M. Siegrist, M. E. Cousin, H. Kastenholz and A. Wiek, Appetite, 2007, 49, 459.

9 M. Siegrist, N. Stampfli, H. Kastenholz and C. Keller, Appetite, 2008, 51, 283.

10 Q. Chaudhry, R. Watkins and L. Castle, in Nanotechnologies in Food, ed. Q. Chaudhry, R. Watkins and L. Castle, RSC Publishing, Cambridge, 2010, p. 1.

11 J. M. Lagaron, L. Cabedo, D. Cava, J. L. Feijoo, R. Gavara and E. Gimenez, Food Addit. Contam., 2005, 22, 994.

12 C. Sanchez, G. J. de A. A. Soler-Illia, F. Ribot, T. Lalot, C. R. Mayer and V. Cabuil, Chem. Mater., 2001, 13, 3061.

13 C. Sanchez, B. Julian, P. Belleville and M. Popall, J. Mater. Chem., 2005, 15, 3559.

14 P. Sanguansri and M. A. Augustin, Trends Food Sci. Technol., 2006, 17, 547.

15 M. Alexandre and P. Dubois, Mater. Sci. Eng., 2000, 28, 1.

16 E. P. Giannelis, Adv. Mater., 1996, 8, 29.

17 S. Sinha Ray and M. Okamoto, Prog. Polym. Sci., 2003, 28, 1539.

18 A. Sorrentino, G. Gorrasi and V. Vittoria, Trends Food Sci. Technol., 2007, 18, 84.

19 L. Introzzi, T. O. Blomfeldt, S. Trabattoni, S. Tavazzi, N. Santo, A. Schiraldi, L. Piergiovanni and S. Farris, Langmuir, 2012, 28, 11206.

20 L. Introzzi, J. M. Fuentes-Alventosa, C. A. Cozzolino, S. Trabattoni, S. Tavazzi, C. L. Bianchi, A. Schiraldi, L. Piergiovanni and S. Farris, ACS Appl. Mater. Interfaces, 2012, 4, 3692.

21 S. Farris, L. Introzzi, J. M. Fuentes-Alventosa, N. Santo, R. Rocca and L. Piergiovanni, J. Agric. Food Chem., 2012, 60, 782 .

22 J. M. Fuentes-Alventosa, L. Introzzi, N. Santo, G. Cerri, A. Brundu and S. Farris, RSC Adv., 2013, 25086.

23 M. Imran, A.-M. Revol-Junelles, A. Martyn, E. A. Tehrany, M. Jacquot, M. Linder and S. Desobry, Crit. Rev. Food Sci. Nutr., 2010, 50, 799.

24 E. L. Bradley, L. Castle and Q. Chaudhry, Trends Food Sci. Technol., 2011, 22, 604.

25 C. Silvestre, D. Duraccio and S. Cimmino, Prog. Polym. Sci., 2011, 36, 1766.

26 J. M. Lagaron and A. Lopez-Rubio, Trends Food Sci. Technol., 2011, 22, 611.

27 N. B. Hatzigrigoriou and C. D. Papaspyrides, J. Appl. Polym. Sci., 2011, 122, 3720.

28 B. A. Magnuson, T. S. Jonaitis and J. W. Card, J. Food Sci., 2011, 76, 126.

29 M. Cushen, J. Kerry, M. Morris, M. Cruz-Romero and E. Cummins, Trends Food Sci. Technol., 2012, 24, 30.

30 J.-W. Rhim, H.-M. Park and C.-S. Ha, Prog. Polym. Sci., 2013, 38, 1629.

31 J. Ging, R. Tejerina-Anton, G. Ramakrishnan, M. Nielsen, K. Murphy, J. M. Gorham, T. Nguyen and A. Orlov, Sci. Total Environ., 2014, 473-474, 9.
32 S. Maisanaba, S. Pichardo, M. Jordá-Beneyto, S. Aucejo, A. M. Cameán and Á. Jos, Food Chem. Toxicol., 2014, 66, 366. 33 X. Guo and N. Mei, J. Food Drug Anal., 2014, 22, 105.

34 X. Liu and Q. Wu, Polymer, 2001, 42, 10013.

35 K. Sterky, H. Jacobsen, I. Jakubowicz, N. Yarahmadi and T. Hjertberg, Eur. Polym. J., 2010, 46, 1203.

36 S. Pavlidou and C. D. Papaspyrides, Prog. Polym. Sci., 2008, 33, 1119.

37 M. Maiti, S. Sadhu and A. K. Bhowmick, J. Appl. Polym. Sci., 2005, 96, 443.

38 T. V. Kosmidou, eXPRESS Polym. Lett., 2008, 2, 364.

39 X. Ye, P. J. Yao, M. M. Xi and L. Q. Zhang, Plast., Rubber Compos., 2013, 42, 50.

40 A. Al-Jabareen, H. Al-Bustami, H. Harel and G. Marom, J. Appl. Polym. Sci., 2013, 128, 1534.

41 K. Kalaitzidou, H. Fukushima and L. T. Drzal, Composites, Part A, 2007, 38, 1675.

42 K. Fukushima, M. Murariu, G. Camino and P. Dubois, Polym. Degrad. Stab., 2010, 95, 1063.

43 J. N. Coleman, U. Khan and Y. K. Gun'ko, Adv. Mater., 2006, 18, 689.

44 M. T. Byrne and Y. K. Gunko, Adv. Mater., 2010, 22, 1672. 45 Y. X. Zhou, eXPRESS Polym. Lett., 2008, 2, 40.

46 S. P. Bao and S. C. Tjong, Polym. Compos., 2009, 30, 1749. 47 X. Chen, S. Wei, A. Yadav, R. Patil, J. Zhu, R. Ximenes, L. Sun and Z. Guo, Macromol. Mater. Eng., 2011, 296, 434.

48 L. Sun, J. Y. O'Reilly, C. W. Tien and H. J. Sue, J. Chem. Educ., 2008, 85, 1105.

49 E. T. Thostenson, Z. Ren and T. W. Chou, Compos. Sci. Technol., 2001, 61, 1899.

50 B. E. Kilbride, J. N. Coleman, J. Fraysse, P. Fournet, M. Cadek, A. Drury, S. Hutzler, S. Roth and W. J. Blau, J. Appl. Phys., 2002, 92, 4024.

51 M. J. Biercuk, M. C. Llaguno, M. Radosavljevic, J. K. Hyun, A. T. Johnson and J. E. Fischer, Appl. Phys. Lett., 2002, 80, 2767.

52 O. Regev, P. N. B. ElKati, J. Loos and C. E. Koning, $A d v$. Mater., 2004, 16, 248.

53 B. K. Price, J. L. Hudson and J. M. Tour, J. Am. Chem. Soc., 2005, 127, 14867.

54 K. S. Coleman, Annu. Rep. Prog. Chem., Sect. A: Inorg. Chem., 2012, 108, 478.

55 N. A. Kotov, Nature, 2006, 442, 254.

56 H. H. Murray, Appl. Clay Sci., 2000, 17, 207.

57 J. C. Miranda-Trevino and C. A. Coles, Appl. Clay Sci., 2003, 23, 133.

58 D. H. Powell, H. E. Fischer and N. T. Skipper, J. Phys. Chem. $B$, 1998, 102, 10899.

59 X. Kornmann, H. Lindberg and L. A. Berglund, Polymer, 2001, 42, 1303.

60 F. Chivrac, E. Pollet and L. Avérous, Mater. Sci. Eng., R, 2009, 67, 1.

61 H. M. Park, W. K. Lee, C. Y. Park, W. J. Cho and C. Ha, J. Mater. Sci., 2003, 38, 909.

62 H. M. Park, M. Misra, L. T. Drzal and A. K. Mohanty, Biomacromolecules, 2004, 5, 2281. 
63 M. Avella, J. J. De Vlieger, M. E. Errico, S. Fischer, P. Vacca and M. G. Volpe, Food Chem., 2005, 93, 467.

64 B. Chen and J. R. G. Evans, Carbohydr. Polym., 2005, 61, 455. 65 B. Chen and J. R. G. Evans, Polym. Int., 2005, 54, 807.

66 H. M. Wilhelm, M. R. Sierakowski, G. P. Souza and F. Wypych, Carbohydr. Polym., 2003, 52, 101.

67 M. F. Brigatti, E. Galan and B. K. G. Theng, in Developments in Clay Science, ed. F. Bergaya, B. K. G. Then and G. Lagaly, Elsevier, 2006, vol. 1, pp. 19-86.

$68 \mathrm{~J}$. Elzea and H. Murray, in Industrial Minerals and Rocks, ed. D. Carr, SME, Littleton, CO, 1994, pp. 233-246.

69 E. Manias, A. Touny, L. Wu, K. Strawhecker, B. Lu and T. Chung, Chem. Mater., 2001, 13, 3516.

70 I. J. Chin, T. Thurn-Albrecht, H. C. Kim, T. P. Russell and J. Wang, Polymer, 2001, 42, 5947.

71 F. Thomas, L. J. Michot, D. Vantelon, E. Montarges, B. Prélot, M. Cruchaudet and J. F. Delon, Colloids Surf., A, 1999, 159, 351.

72 J. Xu, R. K. Y. Li, Y. Xu, L. Li and Y. Z. Meng, Eur. Polym. J., 2005, 41, 881.

73 T. Nogueira, R. Botan, F. Wypych and L. Lona, J. Appl. Polym. Sci., 2012, 124, 1764.

74 C. H. Davis, L. J. Mathias, J. W. Gilman, D. A. Schiraldi, J. R. Shields, P. Trulove, T. E. Sutto and H. C. Delong, J. Polym. Sci., Part B: Polym. Phys., 2002, 40, 2661.

75 W. Joon Choi, H. J. Kim, K. Han Yoon, O. Hyeong Kwon and C. Ik Hwang, J. Appl. Polym. Sci., 2006, 100, 4875.

76 L. V. Todorov and J. C. Viana, J. Appl. Polym. Sci., 2007, 106, 1659.

77 S. Martínez-Gallegos, M. Herrero, C. Barriga, F. M. Labajos and V. Rives, Appl. Clay Sci., 2009, 45, 44.

78 R. S. Rajeev, E. Harkin-Jones, K. Soon, T. McNally, G. Menary, C. G. Armstrong and P. J. Martin, Eur. Polym. J., 2009, 45, 332.

79 K. Soon, E. Harkin-Jones, R. S. Rajeev, G. Menary, P. J. Martin and C. G. Armstrong, Polym. Eng. Sci., 2012, 52, 532 .

80 C. E. Corcione, A. Cavallo, E. Pesce, A. Greco and A. Maffezzoli, Polym. Eng. Sci., 2011, 51, 1280.

81 M. Herrero, S. Martínez-Gallegos, F. M. Labajos and V. Rives, J. Solid State Chem., 2011, 184, 2862.

82 R. Scaffaro, L. Botta, M. Ceraulo and F. P. La Mantia, J. Appl. Polym. Sci., 2011, 122, 384.

83 S. Hayrapetyan, A. Kelarakis, L. Estevez, Q. Lin, K. Dana, Y. L. Chung and E. P. Giannelis, Polymer, 2012, 53, 422.

84 R. Labde, E. A. Lofgren and S. A. Jabarin, J. Appl. Polym. Sci., 2012, 125, E369.

85 M. Modesti, A. Lorenzetti, D. Bon and S. Besco, Polymer, 2005, 46, 10237.

86 M. J. Dumont, A. Reyna-Valencia, J. P. Emond and M. Bousmina, J. Appl. Polym. Sci., 2007, 103, 618.

87 A. Mirzadeh and M. Kokabi, Eur. Polym. J., 2007, 43, 3757.

88 M. A. Osman, V. Mittal and U. W. Suter, Macromol. Chem. Phys., 2007, 208, 68.

89 D. A. Pereira de Abreu, P. Paseiro Losada, I. Angulo and J. M. Cruz, Eur. Polym. J., 2007, 43, 2229.
90 N. Touati, M. Kaci, H. Ahouari, S. Bruzaud and Y. Grohens, Macromol. Mater. Eng., 2007, 292, 1271.

91 M. A. Treece and J. P. Oberhauser, J. Appl. Polym. Sci., 2007, 103, 884 .

92 S. Cimmino, D. Duraccio, C. Silvestre and M. Pezzuto, Appl. Surf. Sci., 2009, 256, S40.

93 M. A. Perez, B. L. Rivas, S. M. Rodrigues, Á. Maldonado and C. Venegas, J. Chil. Chem. Soc., 2010, 55, 440.

94 R. N. Choi, C. I. Cheigh, S. Y. Lee and M. S. Chung, J. Food Sci., 2011, 76, N62.

95 S. Cimmino, C. Silvestre, D. Duraccio and M. Pezzuto, J. Appl. Polym. Sci., 2011, 119, 1135.

96 D. Fischer, J. Müller, S. Kummer and B. Kretzschmar, Macromol. Symp., 2011, 305, 10.

97 M. R. Manikantan and N. Varadharaju, Packag. Technol. Sci., 2011, 24, 191-209.

98 S. P. Lonkar, S. Therias, F. Leroux, J. L. Gardette and R. P. Singh, Polym. Eng. Sci., 2012, 52, 2006.

99 K. Srithammaraj, R. Magaraphan and H. Manuspiya, Packag. Technol. Sci., 2012, 25, 63.

100 Y. Zhong and D. De Kee, Polym. Eng. Sci., 2005, 45, 469.

101 M. Shafiee and A. Ramazani S.A., Macromol. Symp., 2008, 274, 1.

102 S. Joseph and W. W. Focke, Polym. Compos., 2011, 32, 252.

103 R. Wilson, T. S. Plivelic, A. S. Aprem, C. Ranganathaiagh, S. A. Kumar and S. Thomas, J. Appl. Polym. Sci., 2012, 123, 3806.

104 P. M. Gyoo, S. Venkataramani and S. C. Kim, J. Appl. Polym. Sci., 2006, 101, 1711.

105 A. Ammala, A. J. Hill, K. A. Lawrence and T. Tran, J. Appl. Polym. Sci., 2007, 104, 1377.

106 A. Ammala, S. J. Pas, K. A. Lawrence, R. Stark, R. I. Webb and A. J. Hill, J. Mater. Chem., 2008, 18, 911.

107 K. Magniez, B. L. Fox and M. G. Looney, J. Polym. Sci., Part B: Polym. Phys., 2009, 47, 1300.

108 D. Pereira, P. P. Losada, I. Angulo, W. Greaves and J. M. Cruz, Polym. Compos., 2009, 30, 436.

109 F. Touchaleaume, J. Soulestin, M. Sclavons, J. Devaux, M. F. Lacrampe and P. Krawczak, Polym. Degrad. Stab., 2011, 96, 1890.

110 I. Isik-Gulsac, U. Yilmazer and G. Bayram, J. Appl. Polym. Sci., 2012, 125, 4060.

111 S. Sánchez-Valdes, M. L. López-Quintanilla, E. RamírezVargas, F. J. Medellín-Rodríguez and J. M. GutierrezRodriguez, Macromol. Mater. Eng., 2006, 291, 128.

112 S. K. Swain and A. I. Isayev, Polymer, 2007, 48, 281.

113 C. Lotti, C. S. Isaac, M. C. Branciforti, R. M. V. Alves, S. Liberman and R. E. S. Bretas, Eur. Polym. J., 2008, 44, 1346.

114 S. Coiai, M. Scatto, L. Conzatti, F. Azzurri, L. Andreotti, E. Salmini, P. Stagnaro, A. Zanolin, F. Cicogna and E. Passaglia, Polym. Adv. Technol., 2001, 22, 2285.

115 S. M. Ali Dadfar, I. Alemzadeh, S. M. Reza Dadfar and M. Vosoughi, Mater. Des., 2011, 32, 1806.

116 Q. Hu, Y. Fang, Y. Yang, N. Ma and L. Zhao, Food Res. Int., 2011, 44, 1589. 
117 M. H. Abdolrasouli, E. Behzadfar, H. Nazockdast and F. Sharif, J. Appl. Polym. Sci., 2012, 125, E435.

118 M. A. Busolo and J. M. Lagaron, Innovative Food Sci. Emerging Technol., 2012, 16, 211.

119 S. I. Hong and J. W. Rhim, LWT-Food Sci. Technol., 2012, 48, 43.

120 P. Santamaría and J. I. Eguiazabal, Polym. Test., 2012, 31, 367.

121 L. Zhao, F. Li, G. Chen, Y. Fang, X. An, Y. Zheng, Z. Xin, M. Zhang, Y. Yang and Q. Hu, Int. J. Food Sci. Technol., 2012, 47, 572 .

122 M. A. Priolo, K. M. Holder, D. Gamboa and J. C. Grunlan, Langmuir, 2011, 27, 12106.

123 C. H. Chen, C. C. Teng and C. H. Yang, J. Polym. Sci., Part B: Polym. Phys., 2005, 43, 1465.

124 M. Ge and D. Jia, J. Thermoplast. Compos. Mater., 2010, 23, 855.

125 A. Bendahou, H. Kaddami, E. Espuche, F. Gouanvé and A. Dufresne, Macromol. Mater. Eng., 2011, 296, 760.

126 C. Esposito Corcione, P. Prinari, D. Cannoletta, G. Mensitieri and A. Maffezzoli, Int. J. Adhes. Adhes., 2008, 28, 91.

127 C. Esposito Corcione, G. Mensitieri and A. Maffezzoli, Polym. Eng. Sci., 2009, 49, 1708.

128 A. K. Barick and D. K. Tripathy, J. Appl. Polym. Sci., 2010, 117, 639.

129 Y. Qian, C. I. Lindsay, C. Macosko and A. Stein, ACS Appl. Mater. Interfaces, 2011, 3, 3709.

130 J. T. Yeh, C. J. Chang, F. C. Tsai, K. N. Chen and K. S. Huang, Appl. Clay Sci., 2009, 45, 1.

131 S. Donadi, M. Modesti, A. Lorenzetti and S. Besco, J. Appl. Polym. Sci., 2011, 122, 3290.

132 B. Kouini and A. Serier, Mater. Des., 2012, 34, 313.

133 N. Artzi, A. Tzur, M. Narkis and A. Siegmann, Polym. Compos., 2005, 26, 343.

134 M. A. Priolo, D. Gamboa, K. M. Holder and J. C. Grunlan, Nano Lett., 2010, 10, 4970.

135 H. M. Park, X. Li, C. Z. Jin, C. Y. Park, W. J. Cho and C. S. Ha, Macromol. Mater. Eng., 2002, 287, 553.

136 P. Kampeerapappun, D. Aht-ong, D. Pentrakoon and K. Srikulkit, Carbohydr. Polym., 2007, 67, 155.

137 V. P. Cyras, L. B. Manfredi, M. T. Ton-That and A. Vázquez, Carbohydr. Polym., 2008, 73, 55.

138 N. Wang, X. Zhang, N. Han and S. Bai, Carbohydr. Polym., 2009, 76, 68.

139 M. Hassan Nejad, J. Ganster and B. Volkert, J. Appl. Polym. Sci., 2010, 118, 503.

140 M. Hassan Nejad, J. Ganster, A. Bohn, B. Volkert and A. Lehmann, Carbohydr. Polym., 2011, 84, 90.

141 K. Majdzadeh-Ardakani, A. H. Navarchian and F. Sadeghi, Carbohydr. Polym., 2010, 79, 547.

142 W. Gao, H. Dong, H. Hou and H. Zhang, Carbohydr. Polym., 2012, 88, 321.

143 S. F. Wang, L. Shen, Y. J. Tong, L. Chen, I. Y. Phang, P. Q. Lim and T. X. Lu, Polym. Degrad. Stab., 2005, 90, 123.
144 S. I. Hong, J. H. Lee, H. J. Bae, S. Y. Koo, H. S. Lee, J. H. Choi, D. H. Kim, S. H. Park and H. J. Park, J. Appl. Polym. Sci., 2011, 119, 2742.

145 H. Oguzlu and F. Tihminlioglu, Macromol. Symp., 2010, 298, 91.

146 M. Abdollahi, M. Rezaei and G. Farzi, J. Food Eng., 2012, 111, 343.

147 M. Alboofetileh, M. Rezaei, H. Hosseini and M. Abdollahi, J. Food Eng., 2013, 117, 26.

148 P. Krishnamachari, J. Zhang, J. Lou, J. Yan and L. Uitenham, Int. J. Polym. Anal. Charact., 2009, 14, 336.

149 V. P. Martino, A. Jiménez, R. A. Ruseckaite and L. Avérous, Polym. Adv. Technol., 2011, 22, 2206.

150 D. V. Plackett, V. K. Holm, P. Johansen, S. Ndoni, P. V. Nielsen, T. Sipilainen-Malm, A. Södergård and S. Verstichel, Packag. Technol. Sci., 2006, 19, 1.

151 A. C. Wibowo, M. Misra, H. M. Park, L. T. Drzal, R. Schalek and A. K. Mohanty, Composites, Part A, 2006, 37, 1428.

152 P. Kumar, K. P. Sandeep, S. Alavi, V. D. Truong and R. E. Gorga, J. Food Sci., 2010, 75, N46.

153 J. E. Lee and K. M. Kim, J. Appl. Polym. Sci., 2010, 118, 2257.

154 H. J. Bae, H. J. Park, D. O. Darby, R. M. Kimmel and W. S. Whiteside, Packag. Technol. Sci., 2009, 22, 371.

155 P. Mangiacapra, G. Gorrasi, A. Sorrentino and V. Vittoria, Carbohydr. Polym., 2006, 64, 516.

156 J. W. Rhim, S. B. Lee and S. I. Hong, J. Food Sci., 2011, 76, N40.

157 B. Chen and J. R. Evans, Macromolecules, 2006, 39, 747.

158 J. Lu and C. Xiao, J. Appl. Polym. Sci., 2007, 103, 2954.

159 M. Quilaqueo Gutiérrez, I. Echeverría, M. Ihl, V. Bifani and A. N. Mauri, Carbohydr. Polym., 2012, 87, 1495.

160 M. A. Paul, M. Alexandre, P. Degée, C. Henrist, A. Rulmont and P. Dubois, Polymer, 2003, 44, 443.

161 K. Sermsantiwanit and S. Phattanarudee, Prog. Org. Coat., 2912, 74, 660.

162 J. Ahmed, R. Auras, T. Kijchavengkul and S. K. Varshney, J. Food Eng., 2012, 111, 580.

163 F. Tezcan, E. Gunister, G. Ozen and F. B. Erim, Int. J. Biol. Macromol., 2012, 50, 1165.

164 I. Siró, D. Plackett and P. Sommer-Larsen, Packag. Technol. Sci., 2010, 23, 301.

165 M. Żenkiewicz, J. Richert and A. Różański, Polym. Test., 2010, 29, 251.

166 F. J. Rodríguez, M. J. Galotto, A. Guarda and J. E. Bruna, J. Food Eng., 2012, 110, 262.

167 J. Vartiainen, M. Tuominen and K. Nättinen, J. Appl. Polym. Sci., 2010, 116, 3638.

168 M. Lavorgna, F. Piscitelli, P. Mangiacapra and G. G. Buonocore, Carbohydr. Polym., 2010, 82, 291.

169 I. Olabarrieta, M. Gällstedt, I. Ispizua, J. R. Sarasua and M. S. Hedenqvist, J. Agric. Food Chem., 2006, 54, 1283.

170 M. R. Guilherme, L. H. C. Mattoso, N. Gontard, S. Guilbert and E. Gastaldi, Composites, Part A, 2010, 41, 375.

171 H. Dai, P. R. Chang, F. Geng, J. Yu and X. Ma, J. Polym. Environ., 2009, 17, 225. 
172 A. C. Souza, R. Benze, E. S. Ferrão, C. Ditchfield, A. C. V. Coelho and C. C. Tadini, LWT-Food Sci. Technol., 2012, 46, 110.

173 S. Tunc, H. Angellier, Y. Cahyana, P. Chalier, N. Gontard and E. Gastaldi, J. Membr. Sci., 2007, 289, 159.

174 A. Casariego, B. W. S. Souza, M. A. Cerqueira, J. A. Teixeira, L. Cruz, R. Díaz and A. A. Vicente, Food Hydrocolloids, 2009, 23, 1895.

175 S. Tunç and O. Duman, Appl. Clay Sci., 2010, 48, 414.

176 J. W. Rhim, S. I. Hong, H. M. Park and P. K. Ng, J. Agric. Food Chem., 2006, 54, 5814.

177 S. I. Hong and J. W. Rhim, J. Nanosci. Nanotechnol., 2008, 8, 5818.

178 R. Sothornvit, S. I. Hong, D. J. An and J. W. Rhim, LWT-Food Sci. Technol., 2010, 43, 279.

179 J. W. Rhim, S. I. Hong and C. S. Ha, LWT-Food Sci. Technol., 2009, 42, 612.

180 E. Mascheroni, P. Chalier, N. Gontard and E. Gastaldi, Food Hydrocolloids, 2010, 24, 406.

181 E. Mascheroni, V. Guillard, E. Gastaldi, N. Gontard and P. Chalier, Food Control, 2011, 22, 1582.

182 S. A. Jang, G. O. Lim and K. B. Song, Int. J. Food Sci. Technol., 2010, 45, 1883.

183 C. Costa, A. Conte, G. G. Buonocore, M. Lavorgna and M. A. Del Nobile, Food Res. Int., 2012, 48, 164.

184 D. Eberl, Clays Clay Miner., 1978, 26, 327.

185 X. Ma, H. Lu, G. Liang and H. Yan, J. Appl. Polym. Sci., 2004, 93, 608.

186 L. Yang, G. Liang, Z. Zhang, S. He and J. Wang, J. Appl. Polym. Sci., 2009, 114, 1235.

187 Z. Jinhong, L. Xiancai, Z. Jianxi, L. Xiandong, W. Jingming, Z. Qing, Y. Peng and H. Hongping, J. Phys. Chem. C, 2012, 116, 13071.

188 J. He, S. Hong, L. Zhang, F. Gan and Y. S. Ho, Fresenius Environ. Bull., 2010, 19, 2651.

189 X. Wang, Y. Du, J. Luo, B. Lin and J. F. Kennedy, Carbohydr. Polym., 2007, 69, 41.

190 P. R. Chang, D. Wu, D. P. Anderson and X. Ma, Carbohydr. Polym., 2012, 89, 687.

191 H. Deng, P. Lin, S. Xin, R. Huang, W. Li, Y. Du, X. Zhou and J. Yang, Carbohydr. Polym., 2012, 89, 307.

192 X. Li, X. Li, B. Ke, X. Shi and Y. Du, Carbohydr. Polym., 2011, 85, 747 .

193 B. Casal, J. Merino, E. Ruiz-Hitzky, E. Gutierrez and A. Alvarez, Clay Miner., 1997, 32, 41.

194 H. Suquet, C. de la Calle and H. Pezerat, Clays Clay Miner., 1975, 23, 1.

195 D. W. Kim, B. C. Ku, D. Steeves, R. Nagarajan, A. Blumstein, J. Kumar, P. W. Gibson, J. A.Ratto and L. A. Samuelson, J. Membr. Sci., 2006, 275, 12.

196 L. A. Utracki, M. Sepehr and E. Boccaleri, Polym. Adv. Technol., 2007, 18, 1.

197 W. Zhen, C. Lu, C. Li and M. Liang, Appl. Clay Sci., 2012, 57,64 .

198 W. L. Hemme, W. Fujita, K. Awaga and H. Eckert, Dalton Trans., 2009, 7995.
199 F. Bergaya and G. Lagaly, in Developments in Clay Science, ed. B. K. G. T. Faïza Bergaya and L. Gerhard, Elsevier, 2006, pp. 1-18.

200 V. C. Farmer and J. D. Russell, Trans. Faraday Soc., 1971, 67, 2737.

201 A. Okada and A. Usuki, Mater. Sci. Eng., C, 1995, 3, 109.

202 S. Sinha Ray, K. Okamoto and M. Okamoto, Macromolecules, 2003, 36, 2355.

203 J. H. Yeun, G. S. Bang, B. J. Park, S. K. Ham and J. H. Chang, J. Appl. Polym. Sci., 2006, 101, 591.

204 W. Zhen and C. Lu, Appl. Surf. Sci., 2012, 258, 6969.

205 N. Willenbacher, J. Colloid Interface Sci., 1996, 182, 501.

206 Technical Brochure "Laponite as a film forming agent", Laponite: performance additives, Rockwood Additives Limited, Cheshire, United Kingdom. pp. 1-22.

207 P. D. Kaviratna, T. J. Pinnavaia and P. A. Schroeder, J. Phys. Chem. Solids, 1996, 57, 1897.

208 G. F. Perotti, H. S. Barud, Y. Messaddeq, S. J. L. Ribeiro and V. R. L. Constantino, Polymer, 2011, 52, 157.

209 A. Mourchid, E. Lécolier, H. Van Damme and P. Levitz, Langmuir, 1998, 14, 4718.

210 Laponite Additives, Synthetic Silicate Additives, http:// www.laponite.com/faqs.asp\#_What_is_the_5, accessed May 2013.

211 Technical Bulletin Laponite L104/90/A, Laponite: Structure, chemistry and relationship to natural clays, Laporte Absorbents, Cherise, United Kingdom, 1990, pp. 1-15.

212 Laponite ${ }^{\circledR}$ Technical Brochure, Laponite: performance additives, Rockwood Additives Limited: A Rockwood Holdings, Inc. Company, Cheshire, United Kingdom, pp. 1-22, http://www.byk.com/en/additives/product-groups/ rheology/former-rockwood-additives/technical-brochures. html, accessed February 2013.

213 K. Wang, M. Xu, Y. Choi and I. Chung, Polym. Bull., 2001, 46, 499.

214 H. A. Essawy, N. A. Abd El-Wahab and M. A. Abd El-Ghaffar, Polym. Degrad. Stab., 2008, 93, 1472.

215 S. H. Nair, K. C. Pawar, J. P. Jog and M. V. Badiger, J. Appl. Polym. Sci., 2007, 103, 2896.

216 T. U. Patro and H. D. Wagner, Nanotechnology, 2011, 22, 455706.

217 M. Gabr, N. Phong, M. Abdelkareem, K. Okubo, K. Uzawa, I. Kimpara and T. Fujii, Cellulose, 2013, 20, 819.

218 X. Tang and S. Alavi, J. Agric. Food Chem., 2012, 60, 1954.

219 M. F. Traynor, M. M. Mortland and T. J. Pinnavaia, Clays Clay Miner., 1978, 26, 318.

220 T. Sánchez, F. B. Gebretsadik, P. Salagre, Y. Cesteros, N. Guillén-Hurtado, A. García-García and A. Bueno-López, Appl. Clay Sci., 2013, 77-78, 40.

221 H. Van Olphen and J. J. Fripiar, Soil Sci., 1981, 131.

222 K. Fukushima, D. Tabuani and G. Camino, Mater. Sci. Eng., C, 2012, 32, 1790 .

223 M. D. Sanchez-Garcia, E. Gimenez and J. M. Lagaron, J. Appl. Polym. Sci., 2008, 108, 2787.

224 M. S. Żbik, N. A. Raftery, R. St. C. Smart and R. L. Frost, Appl. Clay Sci., 2010, 50, 299. 
225 A. J. F. de Carvalho, A. A. S. Curvelo and J. A. M. Agnelli, Carbohydr. Polym., 2001, 45, 189.

226 K. Kaewtatip and V. Tanrattanakul, Mater. Des., 2012, 37, 423.

227 J. A. Mbey, S. Hoppe and F. Thomas, Carbohydr. Polym., 2012, 88, 213.

228 P. Lu, M. Zhang, P. Qian and Q. Zhu, Polym. Compos., 2012, 33, 889 .

229 L. Cabedo, J. Luis Feijoo, M. Pilar Villanueva, J. M. Lagarón and E. Giménez, Macromol. Symp., 2006, 233, 191.

230 Y. Lvov and E. Abdullayev, Prog. Polym. Sci., 2013, 38, 1690.

231 Y. M. Lvov, D. G. Shchukin, H. Mohwald and R. R. Price, ACS Nano, 2008, 2, 814.

232 G. Cavallaro, D. I. Donato, G. Lazzara and S. Milioto, J. Phys. Chem. C, 2011, 115, 20491.

233 D. Carroli, Geol. Soc. Am. Bull., 1959, 70, 749.

234 Y. Lvov, R. Price, B. Gaber and I. Ichinose, Colloids Surf., A, 2002, 198-200, 375.

235 Y. Lvov and R. Price, Halloysite nanotubes in nanomaterials research, Technical Note, http://www.sigmaaldrich.com/ materials-science/nanomaterials/nanoclay-building/ halloysite-nanotubes.html, accessed May 2013.

236 R. R. Price, B. P. Gaber and Y. Lvov, J. Microencapsulation, 2001, 18, 713.

237 D. G. Shchukin and H. Möhwald, Adv. Funct. Mater., 2007, 17, 1451.

238 D. G. Shchukin, S. V. Lamaka, K. A. Yasakau, M. L. Zheludkevich, M. G. S. Ferreira and H. Mohwald, J. Phys. Chem. C, 2008, 112, 958.

239 E. Abdullayev, R. Price, D. Shchukin and Y. Lvov, ACS Appl. Mater. Interfaces, 2009, 1, 1437.

240 G. S. Machado, K. A. D. de Freitas Castro, F. Wypych and S. Nakagaki, J. Mol. Catal. B: Enzym., 2008, 283, 99.

241 H. Ismail, P. Pasbakhsh, M. N. A. Fauzi and A. Abu Bakar, Polym. Test., 2008, 27, 841.

242 P. Pasbakhsh, H. Ismail, M. N. A. Fauzi and A. A. Bakar, Polym. Test., 2009, 28, 548.

243 P. Pasbakhsh, H. Ismail, M. N. A. Fauzi and A. A. Bakar, Appl. Clay Sci., 2010, 48, 405.

244 H. C. Voon, R. Bhat, A. M. Easa, M. T. Liong and A. A. Karim, Food Bioprocess Technol., 2010, 5, 1766.

245 Y. He, W. Kong, W. Wang, T. Liu, Y. Liu, Q. Gong and J. Gao, Carbohydr. Polym., 2012, 87, 2706.

246 W. Wu, X. Cao, Y. Zhang and G. He, J. Appl. Polym. Sci., 2013, 130, 443.

247 K. Prashantha, B. Lecouvet, M. Sclavons, M. F. Lacrampe and P. Krawczak, J. Appl. Polym. Sci., 2013, 128, 1895.

248 G. Gorrasi, R. Pantani, M. Murariu and P. Dubois, Macromol. Mater. Eng., 2014, 299, 104.

249 P. Russo, S. Cammarano, E. Bilotti, T. Peijs, P. Cerruti and D. Acierno, J. Appl. Polym. Sci., 2014, 131, 39798.

$250 \mathrm{M}$. Soheilmoghaddam and M. U. Wahit, Int. J. Biol. Macromol., 2013, 58, 133.

251 P. Aranda, R. Kun, M. A. Martín-Luengo, S. Letaïef, I. Dékány and E. Ruiz-Hitzky, Chem. Mater., 2008, $20,84$.

252 L. González, A. Rodríguez, A. Marcos-Fernández and A. Del Campo, J. Appl. Polym. Sci., 2001, 79, 714.
253 R. L. Frost and Z. Ding, Thermochim. Acta, 2003, 397, 119.

254 L. Bokobza, A. Burr, G. Garnaud, M. Y. Perrin and S. Pagnotta, Polym. Int., 2004, 53, 1060.

255 G. Tartaglione, D. Tabuani and G. Camino, Microporous Mesoporous Mater., 2008, 107, 161.

256 N. Volle, L. Challier, A. Burr, F. Giulieri, S. Pagnotta and A. M. Chaze, Compos. Sci. Technol., 2011, 71, 1685.

257 H. Shariatmadari, A. Mermut and M. Benke, Clays Clay Miner., 1999, 47, 44.

258 J. Jog, Crystallization in Polymer Nanocomposites, Optimization of Polymer Nanocomposite Properties, WileyVCH Verlag GmbH \& Co. KGaA, 2010, pp. 279-300.

259 J. L. Ahlrichs, C. Serna and J. M. Serratosa, Clays Clay Miner., 1975, 23, 119.

260 M. C. Hermosín and J. Cornejo, Clays Clay Miner., 1986, 34, 591.

261 G. Tartaglione, D. Tabuani, G. Camino and M. Moisio, Compos. Sci. Technol., 2008, 68, 451.

262 A. Marcilla, A. Gómez, S. Menargues and R. Ruiz, Polym. Degrad. Stab., 2005, 88, 456.

263 M. Liu, M. Pu and H. Ma, Compos. Sci. Technol., 2012, 72, 1508.

264 T. D. Hapuarachchi and T. Peijs, Composites, Part A, 2010, 41, 954.

265 F. Chivrac, E. Pollet, M. Schmutz and L. Avérous, Carbohydr. Polym., 2010, 80, 145.

266 B. Giménez, M. C. Gómez-Guillén, M. E. López-Caballero, J. Gómez-Estaca and P. Montero, Food Hydrocolloids, 2012, 27, 475.

267 Z. Sárossy, T. O. J. Blomfeldt, M. S. Hedenqvist, C. B. Koch, S. S. Ray and D. Plackett, ACS Appl. Mater. Interfaces, 2012, 4, 3378.

268 K. Fukushima, D. Tabuani and G. Camino, Mater. Sci. Eng., C, 2009, 29, 1433.

269 A. C. S. Alcântara, M. Darder, P. Aranda and E. Ruiz-Hitzky, Eur. J. Inorg. Chem., 2012, 5216.

270 K. Zhang, J. Xu, K. Y. Wang, L. Cheng, J. Wang and B. Liu, Polym. Degrad. Stab., 2009, 94, 2121.

271 M. F. Brigatti, S. Colonna, D. Malferrari, L. Medici and L. Poppi, Appl. Clay Sci., 2005, 28, 1.

272 L. Wang, X. Wang, Z. Chen and P. Ma, Appl. Clay Sci., 2013, 75-76, 74 .

273 S. Williams-Daryn and R. K. Thomas, J. Colloid Interface Sci., 2002, 255, 303.

274 C. Marcos, Y. Arango and I. Rodriguez, Appl. Clay Sci., 2009, 42, 368.

275 A. Auliawan and E. M. Woo, Polym. Compos., 2011, 32, 1916.

276 A. Auliawan and E. M. Woo, J. Appl. Polym. Sci., 2012, 125, E444.

277 M. J. Fernández, M. D. Fernández and I. Aranburu, Appl. Clay Sci., 2013, 80-81, 372.

278 M. J. Fernández, M. D. Fernández and I. Aranburu, Eur. Polym. J., 2013, 49, 1257.

279 J. Drelich, B. Li, P. Bowen, J. Y. Hwang, O. Mills and D. Hoffman, Appl. Surf. Sci., 2011, 257, 9435.

280 Y. Tsujimoto, A. Yoshida, M. Kobayashi and Y. Adachi, Colloids Surf., A, 2013, 435, 109. 
281 J. P. Gustafsson, Clays Clay Miner., 2001, 49, 73.

282 F. V. C. Cradwick, J. D. Russell, C. R. Masson, K. Wada and N. Yoshinaga, Nat. Phys. Sci., 1972, 240, 187.

283 S. Mukherjee, V. M. Bartlow and S. Nair, Chem. Mater., 2005, 17, 4900.

284 W. Ma, W. O. Yah, H. Otsuka and A. Takahara, J. Mater. Chem., 2012, 22, 11887.

285 C. Clark and M. B. McBride, Clays Clay Miner., 1984, 32, 291.

286 C. Su and J. B. Harsh, Clays Clay Miner., 1993, 41, 461.

287 J. Karube and Y. Abe, Clays Clay Miner., 1998, 46, 322.

288 C. Forano, T. Hibino, F. Leroux and C. Taviot-Guého, in Developments in Clay Science, ed. F. Bergaya, B. K. G. Theng and G. Lagaly, Elsevier, 2006, vol. 1, pp. 1021-1095.

289 M. F. Chiang and T. M. Wu, Compos. Sci. Technol., 2010, 70, 110.

290 F. Li and X. Duan, in Layered Double Hydroxides, ed. X. Duan and D. Evans, Springer, Berlin, 2006, pp. 193-223.

291 L. Moyo, N. Nhlapo and W. Focke, J.Mater. Sci., 2008, 43, 6144.

292 P. Ding, M. Zhang, J. Gai and B. Qu, J. Mater. Chem., 2007, 17, 1117.

293 T. Kameda, T. Yamazaki and T. Yoshioka, Microporous Mesoporous Mater., 2008, 114, 410.

294 T. Sato, H. Fujita, T. Endo, M. Shimada and A. Tsunashima, React. Solids, 1988, 5, 219.

295 M. F. Chiang, E. C. Chen and T. M. Wu, Polym. Degrad. Stab., 2012, 97, 995.

296 S. O'Leary, D. O'Hare and G. Seeley, Chem. Commun., 2002, 1506.

297 M. F. Chiang and T. M. Wu, Composites, Part B, 2012, 43, 2789.

298 M. F. Chiang and T. M. Wu, Appl. Clay Sci., 2011, 51, 330.

299 V. Bugatti, U. Costantino, G. Gorrasi, M. Nocchetti, L. Tammaro and V. Vittoria, Eur. Polym. J., 2010, 46, 418.

300 R. Pucciariello, L. Tammaro, V. Villani and V. Vittoria, J. Polym. Sci., Part B: Polym. Phys., 2007, 45, 945.

301 V. Bugatti, G. Gorrasi, F. Montanari, M. Nocchetti, L. Tammaro and V. Vittoria, Appl. Clay Sci., 2011, 52, 34.

302 G. Gorrasi, V. Bugatti and V. Vittoria, Carbohydr. Polym., 2012, 89, 132.

303 J. B. Dixon, Appl. Clay Sci., 1991, 5, 489.

$304 \mathrm{H}$. Van Olphen, An introduction to clay colloid chemistry: For clay technologists, geologists, and soil scientists, Interscience (Wiley), New York, 1977.

305 http://www.topy.co.jp/english/dept/mica/industrial.html, last access December 2013.

306 P. Dallas, V. K. Sharma and R. Zboril, Adv. Colloid Interface Sci., 2011, 166, 119.

307 A. D. Russell and W. B. Hugo, Prog. Med. Chem., 1994, 31, 351.

308 Q. L. Feng, J. Wu, G. Q. Chen, F. G. Cui, T. N. Kim and J. O. Kim, J. Biomed. Mater. Res., 2000, 52, 662.

309 I. Sondi and B. Salopek-Sondi, J. Colloid Interface Sci., 2004, 275, 177.

310 S. Egger, R. P. Lehmann, M. J. Height, M. J. Loessner and M. Schuppler, Appl. Environ. Microbiol., 2009, 75, 2973.
311 P. Appendini and J. H. Hotchkiss, Innovative Food Sci. Emerging Technol., 2002, 3, 113.

312 S. Sánchez-Valdes, H. Ortega-Ortiz, L. F. Ramos-de Valle, F. J. Medellín-Rodríguez and R. Guedea-Miranda, J. Appl. Polym. Sci., 2009, 111, 953.

313 R. Gottesman, S. Shukla, N. Perkas, L. A. Solovyov, Y. Nitzan and A. Gedanken, Langmuir, 2011, 27, 720.

314 A. M. Fayaz, K. Balaji, M. Girilal, P. T. Kalaichelvan and R. Venkatesan, J. Agric. Food Chem., 2009, 57, 6246.

315 R. Yoksan and S. Chirachanchai, Mater. Sci. Eng., C, 2010, 30, 891.

316 K. Vimala, Y. M. Mohan, K. S. Sivudu, K. Varaprasad, S. Ravindra, N. N. Reddy, Y. Padma, B. Sreedhar and K. MohanaRaju, Colloids Surf., B, 2010, 76, 248.

317 S. Tripathi, G. K. Mehrotra and P. K. Dutta, Bull. Mater. Sci., 2011, 34, 29.

318 R. Tankhiwale and S. K. Bajpai, Colloids Surf., B, 2009, 69, 164.

319 C. Zhu, J. Xue and J. He, J. Nanosci. Nanotechnol., 2009, 9, 3067.

320 S. T. Dubas, P. Kumlangdudsana and P. Potiyaraj, Colloids Surf., A, 2006, 289, 105.

321 J. S. Kim, K. E. Kuk, K. N. Yu, J. H. Kim, S. J. Park, H. J. Lee, S. H. Kim, Y. K. Park, Y. H. Park, C. Y. Hwang, Y. K. Kim, Y. S. Lee, D. H. Jeong and M. H. Cho, J. Nanomed. Nanotechnol., 2007, 3, 95.

322 C. Damm, H. Münsted and A. Rösch, Mater. Chem. Phys., 2008, 108, 61.

323 A. Llorens, E. Lloret, P. A. Picouet, R. Trbojevich and A. Fernandez, Trends Food Sci. Technol., 2012, 24, 19.

324 N. M. Ushakov, A. N. Ulzutuev and I. D. Kosobudskii, Tech. Phys., 2008, 53, 1597.

325 G. Cardenas, J. Diaz, M. F. Melendrez, C. Cruzat and A. Garcia Cancino, Polym. Bull., 2009, 62, 511.

326 A. Fernández, E. Soriano, P. Hernández-Munoz and R. Gavara, J. Food Sci., 2010, 75, 186.

327 C. Chawengkijwanich and Y. Hayata, Int. J. Food Microbiol., 2008, 123, 288.

328 M. L. Cerrada, C. Serrano, M. Sanchez-Chaves, M. Fernandez-Garcia, F. Fernandez-Martin, A. De Andres, R. J. J. Riobóo, A. Kubacka, M. Ferrer and M. FernándezGarcía, Adv. Funct. Mater., 2008, 18, 1949.

329 W. Zhang, Y. Chen, S. Yu, S. Chen and Y. Yin, Thin Solid Films, 2008, 516, 4690.

330 L. Xiao-e, A. N. M. Green, S. A. Haque, A. Mills and J. R. Durrant, J. Photochem. Photobiol., A, 2004, 162, 253.

331 A. Kubacka, C. Serrano, M. Ferrer, H. Lunsdorf, P. Bielecki, M. L. Cerrada, M. Fernández-Garcia and M. FernándezGarcia, Nano Lett., 2007, 7, 2529.

332 S. W. Lee, C. Mao, C. E. Flynn and A. M. Belcher, Science, 2002, 296, 892.

333 E. Celik, Z. Gokcen, N. F. Ak Azem, M. Tanoglu and O. F. Emrullahoglu, Mater. Sci. Eng., B, 2006, 132, 258.

334 R. Dastjerdi and M. Montazer, Colloids Surf., B, 2010, 79, 5. 335 X. Li, Y. Xing, Y. Jiang, Y. Ding and W. Li, Int. J. Food Sci. Technol., 2009, 44, 2161. 
336 X. Li, W. Li, Y. Xing, Y. Jiang, Y. Ding and P. Zhang, Adv. Mater. Res., 2011, 152-153, 450.

337 A. Emamifar, M. Kadivar, M. Shahedi and S. SoleimanianZad, Innovative Food Sci. Emerging Technol., 2010, 11, 742.

338 T. Jin and J. B. Gurtler, J. Appl. Microbiol., 2010, 110, 704.

339 O. Yamamoto, Int. J. Inorg. Mater., 2001, 3, 643.

340 N. Jones, B. Ray, K. K. T. Ranjit and A. C. Manna, FEMS Microbiol. Lett., 2008, 279, 71.

341 L. H. Chen, X. Y. Li, J. C. Rooke, Y. H. Zhang, X. Y. Yang, Y. Tang, F. S. Xiao and B. L. Su, J. Mater. Chem., 2012, 22, 17381.

342 J. Gascon, F. Kapteijn, B. Zornoza, V. Sebastián, C. Casado and J. Coronas, Chem. Mater., 2012, 24, 2829.

343 M. P. Pina, R. Mallada, M. Arruebo, M. Urbiztondo, N. Navascués, O. de la Iglesia and J. Santamaria, Microporous Mesoporous Mater., 2011, 144, 19.

344 C. M. Zimmerman, A. Singh and W. J. Koros, J. Membr. Sci., 1997, 137, 145.

345 Z. Huang, J. F. Su, X. Q. Su, Y. H. Guo, L. J. Teng and C. Min Yang, J. Appl. Polym. Sci., 2009, 112, 9.

346 D. Sirikittikul, A. Fuongfuchat and W. Booncharoen, Polym. Adv. Technol., 2009, 20, 802.

347 Y. Shen and A. C. Lua, Polym. Eng. Sci., 2012, 52, 2106.

348 A. L. Ahmad, M. G. Mohd Nawawi and L. K. So, J. Appl. Polym. Sci., 2006, 99, 1740.

349 O. G. Nik, A. Moheb and T. Mohammadi, Chem. Eng. Technol., 2006, 29, 1340.

350 J. G. Varghese, A. A. Kittur and M. Y. Kariduraganavar, J. Appl. Polym. Sci., 2009, 111, 2408.

351 C. V. Prasad, B. Y. Swamy, H. Sudhakar, T. Sobharani, K. Sudhakar, M. C. S. Subha and K. C. Rao, J. Appl. Polym. Sci., 2011, 121, 1521.

352 H. Sudhakar, C. Venkata Prasad, K. Sunitha, K. Chowdoji Rao, M. C. S. Subha and S. Sridhar, J. Appl. Polym. Sci., 2011, 121, 2717.

353 M. L. Lind, A. K. Ghosh, A. Jawor, X. Huang, W. Hou, Y. Yang and E. M. V. Hoek, Langmuir, 2009, 25, 10139.

354 N. Ma, J. Wei, R. Liao and C. Y. Tang, J. Membr. Sci., 2012, 405-406, 149.

355 G. J. Dahe, R. S. Teotia and J. R. Bellare, Chem. Eng. J., 2012, 197, 398.

356 S. Polarz and B. Smarsly, J. Nanosci. Nanotechnol., 2002, 2, 581.

357 T. Sakano, H. Tamon, M. Miyahara and M. Okazaki, Food Sci. Technol. Int., 1996, 2, 174.

358 T. Sakano, K. Yamamura, H. Tamon, M. Miyahara and M. Okazaki, J. Food Sci., 1996, 61, 473.

359 H. S. Kim and H. J. Kim, J. Appl. Polym. Sci., 2008, 110, 3247. 360 N. Cvetkovic, B. Adnadjevic and M. Nikolic, Beiträge zur Tabakforschung International, 2002, 20, 43.

361 Y. Xu, J. H. Zhu, L. L. Ma, A. Ji, Y. L. Wei and X. Y. Shang, Microporous Mesoporous Mater., 2003, 60, 125.

362 L. Gao, Y. Wang, Y. Xu, S. L. Zhou, T. T. Zhuang, Z. Y. Wu and J. H. Zhu, Clean: Soil, Air, Water, 2008, 36, 270.

363 L. Gao, Y. Cao, S. L. Zhou, T. T. Zhuang, Y. Wang and J. H. Zhu, J. Hazard. Mater., 2009, 169, 1034.
364 A. Marcilla, A. Gómez-Siurana, D. Berenguer, I. MartínezCastellanos and M. I. Beltrán, Microporous Mesoporous Mater., 2012, 161, 14.

365 W. M. Meier and K. Siegmann, Microporous Mesoporous Mater., 1999, 33, 307.

366 G. Cerri, M. Degennaro, M. Bonferoni and C. Caramella, Appl. Clay Sci., 2004, 27, 141.

367 S. Quintavalla and L. Vicini, Meat Sci., 2002, 62, 373.

368 FDA, Inventory of effective food contact substance (FCS) notifications, http://www.accessdata.fda.gov/scripts/fcn/ fcnDetailNavigation.cfm?rpt $=$ fcsListing\&id $=697$, accessed May 2013.

369 EFSA, Opinion of the scientific panel on food additives, flavourings, processing aids and materials in contact with food (AFC) on a request from the Commission related to a 7th list of substances for food contact materials, EFSA J., 2005, 201, 1.

370 EFSA, Scientific Opinion on the safety evaluation of the substance, silver zeolite A (silver zinc sodium ammonium alumino silicate), silver content $2-5 \%$, for use in food contact materials, EFSA J., 2011, 9, 1999.

371 P. Monprasit, C. Ritvirulh, T. Sooknoi, S. Rukchonlatee, A. Fuongfuchat and D. Sirikittikul, Polym. Eng. Sci., 2011, 51, 1264.

372 A. Jacobsson, T. Nielsen, I. Sjöholm and K. Wendin, Food Qual. Prefer., 2004, 15, 301.

373 K. Boonruang, V. Chonhenchob, S. P. Singh, W. Chinsirikul and A. Fuongfuchat, Packag. Technol. Sci., 2012, 25, 107.

374 D. H. Shin, H. S. Cheigh and S. L. Dong, J. Food Eng., 2002, 53, 229.

375 E. Frydrych, Z. Foltynowicz, S. Kowalak and E. Janiszewska, in Studies in Surface Science and Catalysis, ed. R. Xu, Z. Gao, J. Chen and W. Yan, Elsevier, 2007, vol. 170, pp. 1597-1604.

376 F. Ozmihci, D. Balkose and S. Ulku, J. Appl. Polym. Sci., 2001, 82, 2913-2921.

377 D. Balköse, K. Oguz, L. Ozyuzer, S. Tari, E. Arkis and F. O. Omurlu, J. Appl. Polym. Sci., 2011, 120, 1671.

378 J. Biswas, H. Kim, S. Shim and G. Kim, J. Ind. Eng. Chem., 2004, 10, 582.

379 I. E. Yuzay, R. Auras and S. Selke, J. Appl. Polym. Sci., 2010, 115, 2262.

380 H. Pehlivan, D. Balköse, S. Ülkü and F. Tihminlioğlu, Compos. Sci. Technol., 2005, 65, 2049.

381 D. Metın, F. Tihminlioğlu, D. Balköse and S. Ülkü, Composites, Part A, 2004, 35, 23.

382 S. Djoumaliisky and P. Zipper, Macromol. Symp., 2004, 217, 391.

383 H. Pehlivan, D. Balköse, S. Ülkü and F. Tihmınlığlu, J. Appl. Polym. Sci., 2006, 101, 143.

384 I. E. Yuzay, R. Auras, H. Soto-Valdez and S. Selke, Polym. Degrad. Stab., 2010, 95, 1769.

385 H. Zhen, Y. Xiaoxu, P. Xi, Z. Yulong, F. Meifen and Z. Qiang, Thermal degradation study of sodium alginate-zeolite $4 \mathrm{~A}$ composites, Proc. the 17th IAPRI World Conference on Packag., Tianjin, China, Scientific Research Publishing, USA, 2010, pp. 406-409. 
386 R. Thipmanee and A. Sane, J. Appl. Polym. Sci., 2012, 126, 252.

387 M. Terrones, A. R. Botello-Méndez, J. Campos-Delgado, F. López-Urías, Y. I. Vega-Cantú, F. J. Rodríguez-Macías, A. L. Elías, E. Muñoz-Sandoval, A. G. Cano-Márquez, J.-C. Charlier and H. Terrones, Nano Today, 2010, 5, 351.

388 M. Eizenberg and J. M. Blakely, Surf. Sci., 1979, 82, 228.

389 K. S. Novoselov, A. K. Geim, S. V. Morozov, D. Jiang, Y. Zhang, S. V. Dubonos, I. V. Grigorieva and A. A. Firsov, Science, 2004, 306, 666.

390 C. Lee, X. Wei, J. W. Kysar and J. Hone, Science, 2008, 321, 385.

391 A. A. Balandin, S. Ghosh, W. Bao, I. Calizo, D. Teweldebrhan, F. Miao and C. N. Lau, Nano Lett., 2008, 8, 902 .

392 K. I. Bolotin, K. J. Sikes, Z. Jiang, M. Klima, G. Fudenberg, J. Hone, P. Kim and H. L. Stormer, Solid State Commun., 2008, 146, 351.

393 M. D. Stoller, S. Park, Y. Zhu, J. An and R. S. Ruoff, Nano Lett., 2008, 8, 3498.

394 Y. Zhang, Y. W. Tan, H. L. Stormer and P. Kim, Nature, 2005, 438, 201.

395 J. S. Bunch, S. S. Verbridge, J. S. Alden, A. M. van der Zande, J. M. Parpia, H. G. Craighead and P. L. McEuen, Nano Lett., 2008, 8, 2458.

396 L. Imperiali, C. Clasen, J. Fransaer, C. W. Macosko and J. Vermant, Mater. Horiz., 2014, 1, 139.

397 L. Staudenmaier, Ber. Dtsch. Chem. Ges., 1898, 31, 1481.

398 W. S. Hummers and R. E. Offeman, J. Am. Chem. Soc., 1958, 80, 1339.

399 S. Niyogi, E. Bekyarova, M. E. Itkis, J. L. McWilliams, M. A. Hamon and R. C. Haddon, J. Am. Chem. Soc., 2006, 128, 7720 .

400 G. Eda, G. Fanchini and M. Chhowalla, Nat. Nanotechnol., 2008, 3, 270.

401 X. Li, G. Zhang, X. Bai, X. Sun, X. Wang, E. Wang and H. Dai, Nat. Nanotechnol., 2008, 3, 538.

402 G. Eda and M. Chhowalla, Adv. Mater., 2010, 22, 2392.

403 A. Buchsteiner, A. Lerf and J. Pieper, J. Phys. Chem. B, 2006, 110, 22328.

404 S. Bae, H. Kim, Y. Lee, X. Xu, J. S. Park, Y. Zheng, J. Balakrishnan, T. Lei, H. R. Kim, Y. I. Song, Y. J. Kim, K. S. Kim, B. Özyilmaz, J. H. Ahn, B. H. Hong and S. Iijima, Nat. Nanotechnol., 2010, 5, 574.

405 L. Gomez De Arco, Y. Zhang, C. W. Schlenker, K. Ryu, M. E. Thompson and C. Zhou, ACS Nano, 2010, 4, 2865.

406 C. Berger, Z. Song, T. Li, X. Li, A. Y. Ogbazghi, R. Feng, Z. Dai, A. N. Marchenkov, E. H. Conrad, P. N. First and W. A. de Heer, J. Phys. Chem. B, 2004, 108, 19912.

407 M. Sprinkle, M. Ruan, Y. Hu, J. Hankinson, M. Rubio-Roy, B. Zhang, X. Bu, C. Berger and W. A. de Heer, Nat. Nanotechnol., 2010, 5, 727.

408 W. A. de Heer, C. Berger, X. Wu, M. Sprinkle, Y. Hu, M. Ruan, J. A. Stroscio, P. N. First, R. Haddon, B. Piot, C. Faugeras, M. Potemski and J. S. Moon, J. Phys. D: Appl. Phys., 2010, 43, 374007.

409 J. Wintterlin and M. L. Bocquet, Surf. Sci., 2009, 603, 1841.
410 A. Zangwill and D. D. Vvedensky, Nano Lett., 2011, 11, 2092. 411 C. D. Kim, B. K. Min and W. S. Jung, Carbon, 2009, 47, 1610. 412 A. Chakrabarti, J. Lu, J. C. Skrabutenas, T. Xu, Z. Xiao, J. A. Maguire and N. S. Hosmane, J. Mater. Chem., 2011, 21, 9491.

413 W. Zhao, M. Fang, F. Wu, H. Wu, L. Wang and G. Chen, J. Mater. Chem., 2010, 20, 5817.

414 J. Chen, M. Duan and G. Chen, J. Mater. Chem., 2012, 22, 19625.

415 Y. Hernandez, V. Nicolosi, M. Lotya, F. M. Blighe, Z. Sun, S. De, I. T. McGovern, B. Holland, M. Byrne, Y. K. Gun'Ko, J. J. Boland, P. Niraj, G. Duesberg, S. Krishnamurthy, R. Goodhue, J. Hutchison, V. Scardaci, A. C. Ferrari and J. N. Coleman, Nat. Nanotechnol., 2008, 3, 563.

416 A. Ciesielski and P. Samori, Chem. Soc. Rev., 2014, 43, 381. 417 W. Yang, K. R. Ratinac, S. P. Ringer, P. Thordarson, J. J. Gooding and F. Braet, Angew. Chem., Int. Ed., 2010, 49, 2114.

418 Y. Feng, X. Zhang, Y. Shen, K. Yoshino and W. Feng, Carbohydr. Polym., 2012, 87, 644.

419 X. Huang, Z. Yin, S. Wu, X. Qi, Q. He, Q. Zhang, Q. Yan, F. Boey and H. Zhang, Small, 2011, 7, 1876.

420 F. Liu, Y. Piao, K. S. Choi and T. S. Seo, Carbon, 2012, 50, 123.

421 Y. Yao, Z. Lin, Z. Li, X. Song, K. S. Moon and C. P. Wong, J. Mater. Chem., 2012, 22, 13494.

422 M. A. Raza, A. Westwood, A. Brown, N. Hondow and C. Stirling, Carbon, 2011, 49, 4269.

423 M. A. Raza, A. V. K. Westwood, A. P. Brown and C. Stirling, Compos. Sci. Technol., 2012, 72, 467.

424 Y. H. Yang, L. Bolling, M. A. Priolo and J. C. Grunlan, Adv. Mater., 2013, 25, 503.

425 M. H. Tsai, I. H. Tseng, Y. F. Liao and J. C. Chiang, Polym. Int., 2013, 62, 1302.

426 M. H. Tsai, C. J. Chang, H. H. Lu, Y. F. Liao and I. H. Tseng, Thin Solid Films, 2013, 544, 324.

427 I. H. Tseng, Y. F. Liao, J. C. Chiang and M. H. Tsai, Mater. Chem. Phys., 2012, 136, 247.

428 K. H. Liao, Y. Qian and C. W. Macosko, Polymer, 2012, 53, 3756.

429 V. Štengl, D. Popelková and P. Vláčil, J. Phys. Chem. C, 2011, 115, 25209.

430 Y. Zhu, S. Murali, M. D. Stoller, K. J. Ganesh, W. Cai, P. J. Ferreira, A. Pirkle, R. M. Wallace, K. A. Cychosz, M. Thommes, D. Su, E. A. Stach and R. S. Ruoff, Science, 2011, 332, 1537.

431 V. K. Rana, M. C. Choi, J. Y. Kong, G. Y. Kim, M. J. Kim, S. H. Kim, S. Mishra, R. P. Singh and C. S. Ha, Macromol. Mater. Eng., 2011, 296, 131.

432 A. M. Pinto, S. Moreira, I. C. Gonçalves, F. M. Gama, A. M. Mendes and F. D. Magalhães, Colloids Surf., B, 2013, 104, 229.

433 W. L. Song, L. M. Veca, C. Y. Kong, S. Ghose, J. W. Connell, P. Wang, L. Cao, Y. Lin, M. J. Meziani, H. Qian, G. E. LeCroy and Y. P. Sun, Polymer, 2012, 53, 3910-3916. 
434 M. El Achaby, F. Z. Arrakhiz, S. Vaudreuil, E. M. Essassi and A. Qaiss, Appl. Surf. Sci., 2012, 258, 7668.

435 A. A. Al-Ghamdi, F. El-Tantawy, N. Abdel Aal, E. H. ElMossalamy and W. E. Mahmoud, Polym. Degrad. Stab., 2009, 94, 980.

436 A. A. Al-Ghamdi and F. El-Tantawy, Composites, Part A, 2010, 41, 1693.

437 S. Mao, H. Pu and J. Chen, RSC Adv., 2012, 2, 2643.

438 Z. S. Wu, G. Zhou, L. C. Yin, W. Ren, F. Li and H. M. Cheng, Nano Energy, 2012, 1, 107.

439 Z. Liu, J. Li and F. Yan, Adv. Mater., 2013, 25, 4296.

440 C. H. Chang, T. C. Huang, C. W. Peng, T. C. Yeh, H. I. Lu, W. I. Hung, C. J. Weng, T. I.Yang and J. M. Yeng, Carbon, 2012, 50, 5044.

441 N. H. Kim, T. Kuila and J. H. Lee, J. Mater. Chem. A, 2013, 1, 1349.

442 B. Mortazavi, F. Hassouna, A. Laachachi, A. Rajabpour, S. Ahzi, D. Chapron, V. Toniazzo and D. Ruch, Thermochim. Acta, 2013, 552, 106.

443 W. Zheng, X. Lu and S. C. Wong, J. Appl. Polym. Sci., 2004, 91, 2781.

444 H. Kim and C. W. Macosko, Polymer, 2009, 50, 3797.

445 P. J. Hubert, K. Kathiresan and K. Wakabayashi, Polym. Eng. Sci., 2011, 51, 2273.

446 S. Bandla and J. C. Hanan, J. Mater. Sci., 2011, 47, 876.

447 D. Cai, J. Jin, K. Yusoh, R. Rafiq and M. Song, Compos. Sci. Technol., 2012, 72, 702.

448 M. El Achaby, F. E. Arrakhiz, S. Vaudreuil, A. el Kacem Qaiss, M. Bousmina and O. Fassi-Fehri, Polym. Compos., 2012, 33, 733.

449 X. Yang, Y. Zhan, R. Zhao and X. Liu, J. Appl. Polym. Sci., 2012, 124, 1723.

450 J. Wang, X. Wang, C. Xu, M. Zhang and X. Shang, Polym. Int., 2011, 60, 816.

451 H. J. Salavagione, G. Martínez and M. A. Gómez, J. Mater. Chem., 2009, 19, 5027.

452 H. J. Salavagione and G. Martínez, Macromolecules, 2011, 44, 2685.

453 D. Lee, M. C. Choi and C. S. Ha, J. Polym. Sci., Part A: Polym. Chem., 2012, 50, 1611.

454 T. Kuila, P. Khanra, A. K. Mishra, N. H. Kim and J. H. Lee, Polym. Test., 2012, 31, 282.

455 T. Kuila, S. Bose, A. K. Mishra, P. Khanra, N. H. Kim and J. H. Lee, Polym. Test., 2012, 31, 31.

456 H. Kim, S. Kobayashi, M. A. AbdurRahim, M. J. Zhang, A. Khusainova, M. A. Hillmyer, A. A. Abdala and C. W. Macasko, Polymer, 2011, 52, 1837.

457 R. R. Nair, H. A. Wu, P. N. Jayaram, I. V. Grigorieva and A. K. Geim, Science, 2012, 335, 442.

458 B. Min Yoo, H. Jin Shin, H. Wook Yoon and H. Bum Park, J. Appl. Polym. Sci., 2014, 131, 39628.

459 O. C. Compton, S. Kim, C. Pierre, J. M. Torkelson and S. T. Nguyen, Adv. Mater., 2010, 22, 4759.

460 A. M. Pinto, J. Cabral, D. A. P. Tanaka, A. M. Mendesa and F. D. Magalhães, Polym. Int., 2013, 62, 33.

461 J. Gao, F. Chen, K. Wang, H. Deng, Q. Zhang, H. Bai and Q. Fu, J. Mater. Chem., 2011, 21, 17627.
462 A. Ashori, Polym. Eng. Sci., 2013, DOI: 10.1002/pen.23774, in press.

463 Y. Lee, D. Kim, J. Seo, H. Han and S. B. Khan, Polym. Int., 2013, 62, 1386.

464 H.-D. Huang, P.-G. Ren, J.-Z. Xu, L. Xu, G.-J. Zhong, B. S. Hsiao and Z.-M. Li, J. Membr. Sci., 2014, 464, 110.

465 J. Yang, L. Bai, G. Feng, X. Yang, M. Lv, C. Zhang, H. Hu and X. Wang, Ind. Eng. Chem. Res., 2013, 52, 16745.

466 C. Xiang, P. J. Cox, A. Kukovecz, B. Genorio, D. P. Hashim, Z. Yan, Z. Peng, C.-C. Hwang, G. Ruan, E. L. G. Samuel, P. M. Sudeep, Z. Konya, X. R. Vajtai, P. M. Ajayan and J. M. Tour, ACS Nano, 2013, 7, 10380.

467 A. Al-Jabareen, H. Al-Bustami, H. Harel and G. Marom, J. Appl. Polym. Sci., 2013, 128, 1534.

468 C. Wan and B. Chen, J. Appl. Polym. Sci., 2013, 127, 5094.

469 L.-L. Wu, J. Wang, X. He, T. Zhang and H. Sun, Packag. Technol. Sci., 2014, DOI: 10.1002/pts.2058, in press.

470 D. Kim, H. Kwon and J. Seo, Polym. Compos., 2014, 35, 644. 471 P.-G. Ren, H. Wang, H.-D. Huang, D.-X. Yan and Z.-M. Li, J. Appl. Polym. Sci., 2014, 131, 39803.

472 T. K. Ghosh, S. Gope, D. Mondal, B. Bhowmik,Md, M. R. Mollick, D. Maity, I. Roy, G. Sarkar, S. Sadhukhan, D. Rana, M. Chakraborty and D. Chattopadhyay, Int. J. Biol. Macromol., 2014, 66, 338.

473 G. Oberdorster, A. Maynard, K. Donaldson, V. Castranova, J. Fitzpatrick, K. Ausman, J. Carter, B. Karn, W. Kreyling, D. Lai, S. Olin, N. Monteiro-Riviere, D. Warheit and H. Yang, Part. Fibre Toxicol., 2005, 2, 8.

474 G. Oberdörster, E. Oberdörster and J. Oberdörster, Environ. Health Perspect., 2005, 113, 823.

475 A. Nel, T. Xia, L. Madler and N. Li, Science, 2006, 311, 622. 476 K. L. Aillon, Y. Xie, N. El-Gendy, C. J. Berkland and M. L. Forrest, Adv. Drug Delivery Rev., 2009, 61, 457.

477 S. M. Hussain, L. K. Braydich-Stolle, A. M. Schrand, R. C. Murdock, K. O. Yu, D. M. Mattie, J. J. Schlager and M. Terrones, Adv. Mater., 2009, 21, 1549.

478 T. Xia, N. Li and A. E. Nel, Annu. Rev. Public Health, 2009, 30, 137.

479 S. G. Prolongo, A. Jiménez-Suárez, R. Moriche and A. Ureñaet, Eur. Polym. J., 2014, 53, 292.

480 S. Li, M. M. Lin, M. S. Toprak, D. K. Kim and M. Muhammed, Nano Rev., 2010, 1, 5214.

481 V. Ojijo and S. Sinha Raya, Prog. Polym. Sci., 2013, 38, 1543. 482 H. Althues, J. Henle and S. Kaskel, Chem. Soc. Rev., 2007, 36, 1454.

483 R. A. Vaia, K. D. Jandt, E. J. Kramer and E. P. Giannelis, Chem. Mater., 1996, 8, 2628.

484 R. A. Vaia and E. P. Giannelis, Macromolecules, 1997, 30, 7990.

485 H. R. Dennis, D. L. Hunter, D. Chang, S. Kim, J. L. White, J. W. Cho and D. R. Paul, Polymer, 2001, 42, 9513.

486 M. M. Reddy, S. Vivekanandhan, M. Misra, S. K. Bhatia and A. K. Mohanty, Prog. Polym. Sci., 2013, 38, 1653.

487 Y. H. Jin, H. J. Park, S. S. Im, S. Y. Kwak and S. Kwak, Macromol. Rapid Commun., 2002, 23, 135.

488 S. Farris, in The Wiley Encyclopedia of Packaging Technology, ed. K. L. Yam, Wiley \& Sons, 3rd edn, 2009, pp. 285-294. 
489 T. Hielscher, Ultrasonic Production of Nano-size Dispersions and Emulsions, Proceedings of European Nanosystems Conference ENS '05, Paris, 2005.

490 K. S. Suslick, Sci. Am., 1989, 260, 80.

491 C. R. Brenner, Cavitation and Bubble Dynamics, Oxford University Press, 1995.

492 T. G. Leighton, The Acoustic Bubble, Academic Press, 1994.

493 K. S. Suslick, Science, 1990, 247, 1439.

494 K. S. Suslick, Kirk-Othmer Encyclopedia of Chemical Technology, Wiley \& Sons, 4th edn, 1998.

495 K. S. Suslick and D. J. Flannigan, Annu. Rev. Phys. Chem., 2008, 59, 659.

496 J. R. Blake and D. C. Gibson, Annu. Rev. Fluid Mech., 1987, 19, 99.

497 K. S. Suslick and G. J. Price, Annu. Rev. Mater. Sci., 1999, 29, 295.

498 J. H. Bang and K. S. Suslick, Adv. Mater., 2010, 22, 1039.

499 D. G. Shchukin, D. Radziuk and H. Mohwald, Annu. Rev. Mater. Res., 2010, 40, 345.

500 E. Ahmadi, S. Sareminezhad and M. H. Azizi, Food Hydrocolloids, 2011, 25, 1399.

501 F. A. Aouada, L. H. C. Mattoso and E. Longo, Ind. Crops Prod., 2013, 50, 449.

502 X. Feng, X. Wang, W. Xing, K. Zhou, L. Song and Y. Hu, Compos. Sci. Technol., 2014, 93, 76.

503 M. Soheilmoghaddam, M. Uzir Wahit, W. T. Whye, N. I. Akos, R. H. Pour and A. A. Yussuf, Carbohydr. Polym., 2014, 106, 326.

504 M. Lotya, Y. Hernandez, P. J. King, R. J. Smith, V. Nicolosi, L. S. Karlsson, F. M. Blighe, S. De, Z. M. Wang, I. T. McGovern, G. S. Duesberg and J. N. Coleman, J. Am. Chem. Soc., 2009, 131, 3611.

505 D. Nuvoli, M. Rassu, V. Alzari, R. Sanna, G. Malucelli and A. Mariani, Compos. Sci. Technol., 2014, 96, 97.

506 F. Delbecq, F. Kono and T. Kawai, Eur. Polym. J., 2013, 49, 2654.

507 Z. Liu, J. Liu, L. Cui, R. Wang, X. Luo, C. J. Barrow and W. Yang, Carbon, 2013, 51, 148.

508 X. Zheng, Q. Xu, J. Li, L. Li and J. Wei, RSC Adv., 2012, 2, 10632.

509 V. Chabot, B. Kim, B. Sloper, C. Tzoganakis and A. Yu, Sci. Rep., 2013, 3, 1378.

510 J. Fan, Z. Shi, J. Wang and J. Yin, Polymer, 2013, 54, 3921.

511 J. Fan, Z. Shi, Y. Ge, J. Wang, Y. Wang and J. Yin, J. Mater. Chem., 2012, 22, 13764.

512 Z. Sun, S. Pöller, X. Huang, D. Guschin, C. Taetz, P. Ebbinghaus, J. Masa, A. Erbe, A. Kilzer, W. Schuhmann and M. Muhler, Carbon, 2013, 64, 288.

513 P. Mangiacapra, G. Gorrasi, A. Sorrentino and V. Vittoria, Carbohydr. Polym., 2006, 64, 516.

514 U. Costantino, V. Bugatti, G. Gorrasi, F. Montanari, M. Nocchetti, L. Tammaro and V. Vittoria, ACS Appl. Mater. Interfaces, 2009, 1, 668.

515 J. M. Tour, Nat. Mater., 2014, 13, 545.

516 X. J. Chen, J. F. Dobson and C. L. Raston, Chem. Commun., 2012, 48, 3703.
517 K. R. Paton, E. Varrla, C. Backes, R. J. Smith, U. Khan, A. O'Neill, C. Boland, M. Lotya, O. M. Istrate, P. King, T. Higgins, S. Barwich, P. May, P. Puczkarski, I. Ahmed, M. Moebius, H. Pettersson, E. Long, J. Coelho, S. E. O'Brien, E. K. McGuire, B. Mendoza Sanchez, G. S. Duesberg, N. McEvoy, T. J. Pennycook, C. Downing, A. Crossley, V. Nicolosi and J. N. Coleman, Nat. Mater., 2014, 13, 624.

518 A. Sorrentino, G. Gorrasi, M. Tortora, V. Vittoria, U. Costantino, F. Marmottini and F. Padella, Polymer, 2005, 46, 1601.

519 W. Guo and G. Chen, J. Appl. Polym. Sci., 2014, 131, 40565.

520 L. Tammaro, V. Vittoria and V. Bugatti, Eur. Polym. J., 2014, 52, 172.

521 M. Fang, K. Wang, H. Lu, Y. Yang and S. Nutt, J. Mater. Chem., 2009, 19, 7098.

522 G. Gonçalves, P. A. A. P. Marques, A. Barros-Timmons, I. Bdkin, M. K. Singh, N. Emami and J. Grácio, J. Mater. Chem., 2010, 20, 9927.

523 B. Shen, W. Zhai, D. Lu, J. Wang and W. Zheng, RSC Adv., 2012, 2, 4713.

524 S. Stankovich, R. D. Piner, X. Chen, N. Wu, S. T. Nguyen and R. S. Ruoff, J. Mater. Chem., 2006, 16, 155.

525 M. Quintana, A. Montellano, A. E. del Rio Castillo, G. Van Tendeloo, C. Bittencourt and M. Prato, Chem. Commun., 2011, 47, 9330.

526 B. Shen, D. Lu, W. Zhai and W. Zheng, J. Mater. Chem. C, 2013, 1, 50.

527 H. Kim, A. A. Abdala and C. W. Macosko, Macromolecules, 2010, 43, 6515.

528 J. R. Potts, D. R. Dreyer, C. W. Bielawski and R. S. Ruoff, Polymer, 2011, 52, 5.

529 D. Cai and M. Song, J. Mater. Chem., 2010, 20, 7906.

530 Y. Cao, Z. Lai, J. Feng and P. Wu, J. Mater. Chem., 2011, 21, 9271.

531 A. M. Rezadoust, M. Esfandeh, M. H. Beheshty and G. Heinrich, Polym. Eng. Sci., 2013, 53, 809.

532 C. Dazhu, Y. Haiyang, H. Pingsheng and Z. Weian, Compos. Sci. Technol., 2005, 65, 1593.

533 S. Zhu, J. Chen, H. Li and Y. Cao, J. Appl. Polym. Sci., 2013, 128, 3876 .

534 S. Abend and G. Lagaly, Appl. Clay Sci., 2000, 16, 201.

535 D. Burgentzlé, J. Duchet, J. F. Gérard, A. Jupin and B. Fillon, J. Colloid Interface Sci., 2004, 278, 26.

536 J. Labanda and J. Llorens, Rheol. Acta, 2006, 45, 305.

537 H. Van Olphen, J. Colloid Sci., 1964, 19, 313.

538 H. Van Olphen, J. Colloid Sci., 1962, 17, 660.

539 P. F. Luckham and S. Rossi, Adv. Colloid Interface Sci., 1999, 82, 43.

540 E. Tombácz and M. Szekeres, Appl. Clay Sci., 2004, 27, 75.

541 B. Dobias, Coagulation and Flocculation: Theory and Applications, CRC Press, 1993.

542 B. Seentrakoon, B. Junhasavasdikul and W. Chavasiri, Polym. Degrad. Stab., 2013, 98, 566.

543 S. H. Hsieh, F. R. Zhang and H. S. Li, J. Appl. Polym. Sci., 2006, 100, 4311. 
544 Q. G. Du, G. Alagappan, H. Dai, H. V. Demir, H. Y. Yu, X. W. Sun and C. H. Kam, Opt. Commun., 2012, 285, 3238.

545 J. W. Rhim, Carbohydr. Polym., 2011, 86, 691.

546 A. J. Peacock and A. R. Calhoun, Polymer Chemistry: Properties and Applications, Hanser Publishers, 2006.

547 R. N. Wenzel, Ind. Eng. Chem., 1936, 28, 988.

548 A. B. D. Cassie and S. Baxter, Trans. Faraday Soc., 1944, 40, 546.

549 K. Chen, T. Y. Zhang and W. Wei, Adv. Mater. Res., 2011, 311, 92.

550 S. Bhuyan, S. Sundararajan, Y. Lu and R. Larock, Wear, 2010, 268, 797.

551 G. Malucelli and F. Marino, in Abrasion Resistance of Materials, ed. M. Adamiak, InTech, 2012, ISBN: 978-95351-0300-4, http://www.intechopen.com/books/abrasionresistance-of-materials/abrasion-resistance-of-polymer nanocomposites.

552 T. Nielsen and M. Jägerstad, Trends Food Sci. Technol., 1994, 5, 353.

553 C. Sanchez, P. Belleville, M. Popall and L. Nicole, Chem. Soc. Rev., 2011, 40, 696.
554 Nanocor, Multilayer containers featuring nano-nylon MDX6 barrier layers with superior performance and clarity, 2003, http://www.nanocor.com/tech_papers/NOVAPACK03.pdf, last access May 2013.

555 Nanocor, Technical Bulletin, Film and Applications, http:// www.nanocor.com/tech_sheets/I105.pdf, last access October 2013.

556 Plastics Technology, Chasing Nanocomposites, 2004, http:// www.ptonline.com/articles/chasing-nanocomposites, acces sed August 2013.

557 Triton Systems, http://www.tritonsys.com/, last access October 2013.

558 InMat, Ultrahigh barrier coating breakthrough from InMat® reduces food packaging costs and environmental impact, 2009, http:/www.inmat.com/upload/files/inmat_press_ release_05072009.pdf, last access September 2013.

559 NanoPack, NanoSeal ${ }^{\mathrm{TM}}$ - Barrier Coating, OPP Barrier Coated Film, Polypropylene Film, Liquid Coating, http:// www.nanopackinc.com/products.asp, last access October 2013.

560 S. Farris, C. A. Cozzolino, L. Introzzi and L. Piergiovanni, Packag. Technol. Sci., 2009, 22, 359. 